\title{
Paleobiology of Climactichnites, an Enigmatic Late Cambrian Fossil
}

1.)

SMITHSONAAN CONTRIBUTIONS TO PALEOBIOLOGY - NUMBER 74 


\title{
SERIES PUBLICATIONS OF THE SMITHSONIAN INSTITUTION
}

Emphasis upon publication as a means of "diffusing knowledge" was expressed by the first Secretary of the Smithsonian. In his formal plan for the institution, Joseph Henry outlined a program that included the following statement: "It is proposed to publish a series of reports, giving an account of the new discoveries in science, and of the changes made from year to year in all branches of knowledge." This theme of basic research has been adhered to through the years by thousands of titles issued in series publications under the Smithsonian imprint, commencing with Smithsonian Contributions to Knowledge in 1848 and continuing with the following active series:

\author{
Smithsonian Contributions to Anthropology \\ Smithsonian Contributions to Botany \\ Smithsonian Contributions to the Earth Sciences \\ Smithsonian Contributions to the Marine Sciences \\ Smithsonian Contributions to Paleobiology \\ Smithsonian Contributions to Zoology \\ Smithsonian Folklife Studies \\ Smithsonian Studies in Air and Space \\ Smithsonian Studies in History and Technology
}

In these series, the Institution publishes small papers and full-scale monographs that report the research and collections of its various museums and bureaux or of professional colleagues in the world of science and scholarship. The publications are distributed by mailing lists to libraries, universities, and similar institutions throughout the world.

Papers or monographs submitted for series publication are received by the Smithsonian Institution Press, subject to its own review for format and style, only through departments of the various Smithsonian museums or bureaux, where the manuscripts are given substantive review. Press requirements for manuscript and art preparation are outlined on the inside back cover.

Robert McC. Adams

Secretary

Smithsonian Institution 
SMITHSONIAN CONTRIBUTIONS TO PALEOBIOLOGY • NUMBER 74

\section{Paleobiology of Climactichnites, an Enigmatic Late Cambrian Fossil}

Ellis L. Yochelson

and Mikhail A. Fedonkin

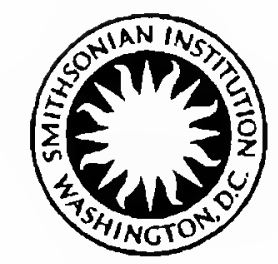

SMITHSONIAN INSTITUTION PRESS

Washington, D.C. 


\section{A B S T R A C T}

Yochelson, Ellis L., and Mikhail A. Fedonkin. Paleobiology of Climactichnites, an Enigmatic Late Cambrian Fossil. Smithsonian Contributions to Paleobiology, number 74, 74 pages, frontispiece, 58 figures, 1993.-Climactichnites wilsoni Logan, 1860, is redescribed from field investigations and specimens in various museums. Climactichnites youngi Todd, 1882, and $C$. fosteri Todd, 1882, are placed in synonymy. The species is known only from its trail, consisting of raised bars and impressed furrows, bounded by two parallel, raised lateral ridges. This structure is interpreted as being formed from damp sand, redistributed and molded by the animal. At a few localities, an oval impression occurs at the origin of the trail; a new locality for this rare feature was found in Wisconsin. In Quebec a trail crossing over itself was found; this phenomenon was known from only one other locality.

All occurrences of Climactichnites are in the Late Cambrian; specimens are known from New York, Quebec, Ontario, Wisconsin, and Missouri. This fossil is probably confined to the Dresbachian, the earliest stage of the tri-part Late Cambrian. All examples of trails are in sandstones; these are interpreted as sand flats that were just above water during low tide in the shallow epicontinental sea.

A variety of animals have been proposed as the trail maker; they include several different kinds of arthropods, mollusks, and "worms." Each proposal has weak points and none of the suggested animal groups has appropriate morphology to produce the marking. The animal is reconstructed as relatively low, broad, and about twice as long as wide. It is hypothesized that the tough body integument secreted mucus which facilitated movement and aided in preservation of the trail. A large flap covered most of the outside body and extended laterally over the muscular foot. Free edges of the flap on either side of the body compressed and molded damp sand into parallel bounding ridges. Respiratory organs may have been present below the flap edges, kept moist by being partially enclosed. By moving the edges of these lateral flaps, the organism may have been able to swim when in water.

Most trails of Climactichnites are interpreted as a consequence of feeding activity. If so, food was taken in through a circular mouth located anteriorward on the ventral surface; this morphologic feature is inferred from circular markings seen on a few bars. As reconstructed, the sand under the animal was compressed anteriorly and laterally; the animal then brushed particles forward into a small dune-like bar, probably by the action of cilia on its ventral surface. Sand dwelling microorganisms displaced by brushing were concentrated centrally, obviating ingestion of large amounts of sediment. What sediment was taken in was released at irregular intervals through a posterior anus; medial marking on parts of some trails are interpreted as fecal strings. The complex clamping and brushing behavior, implies a well-developed nervous system.

No body fossils are known in the Vendian or in the Paleozoic that could have constructed this form of trail. The proposed method of feeding, if correctly interpreted, is unique. Thus the trail of Climactichnites may constitute the work of an otherwise unknown phylum in the animal kingdom.

OFFICIAL PUBLICATION DATE is handstamped in a limited number of initial copies and is recorded in the Institution's annual report, Smithsonian Year. SERIES COVER DESIGN: The trilobite Phacops rana Green.

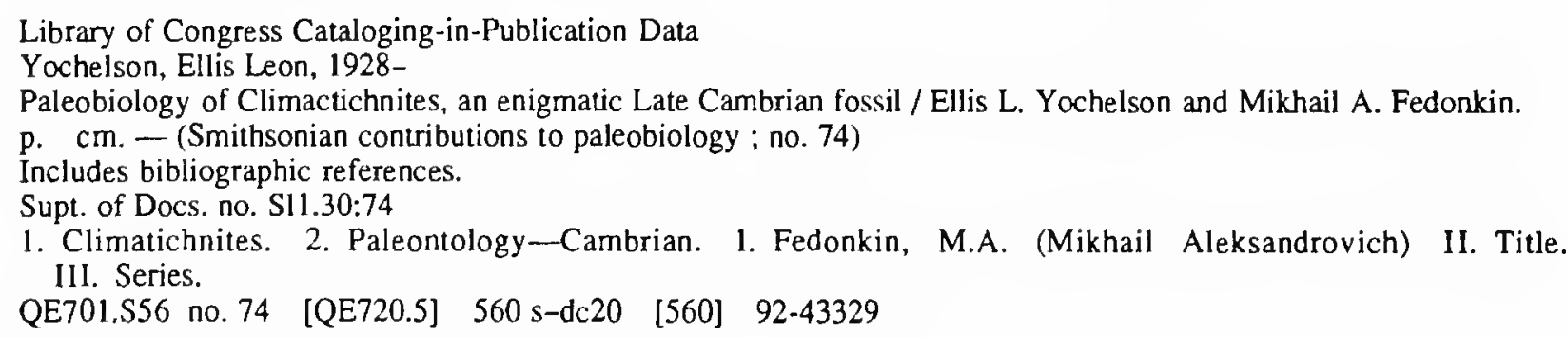

(2) The paper used in this publication meets the minimum requirements of the American National Standard for Permanence of Paper for Printed Library Materials Z39.48-1984. 


\section{Contents}

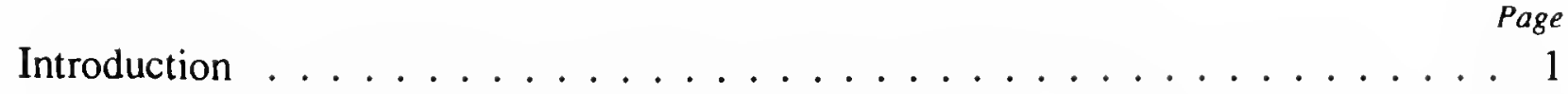

Repositories ....................... 1

Acknowledgments .................... 2

Historical Account . . . . . . . . . . . . . . . . 3

Geographic Distribution . . . . . . . . . . . . . . . 5

Stratigraphic Range . . . . . . . . . . . . . . . . . . 9

Environmental Setting . . . . . . . . . . . . . . . . . . 12

Systematic Paleontology . . . . . . . . . . . . . . . . 18

Phylum Incertae Sedis . . . . . . . . . . . . . . . . . . . . . . 18

Genus Climactichnites Logan, $1860 \ldots \ldots$. . . . . . . . . . . 19

Climactichnites wilsoni Logan, $1860 \ldots \ldots$. . . . . . . . . . 19

Details of Morphology . . . . . . . . . . . . . . . . . . . . . 21

Abundance and Size Distribution of Trails . . . . . . . . . . . 33

Earlier Views on the Origin of Climactichnites . . . . . . . . . . . 35

Comments on Earlier Hypotheses of Origin . . . . . . . . . . . . . 44

Altemative Hypotheses . . . . . . . . . . . . . . . . 663

Paleoecological Interpretation of Climactichnites . . . . . . . . . 63

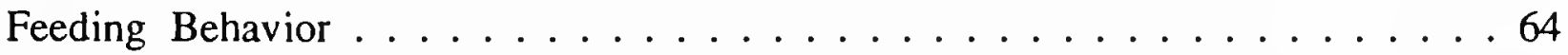

Locomotion and Trail Formation .................... . . . . . . . .

Climactichnites and the Early Ichnological Record . . . . . . . . . . . 67

Reconstruction of Climactichnites . . . . . . . . . . . . . . 68

Ichnogenera and High-level Taxa . . . . . . . . . . . . . . 70

Discussion . . . . . . . . . . . . . . . . . 70

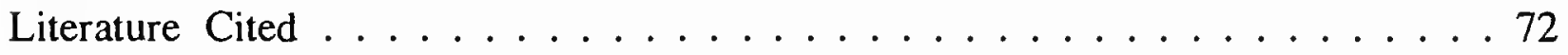






FRONTISPIECE.-A large slab on public display off the east side of the Rotunda on the first floor of the National Museum of Natural History. Smithsonian Institution, Washington, DC. This material was collected by C.D. Walcott in 1886 from "Rogier's Farm, one mile west of Beauhar nois, Quebec" (locality 10). Numerous trails of Climactichnites wilsoni Logan in varying orientation cover the surface of the ripple-marked slab of Late Cambrian "Potsdam" Sandstone. The area at the lower left bears faint markings of Protichnites, some of which obscure portions of the Climactichnites trails. Photograph by V. Krantz, USNM. 


\title{
Paleobiology of Climactichnites, an Enigmatic Late Cambrian Fossil
}

\author{
Ellis L. Yochelson \\ and Mikhail A. Fedonkin
}

\section{Introduction}

Clark and Usher (1948:26l) wrote: "Of the few fossils found in the potsdam sandstone none have been of wider interest than Climactichnites." Not only is this an accurate statement, despite lack of capitalization of the formational name, but that work of more than four decades ago constitutes virtually the last contribution of new observations on this fossil. During September, 1990, we engaged in intensive field and laboratory investigation of this fossil in an effort to better characterize and understand it. Climactichnites Logan, 1860, is known only from its trail, which superficially resembles that of a motorcycle tire print; one, however, which was impressed on damp sand that has been hardened into rock for slightly more than 500 million years.

In 1886, Charles Doolittle Walcott was interested in obtaining specimens of the coeval Protichnites Logan, a trace fossil which obviously possessed multiple legs and apparently a median spike-like posterior telson. As a result of his efforts, an exceptionally large slab containing numerous examples of both Climactichnites and Protichnites were collected from "a mile west of Beauhamois, Quebec" (Walcott, 1912:277). Four men were employed for almost a week in the quarrying of large pieces of a sandstone layer; the material removed probably weighs nearly three tons and transporting it from the outcrop to Washington, D.C. was a heroic operation.

It is not known whether this sandstone was exhibited in the original United States National Museum, now the Arts and Industries Building (Smithsonian Institution, Washington, D.C.), but for many years the slabs were displayed on a low pedestal in the Hall of Invertebrate Life in the "New National Museum" (National Museum of Natural History, Smithsonian Institution). Forty years later, when the exhibits were changed,

Ellis L. Yochelson, Research Associate, Department of Paleobiology, National Museum of Natural History, Smithsonian Institution, Washington, D.C. 20560. Mikhail A. Fedonkin, Paleontological Institute, Russia Academy of Sciences, 117868 Moscow, Russia. they were placed in storage. When the paleontological displays were reconstructed for the third time, the stratum was carefully assembled and the cracks between pieces were restored by Mr. John Ott, under the general direction of Mr. Frederick J. Collier. The bedding plane now stands vertically, as the largest known public exhibit of Climactichnites, and serves as an introduction to the museum visitor of the wonders of the fossil record. Curiously, this bedding plane has never been illustrated, nor studied in detail. We reproduce this reconstructed bedding plane as an appropriate Frontispiece to our study.

With this slab as the point of departure, the aim of our study is to summarize the geologic and geographic distribution of Climactichnites and to describe the characteristics of its trail, which is documented by a large number of specimens. From this information, we have attempted to interpret the ecology and life habit of the trace-maker. Finally, from this data and from our inferences we have reconstructed the morphology of the animal. Our photographic documentation permits those who may not accept our conclusions to consider further this most enigmatic, but most interesting, fossil.

REPOSITORIES.-The following abbreviations are used for institutions housing specimens used in this study.

$\begin{array}{cl}\text { AMNH } & \begin{array}{l}\text { American Museum of Natural History, New } \\ \text { York, NY }\end{array} \\ \text { GSC } & \begin{array}{l}\text { Geological Survey of Canada, Ottawa, On- } \\ \text { tario, Canada }\end{array} \\ & \begin{array}{l}\text { Miller Museum, Queens University, Depart- } \\ \text { ment of Geological Science, Kingston, On- } \\ \text { tario, Canada }\end{array} \\ \text { MPM } & \begin{array}{l}\text { Milwaukee Public Museum, Milwaukee, WI } \\ \text { New York State Museum, New York State } \\ \text { GYSM }\end{array} \\ \text { PNH } & \begin{array}{l}\text { Pratt Museum of Natural History, Amherst } \\ \text { College, Department of Geology, Amherst, } \\ \text { MA }\end{array}\end{array}$




$\begin{array}{ll}\text { RM } & \begin{array}{l}\text { Peter Redpath Museum, McGill University, } \\ \text { Montreal, Quebec, Canada }\end{array} \\ \text { ROM } & \begin{array}{l}\text { Royal Ontario Museum, Toronto, Ontario, } \\ \text { Canada }\end{array} \\ \text { SMM-P } & \begin{array}{l}\text { Science Museum of Minnesota, St. Paul, MN } \\ \text { USNM }\end{array} \\ & \begin{array}{l}\text { National Museum of Natural History (for- } \\ \text { merly the United States National Museum), } \\ \text { Smithsonian Institution, Washington, DC }\end{array}\end{array}$

ACKNOWLEDGMENTS.-Fedonkin thanks the Office of Fellowship and Grants, Smithsonian Institution, for the opportunity to visit Washington, D.C., under the short term visitors' program. Yochelson thanks the Office of the Director, National Museum of Natural History, for travel funds allowing both to examine Climactichnites on the outcrop and to study slabs with this fossil in the collections of a number of museums. The Field Museum of Natural History and Harvard University supported the travel of Fedonkin to examine specimens at those institutions. Late in 1990, Amherst College provided funds for a visit by Yochelson to examine specimens in the Pratt Museum, and in 1991 the University of Wisconsin provided funds for a visit by him to a new locality in that state.

Many persons cooperated to make our field season a success. In Wisconsin, Mr. and Mrs. William Nemke, Harley, Wisconsin, kindly allowed access to the Northern Stone Company quarry, and also contributed several specimens to the National collections. Dr. Jean L. Hoff, Department of Geology, University of Wisconsin-Eau Claire, guided us to choice specimens in the field, and later provided a large latex replica from one outcrop. Dr. Klaus Westphal, Geology Museum, University of Wisconsin-Madison, allowed access to an exhibited specimen in his charge. Dr. Robert H. Dott, Jr., Department of Geology and Geophysics, University of Wisconsin-Madison, provided significant discussion, field data, and a field excursion in 1991. At the Milwaukee Public Museum, Dr. Peter M. Sheehan, allowed access to the fossil collections, and Ms. Paula Sumpter was particularly helpful in arranging for us to examine and photograph an exhibited specimen and further assisted with photography in the research collections.

In Ontario, Ms. Janet B. Waddington, Royal Ontario Museum, Toronto, diligently searched the collections and found a hitherto unreported topotype of Climactichnites wilsoni. Dr. Guy M. Narbonne, Department of Geological Sciences, Queen's University, Kingston, allowed the photography of two unusual slabs in the departmental collections of the Miller Museum (Yochelson and Fedonkin, 1991). He and Dr. Robert Dalrymple of that department provided significant discussion and field data. At Perth, Mr. Douglas McNicol, Curator of the Archibald W. Campbell Memorial Museum, located yet another topotype. In Ottawa, Dr. Thomas E. Bolton, Geological Survey of Canada, arranged for Sir William Logan's type slab to be uncrated and reassembled for our inspection.
In Quebec, Ms. Delise Allison, Peter Redpath Museum, McGill University, greatly assisted in photography of a slab on display, earlier illustrated by Sir William Dawson, and located several plaster casts which he had made. At St. Hermas, Mme. Yvonne Leroux kindly permitted us to examine outcrops on her property.

In New York, Dr. J. Mark Erickson, Department of Geology, St. Lawrence University, and Dr. Richard H. Lindemann, Department of Geology, Skidmore College, accompanied us in the field. Dr. Ed Landing, State Paleontologist allowed access to specimens in his charge; Mr. Charles ver Straaten arranged for us to photograph a displayed slab in advance of the opening of the New York State Museum, Albany, and materially assisted with assembling heavy slabs in the research collections. Finally, at the American Museum of Natural History, New York, Mr. Sidney Horenstein located a slab in a basement storeroom, which revealed significant data.

Mr. R. Eng, formerly of the Museum of Comparative Zoology, Harvard University, and Dr. M. Nitecki, Field Museum of Natural History, Chicago, aided Fedonkin, as did Dr. E.S. Belt assist Yochelson at the Pratt Museum of Natural History. Dr. Bruce R. Erickson, The Science Museum of Minnesota, St. Paul, in 1989 allowed Yochelson access to specimens he had collected; further, he provided an unpublished sketch of these trails as they were on the outcrop, several photographs, and a plaster cast. At a late stage in this study, Dr. A.C. Spreng, University of Missouri-Rolla, kindly supplied a photograph of a slab from that state and Dr. David W. Houseknecht, University of Missouri-Columbia, supplied unpublished information on the Lamotte Sandstone. In 1991, Mr. Robert Pody, Harrisburg, Pennsylvania, donated a specimen to the University of Wisconsin, thereby directing attention to a new stratigraphically significant locality.

Many persons responded to inquiries concerning potential localities, possible repositories of specimens, general information on geology, or provided helpful suggestions. These include: Dr. C. Galvin, Springfield, Virginia; Dr. D.J. Geist, University of Idaho; Dr. R.N. Ginsberg, University of Miami; Dr. Yvon Globensky, Québec Departement de l'Exploration Geologique et Minérale, Montreal; Dr. G.D. Johnson, Dartmouth College; Drs. R.M. Linsley and Bruce Selleck, Colgate University; Dr. Carl Mendelsohn, Beloit College; Dr. A.K. Rindsberg, Alabama Geological Survey, Tuscaloosa; Dr. A. Yu Rosanov, Paleontological Institute, Moscow; Dr. W.A.S. Sarjeant, University of Saskatoon; Dr. Colin Steam, McGill University; and Mr. David Williams, Ontario Department of Transportation, Toronto. Mr. Lance Erickson, age 8, made a careful pencil rubbing of a slab on Wellesley Island, New York.

At the National Museum of Natural History, considerable photographic assistance was rendered by Mr. Victor Kranz and the photographic laboratory of the museum. Mr. Keith Moore, U.S. Geological Survey, gave equally valuable help. Ms. Susan Socks, U.S. Geological Survey, greatly assisted in word processing. An earlier draft of this manuscript was read by Dr. 
Robert H. Dott, Jr., University of Wisconsin-Madison, Dr. Rodney M. Feldmann, Kent State University, and Dr. Kristian Fauchald, Department of Invertebrate Zoology, National Museum of Natural History, and improved by their comments. Dr. T.M. Bown, U.S. Geological Survey, Denver, Dr. Bruce Runnegar, University of California, Los Angeles, and an anonymous critic, further improved the manuscript.

Ms. Mary Parrish, scientific illustrator in the Department of Paleobiology, is to be credited with the reconstruction presented herein. She asked insightful questions which forced us to be specific where we had generalized. In spite of numerous iterations, she remained cheerful, and the results of her nimble pen graphically summarize our conclusions.

\section{Historical Account}

More than a century ago, Sir William Logan (1860) described a large and striking trackway that was found at Perth, Ontario, by Dr. James Wilson, a medical doctor and important local geologist-naturalist. Logan named it Climactichnites Wilsoni after its discoverer (capitalization of patronyms was then the accepted practice in nomenclature); the generic name refers to its similarity in appearance to a rope ladder. The specimens were collected in December 1859 by James Richardson, who built a fire in the local quarry to heat the rock and then quenched it with snow to crack the rock. Zazlow (1975:73) discusses the discovery, which followed by a decade the even more dramatic discovery by Logan (1851) of Protichnites in the Potsdam Sandstone. This is another enigmatic form, but one more readily interpreted as the trackway of a multi-legged organism striding over unconsolidated sand.

At the time the above two fossils were named, they were virtually the only organic remains known from the Potsdam Sandstone. They were also thought to be nearly the oldest fossils in the world. In the geologic understanding of the time, the Potsdam Sandstone was essentially the first geologic formation above the ancient basement rocks of the "Primary" in North America, and it was stratigraphically below the highly fossiliferous "Silurian." The relationship of the Potsdam Sandstone to the Cambrian System, named by Sedgwick from north Wales, was not yet evident, and the correlation of this sandstone to the Primordial Fauna of Barrande, described from Bohemia, was only just being established. The Potsdam Sandstone, named from Potsdam, New York, was the first stratigraphic name used by the New York State Natural History Survey.

A lifelong bachelor, Logan lived in the building of the Geological Survey of Canada. After describing his living arrangements, Bell (1907:6) wrote:

Such was the room in which Logan worked, but about 1860 a new feature was introduced in the shape of an immense slab of sandstone which entirely covered the wall on one side. This slab was from Perth in Upper Canada and was traversed by crustacean tracks called Climactichnites Wilsoni. Every morning
Sir William gazed on this slab with fond admiration, first with one eye and then with the other, as he held his towel and dried his face with alternate hands.

Logan was an astute observer, both as a geologist and in his sole effort as a paleontologist. In his 1860 publication, he noted the crenulated margin of the lateral ridges, the variation in shape of bars and furrows between these ridges, and the local presence and irregularity of a medial ridge, all key features for interpretation. Five drawings, clearly illustrating these features, accompanied the description and discussion (Figure 1). Because of the remarkable nature of this fossil and its geologic occurrence, Logan's original report was republished in the American Journal of Science the following year (Logan, 1861). Hall (1889) again republished Logan's account, unchanged except for combining Logan's five figures onto one plate.

Four years time after the type material was collected, plaster casts were made of portions of slabs and sent to Professor Edward Hitchcock of Amherst College. These unfigured casts are in the collection of the Pratt Museum under numbers $58 / 1-58 / 8$, Hitchcock is rightly considered the "father" of paleoichnology from his work on footprints in the Connecticut River valley Mesozoic. Unfortunately no correspondence between Logan and Hitchcock can be located which bears on this scientific exchange. Hitchcock died in 1864 before he could present an opinion as to the formation of the trail.

From the time of its first description, Climactichnites engendered speculation as to the nature of the elusive trace-making animal. Even its nature as the trail of an animal was questioned by Chapman (1877), who considered it a fucoid. In an extent of the geographic range of the genus, Todd (1882) described specimens from New Lisbon, Wisconsin, which he named Climactichnites Youngi, again a patronym after the discoverer, Reverend A.A. Young, and Todd provisionally suggested yet another name, C. Fosteri. Reproduction of earlier illustrations of the trace fossil appeared in several textbooks of the time, though none contributed new data.

The Smithsonian Archives retain letters of a collector, Cooper Curtice, whom Walcott sent to Wisconsin. On August 16,1884 , Curtice reported to Walcott that he had been to New Lisbon and contacted Reverend Young.

Luckily we found Mr. Fish working in his quarry. Together we uncovered a slab about $5 \mathrm{ft}$ by $3^{1} / 2 \mathrm{ft}$ which showed the tracks admirably. It weights $600-800$ lbs... There were 3 pieces showing various tracks that are very desirable in the sidewalks. We arranged with the owners that these should be replaced by new stones and they are to be shipped. Procured a slab a foot square at Camp Douglas by gift which in its way is neat, clearly cut and better than anything figured or that I have seen yet. It probably teaches more. Rev. Young is enthusiastic and generous of time but pastor of a small church. I left just about enough money with him to cover expenses.

This material cannot be traced and may have been discarded in the move a quarter of a century later to the "new" National Museum.

In 1888, local quarrying for paving material at Port Henry, New York, yielded abundant trails. Hall (1889) persuaded the 


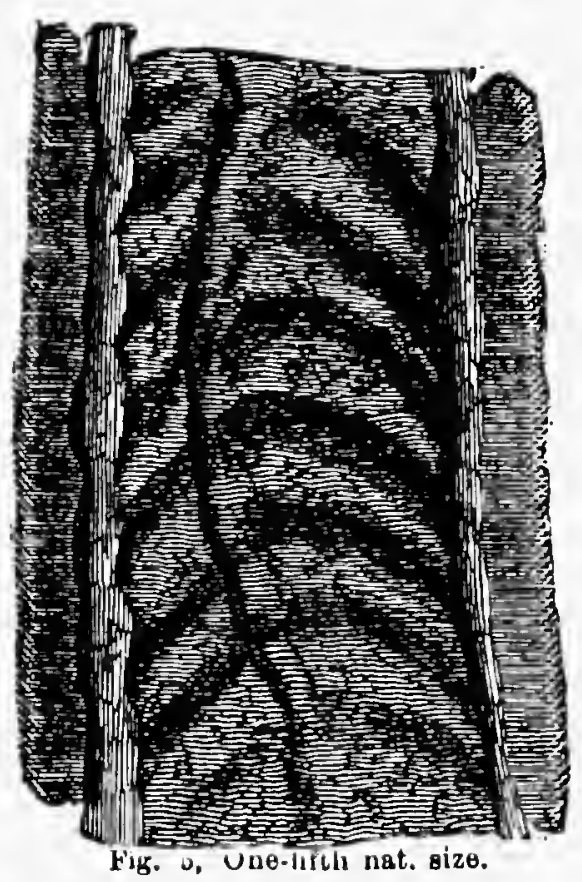

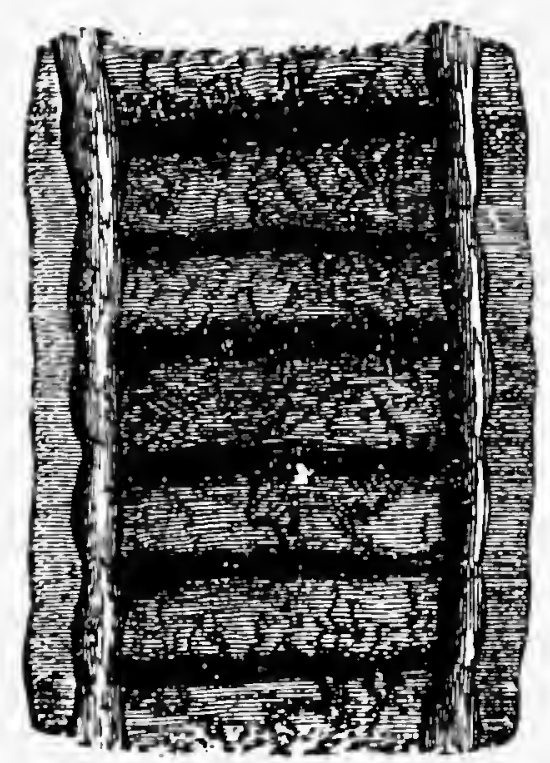

Fig. 2, One-fifth nat. 8 lze.

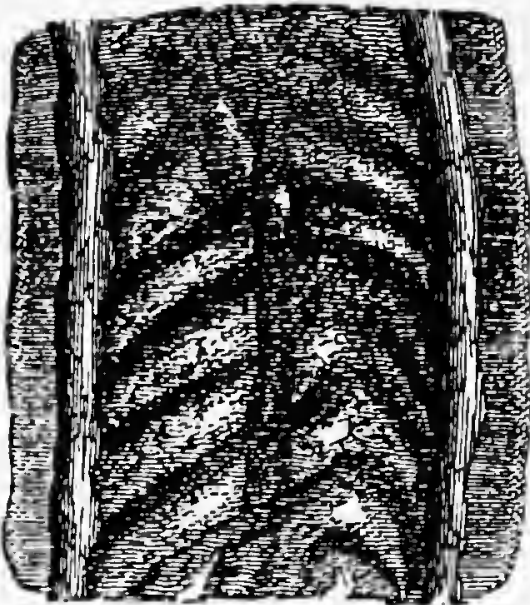

Fig. 4, Ono-fiftl nat. size.

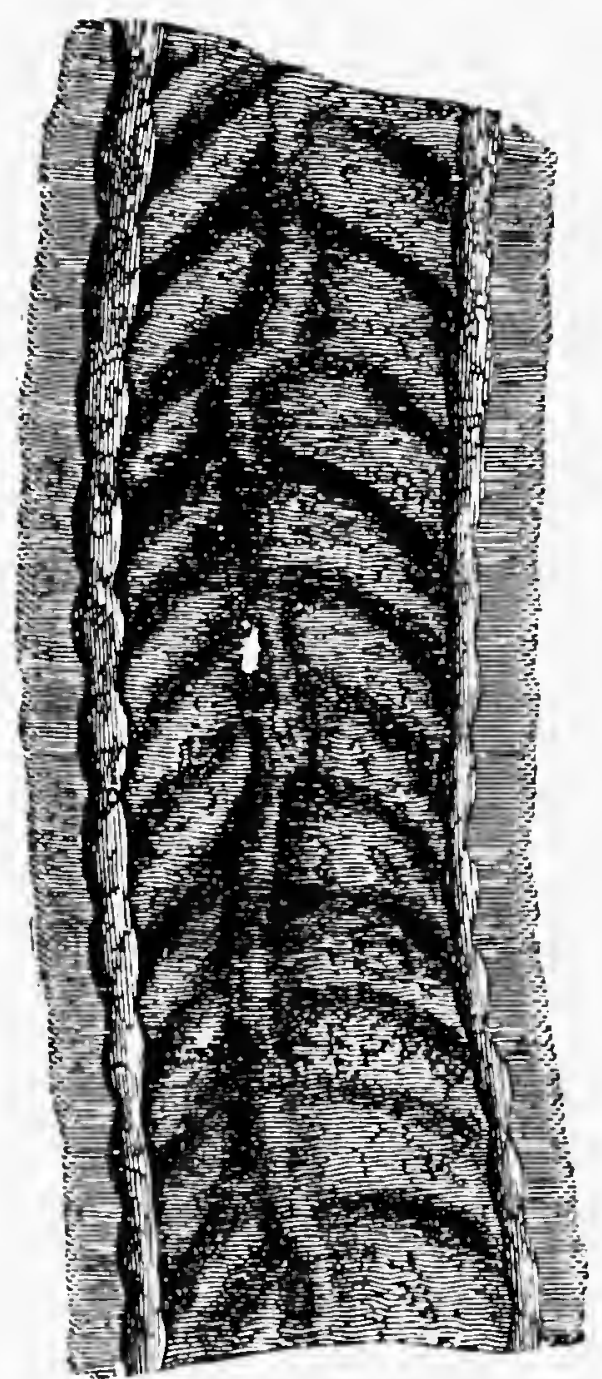

Fig. 3. One-fifth nat. size.

Fig. 1, One-thirtleth nat. size.

FIGURE 1.- Copy of the original illustrations of Climactichnites wilsoni from Logan (1860), rearranged in order but bearing his captions. When compared to the original, illustrated in Figure 18, Logan's figure I is reversed. The other four may also be drawn as positives, rather than sole markings, but this point is not entirely clear.

town council to send part of their new sidewalk to the New York State Museum at Albany in return for comparable non-fossiliferous paving blocks. Another very large slab from the same area, probably nearly half a ton in weight, is in the Milwaukee Public Museum; its history is unknown.

Just after the turn of the century, a large assemblage of Climactichnites trails was found at Mooers, in northern New York. Woodworth (1903) in his account of this discovery and interpretation of the fossils described an important new feature of morphology, an oval-shaped impression at one end of some of the trails, plus a few of these impressions separate from any trails. Clarke (1905) published a sketch of the outcrop showing the distribution of trails and oval impressions, but did not discuss them in any detail, confining his remarks to the efforts made to quarry a large portion of this outcrop and transport it to Albany. Walcott (1912) described another oval impression 
from Wisconsin, one sent to him in 1886 by Reverend Young who had discovered the material described by Todd. So far as we know, receipt of this oval impression and Walcott's collecting at Beauharnois, Quebec, the same year were coincidental.

In a masterful paper, Burling (1917) provided careful description and interpretation of Climactichnites. He proposed that the animal moved away from the oval impression, not towards it as had been suggested by Woodworth. Clark and Usher (1948) sketched trails that crossed over themselves and confirmed the direction of movement which had been inferred by Burling. Finally, Summerson (1951) briefly noted the occurrence of the fossil in Missouri and documented this with a sketch. That material was compared with a slab of Climactichnites from the "Potsdam Sandstone," provenance unknown, which was outside of Orton Hall, Ohio State University, but was subsequently stolen (Dr. S. Bergstrom, oral communication, 1991).

In part because of the large size of the fossils, there has been a dearth of photographic illustrations. For the first five decades that this fossil was known, most information was conveyed by sketches, and these at a greatly reduced size. Walcott (1912) and, to a lesser extent, Burling (1917) did use photographs to supplement discussion. Burling photographed two of the oval impressions on a plaster cast, and Abel (1935) provided the only photograph heretofore of an actual specimen of the oval impressions from Mooers; both illustrations were at a greatly reduced size. Photographs of trails on the outcrop were not published until quite recently (Globensky, 1987). Dawson (1890) published a photograph of a slab, lacking in some details because of the prevailing methods of reproduction. A hundred years later, a clear illustration of this same slab was published (Stearn and Carroll, 1989, fig. 20-2).

As a consequence of the limited number and small size of illustrations, the great amount of individual variation and many of the details of trail formation were not recognized, even though these points were indicated in the original sketches of Logan (1860). We judge that the illustrations provided herein are the single most significant aspect of our effort. For most illustrations, all or part of a scale $15 \mathrm{~cm}$ long is included; in a few, the photographic scale is in both centimeters and inches marked by alternating black and white intervals.

The only reference we have been able to find to a species of Climactichnites outside of North America is that of C. mathieui Sun (1924:16), named from the Lower Cambrian Manto Shale of north China. This trail, if it is a trail, is about half the width of the smallest Climactichnites we have observed. Only a short length is preserved which shows a prominent $V$, but we see no indication of lateral ridges. In the absence of that important morphological feature, we remove this species from the genus. Because of the lack of detail presented in the single illustration, we are unable to reassign the species and will not consider it further in our discussion.

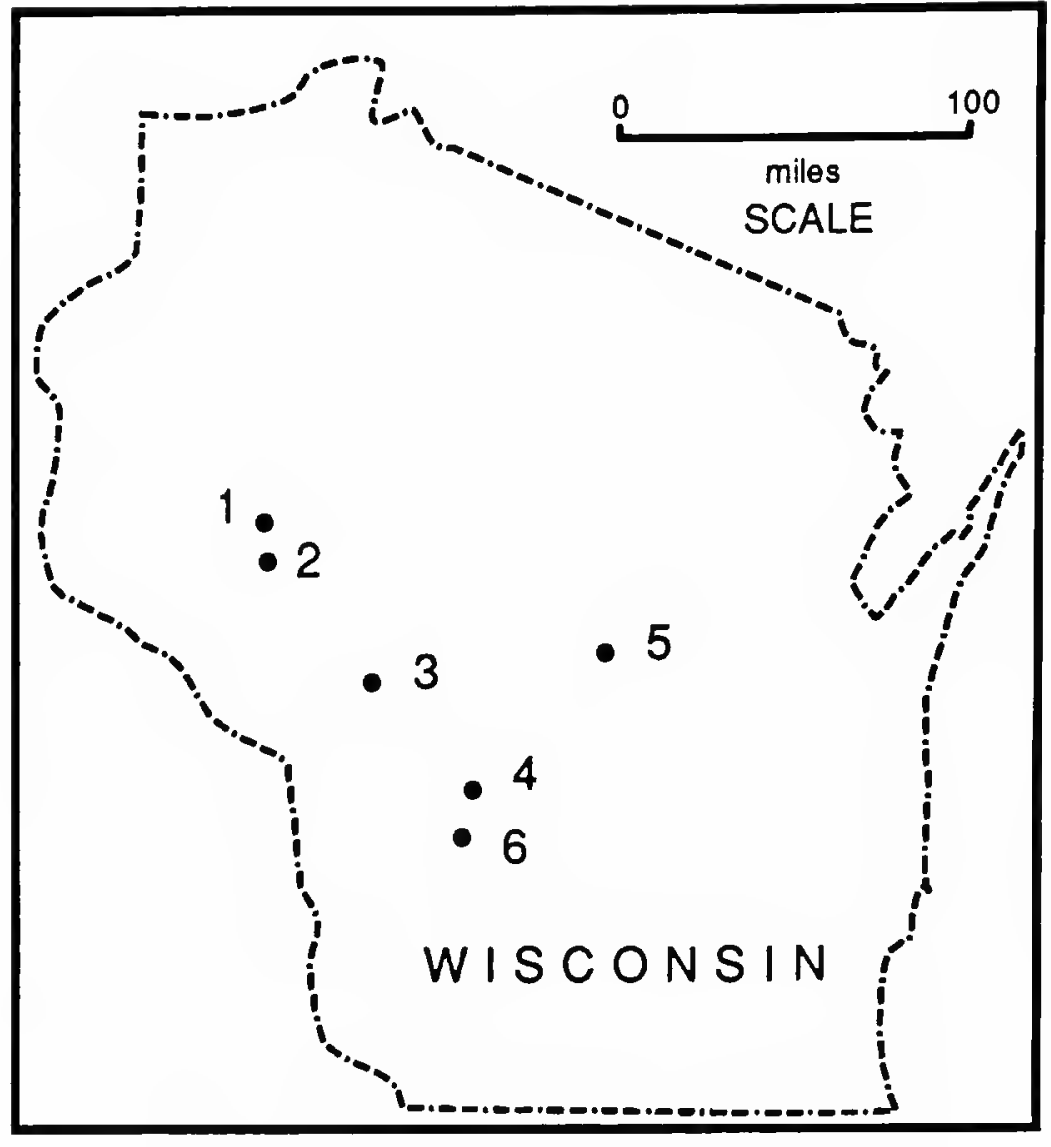

FIGURE 2.- Outline map of Wisconsin, showing localities mentioned in the text. (1) Chippewa Falls; (2) Eau Claire; (3) Black River Falls; (4) New Lisbon; (5) Stevens Point; (6) Mauston.

\section{Geographic Distribution}

In many sequences, body fossils are more common than trace fossils, for bedding plane surfaces are often required to expose horizontal traces. In dealing with Climactichnites, an unusually large horizontal trail, we have been impressed with how much discovery of the fossil depends on the presence of a large bedding plane surface. Exposures of such do occur naturally, but in platform regions in northern climates where soil is present, they are far less common than are vertical exposures. We have been unable to find any indication of Climactichnites in any of the vertical exposures we examined, including the walls of quarries known to have yielded these fossils. Collection of Climactichnites has been greatly influenced by artificial exposures. Thus, the type localities for the named species are tiny, abandoned quarries from which stone for local use was obtained a century or more ago. To discover these traces, a quarry must not only be opened for flagstone, but its operation must intersect the proper layer, and the material exposed must come to the attention of an interested person who has the resources for large-scale collecting. Viewed from this aspect, it is surprising that so many localities for Climactichnites exist and so many specimens are in museums.

Climactichnites is known in Wisconsin from six general areas (Figure 2); localities numbered 1-6 are used in the text and refer to this figure. Dr. J.L. Hoff reported to us an occurrence in the Irvine Zoological Park at Chippewa Falls (1). With Dr. Hoff, we investigated at least a dozen locations along a kilometer of the Chippewa River in Eau Claire (2), each of 


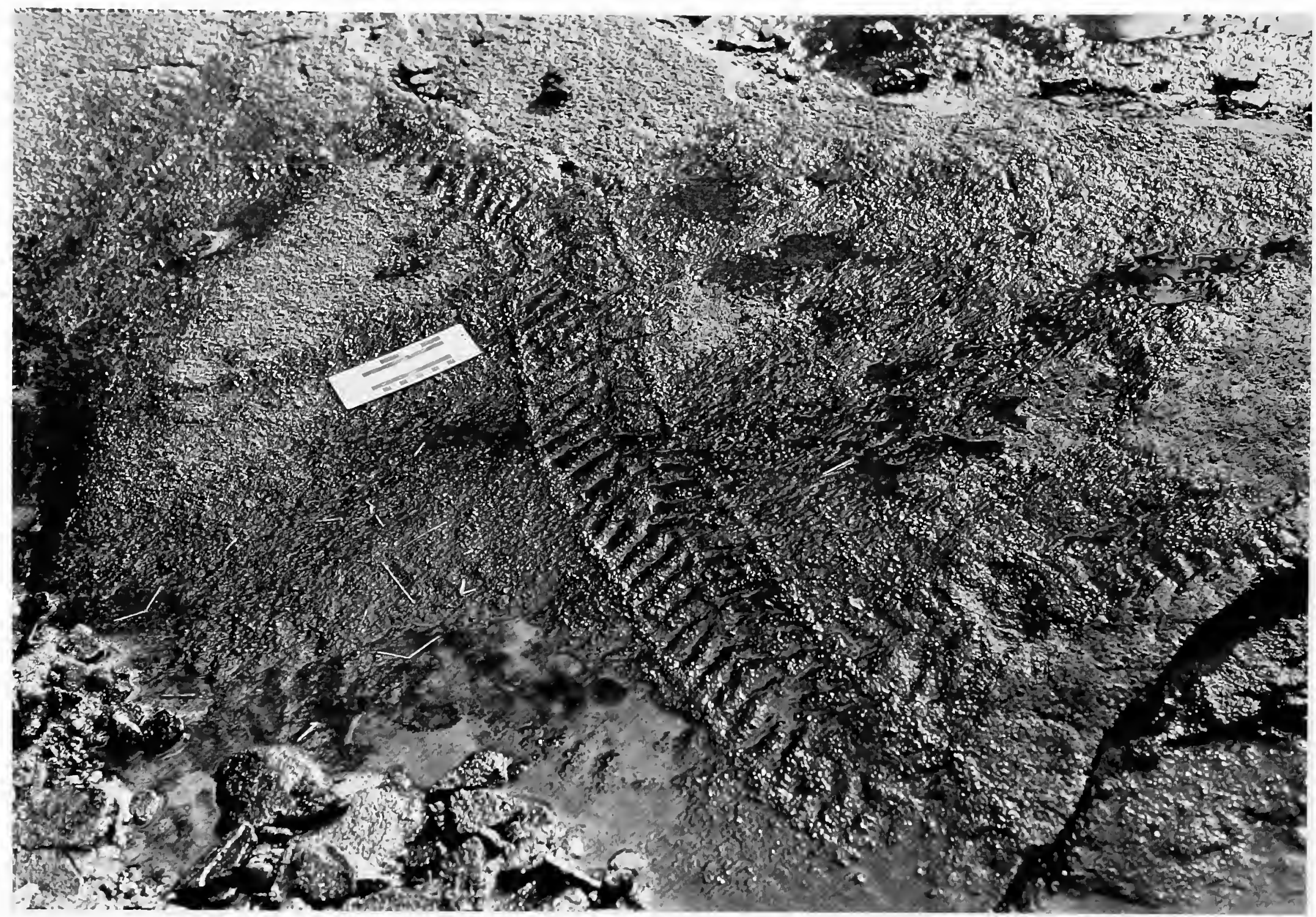

FIGURE 3.-Outcrop of cross-bedded Mount Simon Sandstone, exposed at low water level, on the west bank of the Chippewa River, Eau Clair, Wisconsin (2). The wide trail was made by a Climactichnites moving toward the lower right and crossing another trail at right angles. In the upper left, another trail is also at right angles, but is on a layer about $1 \mathrm{~cm}$ higher in the section. Scale is indicated by a $10 \mathrm{~cm}$ ruler.

which shows several trails when the water level is low; specimens are most common on the west bank (Figure 3), but are present on both sides of the river. Near Black River Falls (3) two separate occurrences are known. Dr. R.H. Dott, Jr. has shown us photographs of a large trail along the Halls Creek tributary of the Black River. In 1976, Dr. B.R. Erickson collected Climactichnites from just below Polly Falls on the Robinson Creek tributary; this material is now at the Science Museum of Minnesota.

The type locality for $C$. young $i$ is "two quarries located near the Lemonweir River. They are about four miles north of the village of New Lisbon" (Todd, 1882:276). We were able to locate one obvious abandoned quarry and another small former operation about six kilometers from New Lisbon (4) in the $\mathrm{SW}^{1 / 4}, \mathrm{NE}^{1} / 4$, Sec. 19 , T. 17 N, R. 3 E, Juneau County, but both are overgrown and no bedrock is exposed. At the Northern Stone Company quarry, about five kilometers northeast of Stevens Point, Wisconsin, in the $\mathrm{NE}^{1} / 4, \mathrm{NE}^{1} / 4, \mathrm{Sec} .34, \mathrm{~T} .26 \mathrm{~N}$,
R. 8 E, Marathon County (5), Mr. W. Nemke showed us a large quarry surface containing these fossils (Figure 4). Another layer about $2 \mathrm{~m}$ higher in the section has also yielded Climactichnites, but large surfaces of this layer were no longer available.

Finally, near Mauston (6) two occurrences are known. In field notes written in 1927, Gilbert Raasch reported a quarry surface in the $\mathrm{NE}^{1 / 4}, \mathrm{NE}^{1} / 4$, Sec. 16, T. $13 \mathrm{~N}, \mathrm{R} .4 \mathrm{E}$, Juneau County, which was covered with Climactichnites. This locality is now overgrown and nothing can be observed. However, in 1991 , specimens were found by Mr. R. Pody in a road cut on the east side of Country Road K, near the north line of Section 31 , in the $\mathrm{NE}^{1 / 4}, \mathrm{NW}^{1} / 4$, Sec. 6, T. $14 \mathrm{~N}, \mathrm{R} .4 \mathrm{E}$, Juneau County.

As noted above, Climactichnites has been reported from Missouri by Summerson (1951:533). "It is in a small highway cut on the north side of Missouri State Highway 70, about 7 miles west of Fredericktown (NE NW SE, sec. 8, T. 33 N. R. 6 E.)" (Figure 5). No other occurrences have been reported in the 


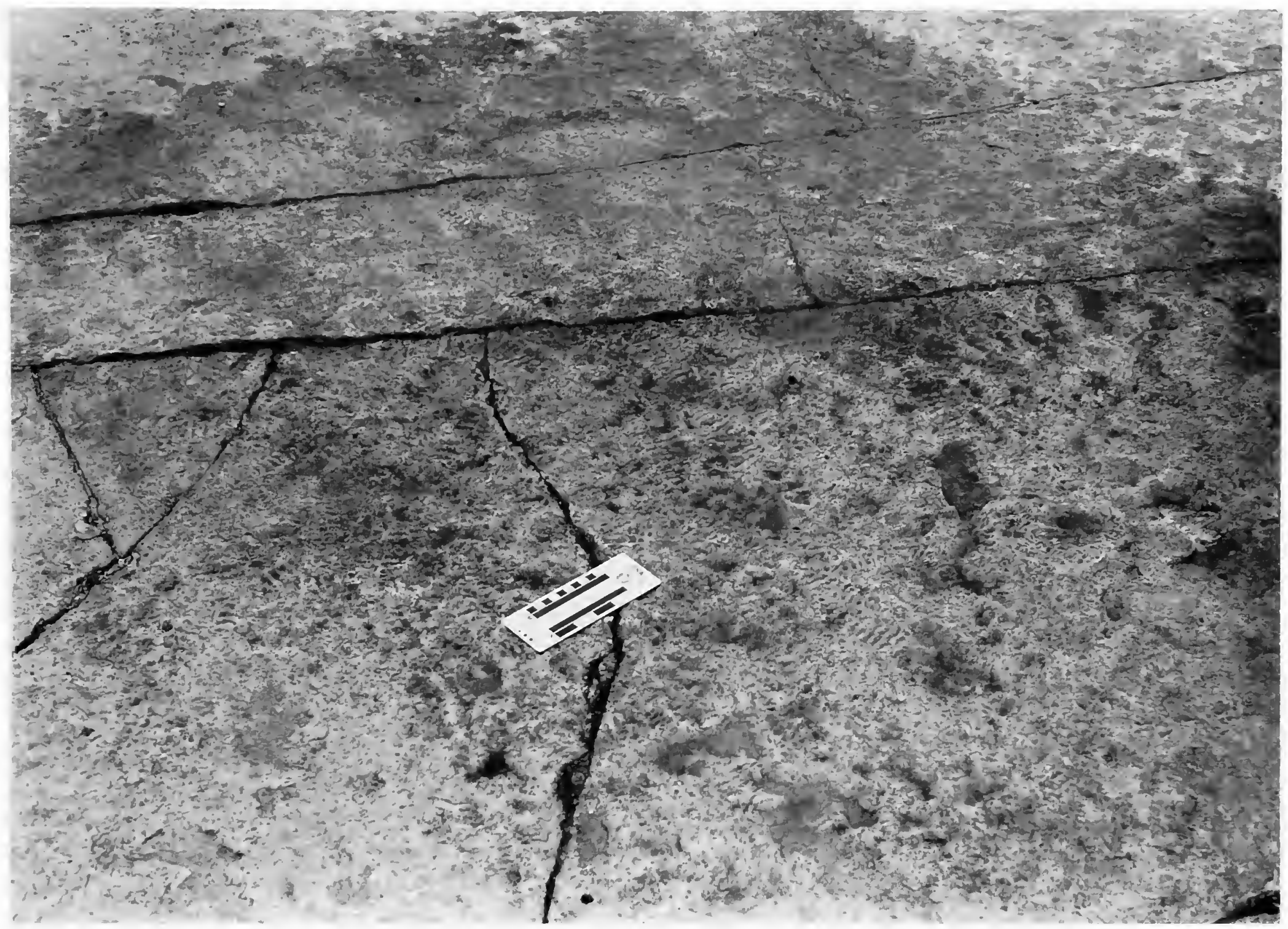

FIGURE 4.-A small portion of the working floor, as it was in 1990, in the Northern Stone Company quarry near Stevens Point, Wisconsin (5). Obscure, but numerous, narrow trails of Climactichnites occur in various orientations throughout the entire field of view. Scale is indicated by a $10 \mathrm{~cm}$ ruler.

literature or are known to geologists we have consulted that are working in the state.

Figure 6 summarizes occurrences in southern Canada and New York; localities numbered 7-14 are used in the text and refer to this figure. In Ontario, Climactichnites is known from two widely separated localities. According to Dr. G.M. Narbonne, a small quarry about $1 \mathrm{~km}$ northeast of the village of Battersea (7), some $25 \mathrm{~km}$ north of Kingston, produced two slabs now in the possession of Queen's University (Yochelson and Fedonkin, 1991). At Perth (8), the precise type locality, in Mr. Glyn's quarry "about a mile from the town..." as it existed in 1859 , cannot be located with any certainty and might now be covered by buildings. A geologic map of the area (Wilson and Dugas, 1961) noted reports of this fossil in Concession III, Lot 6. Through the assistance of Mr. D. McNicol, we were able to locate a small long-abandoned quarry in this area, but did not observe any of the fossils of concern.
Globensky (1987:4, pl. 1) reported and illustrated several large trails of Climactichnites on outcrops about $45 \mathrm{~km}$ west-northwest of Montreal, Quebec, approximately $2 \mathrm{~km}$ north from the village of St. Hermas (9) (Figure 7). We were able to examine those specimens, and found another nearby bedding plane, no more than a meter different in stratigraphic level, upon which were additional examples; Protichnites is also abundant at this locality. As noted above, in 1886, C.D. Walcott collected a large slab bearing numerous trails from "one mile south of Beauharnois" (10) (Frontispiece), about 15 $\mathrm{km}$ southwest of Montreal. No exposures were seen in the vicinity of the town and again the locality may have been a small local quarry, now lost. About $3 \mathrm{~km}$ to the west, a large deep quarry at Melocheville (10) at one time had specimens exposed on the quarry floor (Clark and Usher, 1948); however, the floor is now covered with debris and part of the quarry has been refilled with slag from a nearby aluminum reduction operation. We have been unable to locate any specimens which 


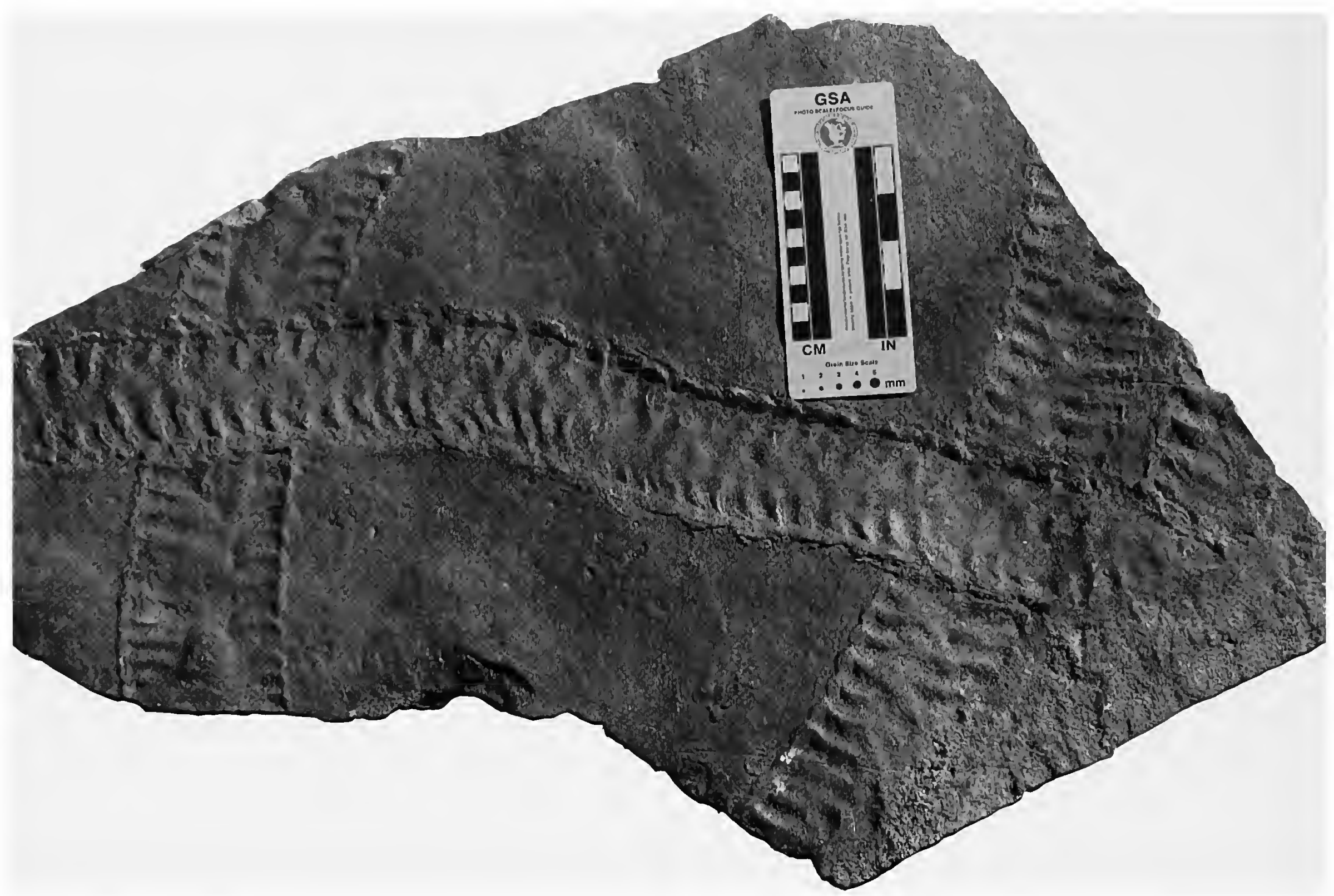

FlGURE 5.-Photograph of slab of Lamotte Sandstone from seven miles north of Fredericktown, Missouri. This slab was sketched by Sumerson (1951), who also noted the presence of Protichnites; these occur just to the left of the trail on the lower right of the slab. There are four Climactichnites trails, one at the left and two at the right, all crossed by a longer one at right angles formed by an animal moving from right to left. The trail at the far right is not well preserved and is best seen near the extreme right of the photograph. Photograph courtesy of Dr. A.C. Spreng, University of Missouri-Rolla. Department of Geology and Geophysics collections, number 7283. Scale is indicated by a $10 \mathrm{~cm}$ ruler.

might have been collected from this quarry or even any photographs of the specimens.

In New York, at the Minna Anthony Common Nature Center on Wellesley Island (11), near Alexandria Bay, a slab bearing Climactichnites is part of a "geological wall" just outside the building. Apparently it was collected from a site on the island but, according to Dr. J.M. Erickson, a small local quarry which might have yielded it is overgrown and has no outcrop. At Mooers (12), also in extreme northern New York, a large part of a bedding plane surface was obtained as a result of two months quarrying (Clarke, 1905). No outcrop is now exposed and only a single rotted railway tie marks the spot. In contrast, we were able to examine a large number of specimens exposed on one bedding plane at Au Sable Chasm (13), Keeseville, a locality reported by Van Ingen (1902) (Figure 8). The locality is east of the steel bridge along the old state highway and just below the dam constructed on the site of Alice Falls in the Au
Sable River. Finally, at Port Henry (14), where Hall (1889:25) convinced the local authorities to donate their sidewalk, we were unable to find any significant outcrops of sandstone. According to residents, there are no local flagstone quarries in operation. The limited number of outcrops of the Potsdam Sandstone and the current lack of Climactichnites specimens in any of the outcrops in this area and at Mooers was independently confirmed by Dr. R.H. Lindemann. Dr. B. Selleck also has not observed this fossil in situ at Port Henry.

To summarize, Climactichnites is known from northeastem and north-central North America. It is widely scattered through outcrops, which if connected would indicate its distribution through an area of several thousands of square kilometers. To the best of our knowledge, the fossil is unknown from other localities in North America or elsewhere, and this trace-making animal could have been endemic to this area. All known occurrences of Climactichnites are in sandstones, a point considered in more detail below. 


\section{Stratigraphic Range}

Climactichnites occurs in rocks that contain virtually no body fossils, so it is therefore difficult to obtain any independent data as to its range. Characteristically, the units in which it is present are dated by trilobites, and occasionally other forms, that occur in the next overlying stratigraphic unit. In most regions, the base of the sandstone bearing Climactichnites is marked by a profound unconformity with the underlying Precambrian. Many years ago, Walcott elaborated the concept of a flooding of the North American continent during the Cambrian, with Upper Cambrian deposits widespread on the cratonic platform, and older beds restricted to continent marginal zones. From this evidence one may assume that there is no basis for suggesting that rocks yielding Climactichnites are Middle Cambrian or older, though such an unlikely prospect cannot be completely refuted.

The Late Cambrian in North America is divided into three stages, Dresbachian, Franconian, and Trempeleauan. Resser (1933) listed the Mount Simon Formation of Wisconsin as the basal unit of the standard Upper Cambrian section, but without any faunal zone indicated for this interval, for it contains no trilobite remains. In a subsequent correlation table, Resser (1938:20) denoted a zone of Climactichnites as the basal interval of the Dresbachian, but without any explanation. Raasch (1939:87) briefly mentions a Climactichnites fauna. In a later correlation chart (Howell et al., 1940), a Climactichnites zone was not mentioned and the Cedaria Zone appeared as basal Dresbachian.

In many of the earlier stratigraphic studies in Wisconsin the Mount Simon Formation below and Eau Claire Formation above were included in Dresbachian time. More recently, the Eau Claire has been restricted and the former upper part has been named the Wonewoc Formation; the Wonewoc is divided into the thick Galesville Sandstone Member and the thin Ironton Member. It is now recognized that beds once interpreted as simple sheet sands in fact represent a complex of intertonguing units deposited in environments ranging from fully terrestrial to fully marine.

Of the occurrences in Wisconsin, localities 1 through 3 are definitely in the lower part of the Mount Simon Sandstone. The locality at the Northem Stone Company quarry (5) is less readily assigned because of the paucity of outcrops in the area, but investigations by Dr. R.H. Dott, Jr., in 1991 indicate that almost certainly the material quarried is from the Mount Simon Formation. This interpretation is supported by information from a local well that suggests the occurrence may be low in that unit. Along the Chippewa River (2), all occurrences appear to be confined to a single stratigraphic unit a few meters thick (Dr. J.L. Hoff, oral communication, 1990); the overlying beds contain Skolithos, Arenicolites, and Rusophycus. The two occurrences along the Black River (3) may be quite low in the formation and extremely close stratigraphically (Dr. R.H. Dott, Jr., oral communication, 1990).

However, the new locality, found in 1991 by Mr. R. Pody, 5

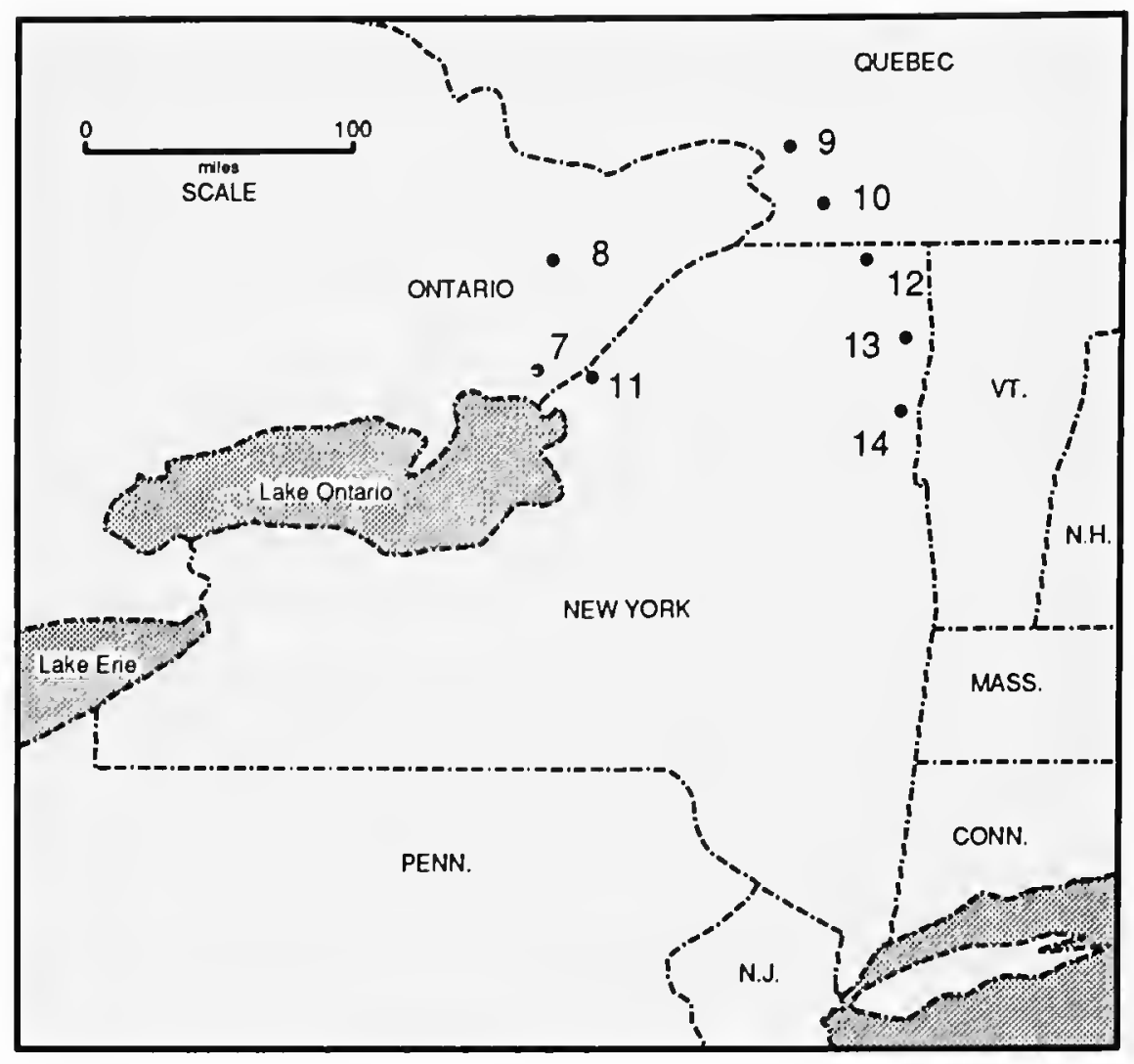

FIGURE 6.- - Outline map of parts of Ontario, Quebec, and New York, showing localities mentioned in the text. (7) Battersea, Ontario; (8) Perth, Ontario; (9) St. Hermas, Quebec; (10) Beauharnois-Melocheville, Quebec; (11) Wellesley Island, New York; (12) Mooers, New York; (13) Keeseville, New York; (14) Port Henry, New York.

mi south of Mauston (6), is younger, though still within the Dresbachian. Specimens occur high in the Galesville Member of the Wonewoc Formation, a non-feldspathic, pure quartz sandstone. The Galesville is interpreted as a sedimentological complex, locally having cross-bedded terrestrial dunes in the lower part, lower-angle cross bedding in the medial portion, and more planar bedding above. The Climactichnites specimens occur low in the planar-bedded unit, which from sedimentological evidence is judged to be a beach deposit. About three meters above the bed bearing the trails, the thin Ironton Member yields numerous tubes of Skolithos; it is interpreted as a littoral marine bed deposited during transgression of the Wonewoc sea (Dott et al., 1986).

The beds in this part of Wisconsin are nearly flat lying. Based on the regional dip of less than one degree, it is probable that the specimens collected from New Lisbon (5) are from the Galesville Member of the Wonewoc Formation, rather than from the Mount Simon; because of large areas of alluvial cover between New Lisbon and Mauston, this stratigraphic assignment cannot be proven. The quarry floor observed by Raasch near Mauston (6) is less readily dated but could also be in the Galesville, based on its elevation.

The new discovery at Mauston (6) makes it obvious that Climactichnites is not confined to a single instant of time, but does have a stratigraphic range through most of the type Dresbachian. Approximately $100 \mathrm{~m}$ of sediment, predominately sandstone, was deposited in Wisconsin from low in the Mount Simon to high in the Galesville.

The sole occurrence in Missouri is in the Lamotte Sandstone 


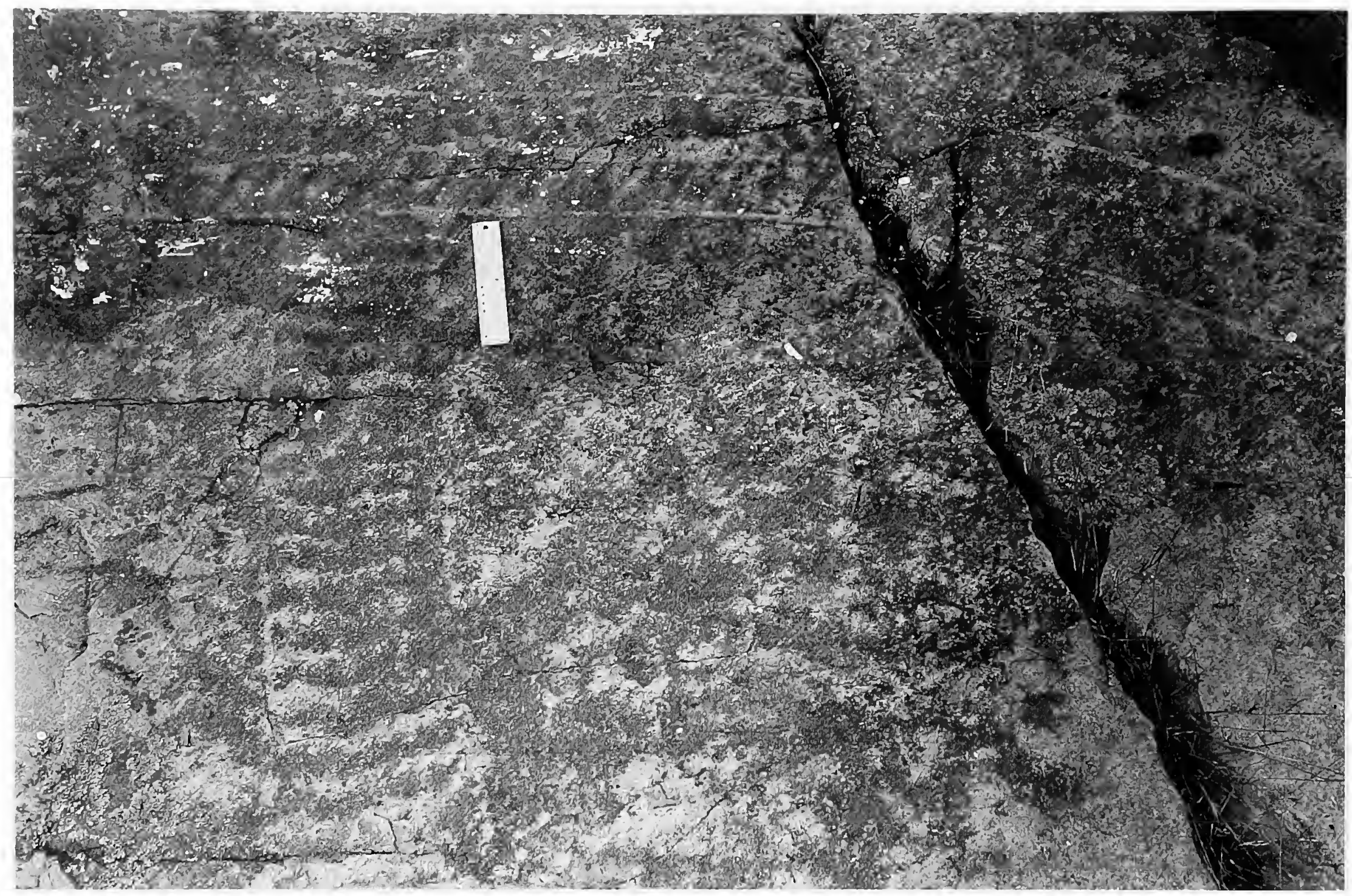

FIGURE 7.-A bedding plane of the Cairnside Formation at St. Hermas, Quebec (9), bearing two very wide trails of Climactichnites. The longer trail, in the backround, formed by an animal moving from right to left, shows a medial marking, which is variable in position relative to the bounding lateral ridges. The trail at the left, formed by an animal moving toward the top of the photograph, shows no such feature. The white blotches at the upper left are plaster of Paris left by an unknown investigator. Scale is indicated by a $15 \mathrm{~cm}$ ruler.

(Summerson, 1951), a unit traditionally considered Dresbachian and correlated to the Mount Simon of Wisconsin. The Lamotte varies greatly in thickness, for locally it fills valleys between buried hills. Houseknecht (1975) found an additional slab bearing Climactichnites as float at the site of the original report, SW $1 / 4, \mathrm{NW}^{1} / 4, \mathrm{SE}^{1} / 4$, Sec. 5 , T. $33 \mathrm{~N}, \mathrm{R} .6$ E. The total thickness of the section exposed in a road cut at this locality is only about $10 \mathrm{~m}$ and $\mathrm{Dr}$. W. Houseknecht is convinced that the fossil occurs very high in the Lamotte. The Bonneterre Dolomite, which overlies the Lamotte Sandstone, has yielded the Dresbachian Cedaria fauna.

In New York, the earliest biostratigraphic information that we are aware of concerning Climactichnites is that of Van Ingen (1902). He made a detailed study of the Au Sable Chasm section at Keeseville (12), and noted that no organic remains were found in the lower part of the formation. "The middle part of the formation has afforded only the Climactichnites tracks at the Birmingham bridge, and numerous irregular, unidentified worm borings and trails" (Van Ingen, 1902:544). Van Ingen developed a zonal scheme based on the few body fossils and other traces found; several species of inarticulate brachiopods and the trilobites Conocephalites verrucosa Whitfield and Ptychoparia minuta Conrad were reported by him, some distance above the Climactichnites bed. Fisher (1968:16) mapped the region in detail and reported Climactichnites in the unnamed medial member of the Potsdam Sandstone. The overlying Keeseville Member is dated by him as Dresbachian because of the occurrences of the earlier named trilobites. Many bedding planes are exposed below the dam and in Au Sable Chasm itself, but except for this single layer no other occurrence of Climactichnites are known. Protichnites occurs with Climactichnites and on bedding planes a few meters below the Climactichnites layer.

The composite section in and around Keeseville may be divided into several sedimentological cycles (Dr. B. Selleck, oral and written communications, 1990). Older non-marine sandstones are followed by Dresbachian subtidal deposits, representing a rapid transgression. These are followed by a 


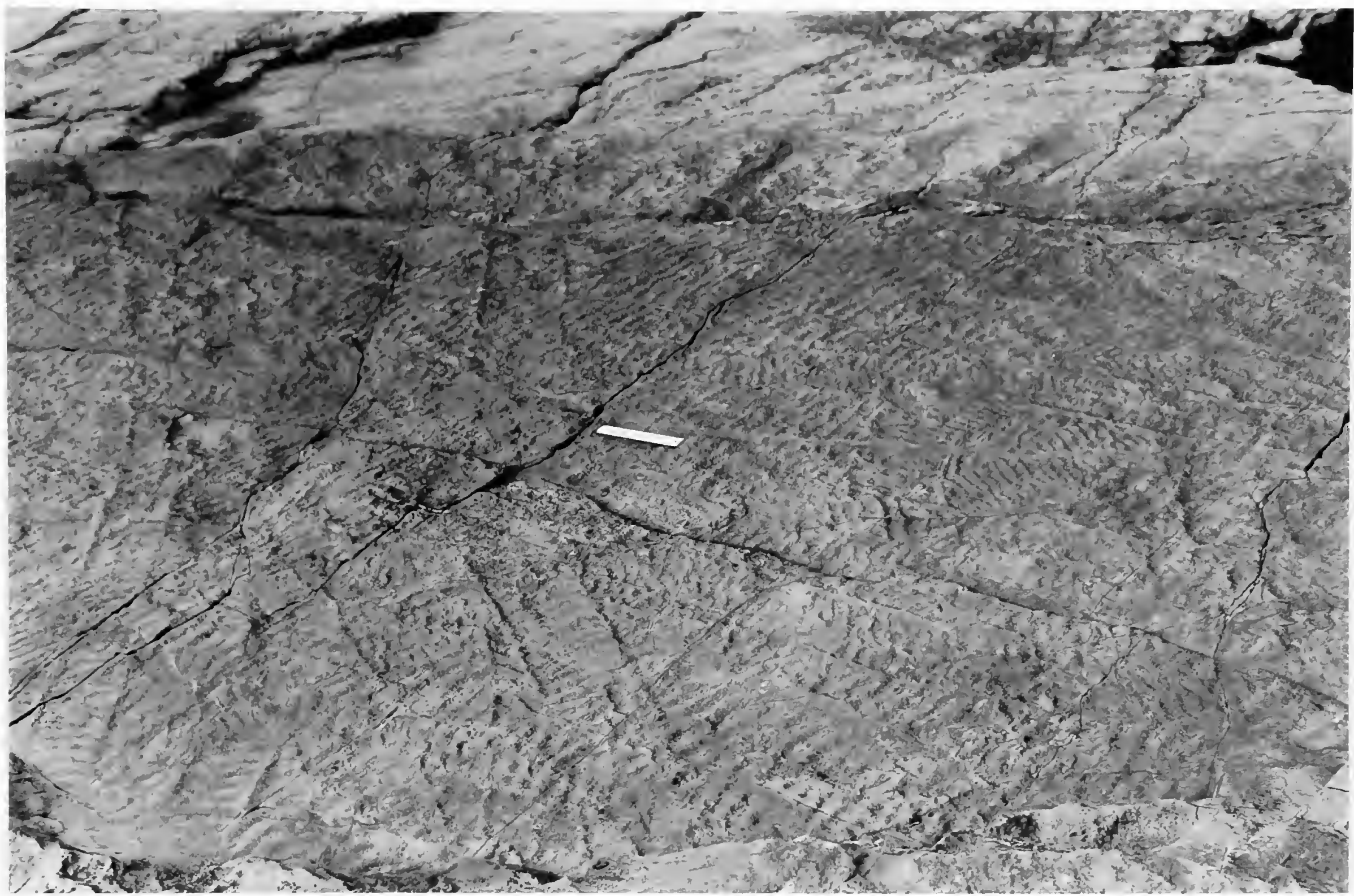

FIGURE 8. - A bedding plane of Potsdam Sandstone in the temporarily dry bed of the Au Sable River just below the dam at Keeseville, New York (13). The surface is almost totally obscured, or bioturbated, by wide trails of Climactichnites, but in the lower right center a pattern of low amplitude asymmetric ripple marks can be observed. Scale is indicated by a $15 \mathrm{~cm}$ ruler.

regressive phase of peritidal deposits in which Climactichnites occurs. Correlation by Selleck of these cycles to Port Henry (13), suggests that the material obtained there a century ago might be at essentially the same stratigraphic interval as at Keeseville. In the absence of any specimens precisely located, this is the best estimate of stratigraphic position that can be made.

In southern Ontario, traditional usage of Potsdam Sandstone has been refined, and the Potsdam Group is now divided into the Covey Hill Formation below, and the Nepean Sandstone above. The Covey Hill is confined to downdropped fault blocks and its relationship to the Nepean is not known in detail. In more general terms, the Nepean Formation thins northward. At its type locality, just to the south of Ottawa, it is of Arenigian age, based on conodonts (Brand and Rust, 1977). No other precise dates are available for this sandstone sequence elsewhere in the province. To some extent, the late Early Ordovician date at the top of the Nepean has influenced views on the age of the entire group.

In southern Quebec, the interval of sandstone deposition is generally thicker than in Ontario and is divided into the Covey Hill Formation below, a unit about $500 \mathrm{~m}$ thick, and the $150 \mathrm{~m}$ thick Cairnside Formation. Globensky (1987:46) reported Climactichnites in the Covey Hill, but reexamination of the outcrop at St. Hermas has convinced him that because of both the pronounced cross-bedding and the pink hue, produced by a high feldspar content of the sandstone, these fossils occur low in the Caimside. (Dr. Y. Globensky, oral communication, 1990). He also noted that at a former locality near Montreal, no longer available, a tongue of feldspathic sandstone of the Caimside occurs within the Covey Hill and this contained Climactichnites (Dr. Y. Globensky, written communication, 1990).

In discussing the problem of a fossil restricted to a particular facies, it is necessary to differentiate, if possible, the issues of habitation from those of preservation. In a general sense, the history of the Late Cambrian in eastern and central North America is that of a broad, intertidal and subtidal sand flat gradually encroaching on the source area by relative rise in sea level, so that by later Cambrian time the influx of siliceous 
particles was checked by the submergence of the source area. Deposition of carbonates then became the norm. If one accepts an interval of about 30 million years for the Late Cambrian, the Dresbachian interval was probably 5-10 million years in length; even during that relatively short time, generally similar conditions must have existed in various parts of this vast sheet of sand.

Both Drs. R.H. Dott, Jr., and R. Dalrymple independently noted that the Mount Simon in Wisconsin and the lower part of the Covey Hill, as used near Kingston, Ontario, differ principally from sandstone beds higher in the section by containing significantly greater amounts of feldspar. However, the presence of feldspar is associated with small grain size, not with age. The new occurrence in the Galesville Member of the Wonewoc Formation indicates that Climactichnites occurs in non-feldspathic beds. This is a facies-related fossil, as indeed all are to a greater or lesser extent. We suggest that the animal preferred a fine-sand beach over one of coarser sand, and that is the reason for its more common occurrence in feldspathic-rich units.

There is no theoretical reason why any particular fossil necessarily should be either long-ranging or appear and disappear almost simultaneously. Two alternative possibilities therefore exist for stratigraphic interpretation. Climactichnites could be closely tied to a particular facies and therefore time transgressive through the Late Cambrian and perhaps into the early Early Ordovician. Alternatively, it may have been such a specialized form that it existed for only a short interval.

Although there is little basis for choice between these two altematives, the limited stratigraphic evidence suggests to us that, even with the discovery of a younger occurrence, Climactichnites may be quite restricted in a time sense and further restricted to one facies within the transgressive sandstone. Clearly the Cambrian sea did not transgress from New York to Wisconsin instantaneously, yet the overlying faunas in both regions are of Dresbachian age. The same age relations exist in transgression from Missouri northward to Wisconsin.

In addition, if our interpretation and reconstruction of Climactichnites is valid, it may have been an "experimental" form and perhaps, therefore, less likely to have a long vertical range; its endemism adds a slight bit of additional support to this view.

Even though negative evidence can be destroyed in an instant, we know of no reports of Climactichnites in overlying Cambrian beds which can be dated as younger than Dresbachian. We judge this absence to be consistent with the view that Climactichnites was more restricted by time than by facies. If the interpretation of a restricted time interval is correct, this fossil may have utility as an indicator of age in beds that are otherwise nearly barren of fossils. One consequence of this suggestion is germane to southern Ontario. Assuming the type locality for Climactichnites at Perth (8) is Dresbachian and the
Nepean Sandstone at Ottawa is Arenigian, a major disconformity exists in the section.

\section{Environmental Setting}

At the field localities where Climactichnites has been observed, the Potsdam Sandstone and its stratigraphic equivalents show depositional features of an environment varying from exceedingly shallow water to temporarily subaerial, in effect from the high tidal zone to the peritidal zone. The issue of the height of tides in the past is a difficult one to approach, but because of the damping effect of a vast shelf area, it seems unlikely that tides exceeded more than one to two meters and probably were closer to the former (Dr. R.N. Ginsberg, written communication, 1990). If the moon was somewhat closer to the earth during Cambrian times, tidal amplitude and frequency would have increased, and, as a consequence, more fine clay-sized particles would have been winnowed out from the sand.

The overall geographic setting for Climactichnites could well have been similar to that of the present North Sea coast of Germany at extremely low tide, but with sediments predominately of fine sand size rather than clay size. The concept of tidal movement altemately covering and exposing such large flats has been used freely in the literature to indicate change in water level, and is useful in interpreting Cambrian sandstones. For example, Dreise, Byers, and Dott (1981) divided the Mount Simon into three lithofacies; Climactichnites occurs within what is generalized as "shallow subtidal deposition in a relatively high-energy regime." As a partial alternative to reliance on tidal mechanisms to explain some sedimentological features, Ginsberg (in Dott and Byers, 1981:345) has suggested that strong winds at irregular intervals might have drained off water, which was only a few meters deep in an epicontinental sea, and that desiccation cracks could have formed during such an event.

A spurious relationship between width of the trails and energy level originally confused us. At the Northern Stone Company quarry (5), the present working surface is covered by abundant trails $4-6 \mathrm{~cm}$ in width, smaller than average (Figure 4). The relatively fine size of the quartz grains and the absence of pronounced ripples was interpreted to indicate quiet water conditions. About a meter higher in the section, a thickerbedded and very slightly coarser sandstone bed carries trails $8-10 \mathrm{~cm}$ in width. Adjacent to both levels, but not directly associated with either, are asymmetrical ripple-marked sandstone beds without any preferred orientation of these current ripples among the layers. One of these layers is furrowed by worm-like trails cutting across the ripples (Figure 9). Specimens of Climactichnites from this locality in the Milwaukee Public Museum collected some years earlier show still slightly wider trails on ripple-marked slabs, the ripples again being slightly higher in amplitude than any we observed on the outcrop and nearly symmetrical in cross-section. 


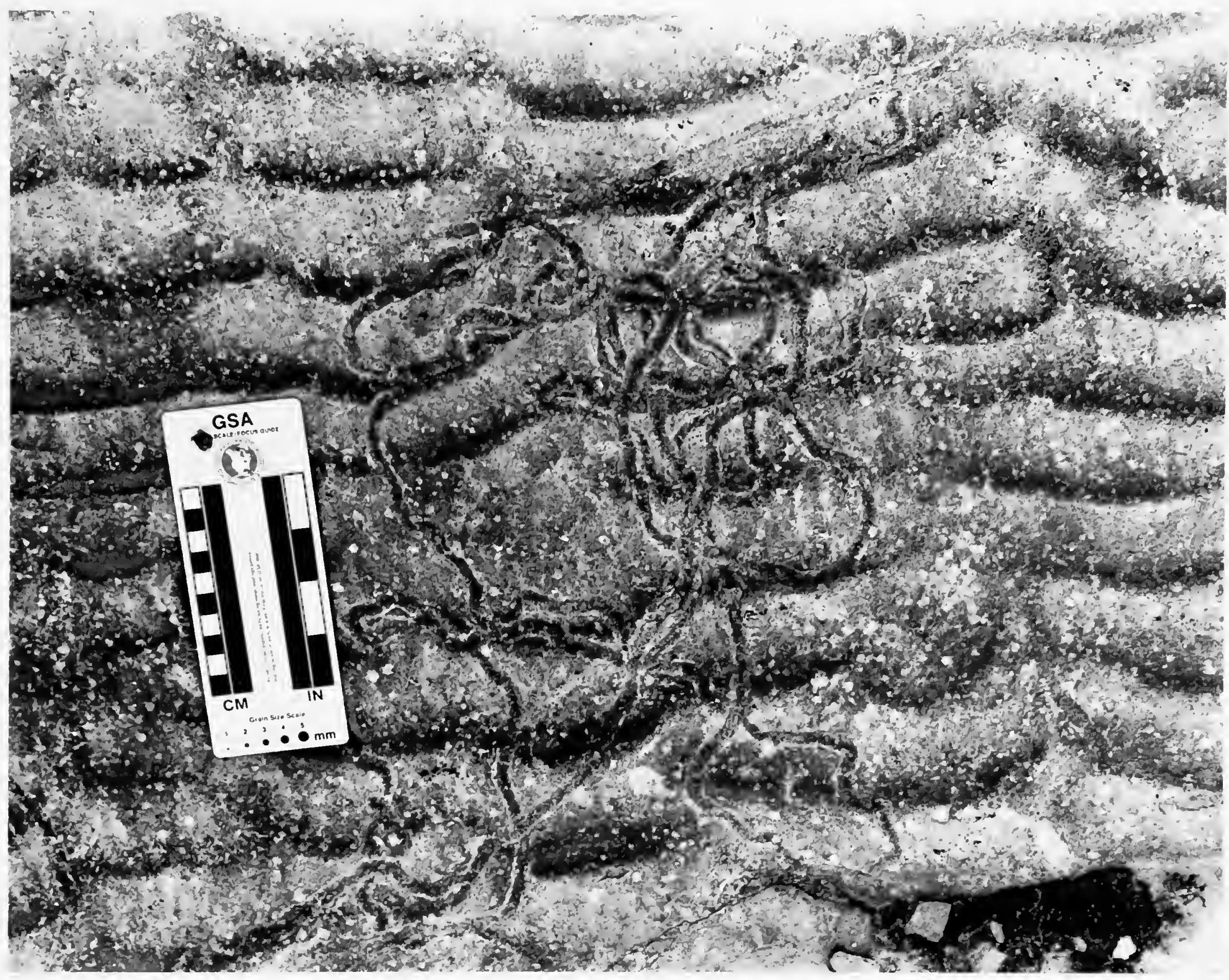

FIGURE 9.--Ripple-marked sandstone in the Northern Stone Company quarry, Wisconsin (5), about two meters above the working floor. Gordia-like trails cut through the asymmetrical interference ripples. Scale is indicated by a $10 \mathrm{~cm}$ ruler.

However, further observations confirmed that there is no obvious correlation between grain size, ripple height, or other potential indicators of energy level in the epicontinental sea, and the width of Climactichnites trails. Along the Chippewa River at Eau Claire, Wisconsin (2), trails ranging from 15-20 $\mathrm{cm}$ in width occur in a cross-bedded sandstone. This unit shows bimodal direction of cross bedding and is interpreted as a tidal deposit (Dr. J.L. Hoff, oral communication, 1990); Climactichnites crosses the low ridges and swales of the bedding planes. In contrast, trails from Perth, Ontario (8), are as wide as those from Eau Claire, yet occur in fine-grained sandstone; the paucity of ripple marks suggests quiet water. At Perth, only low-angle "herring-bone" cross-bedding in a bed $3 \mathrm{~cm}$ thick was seen on the wall of a local quarry, and there was no indication of any pronounced large set cross-bedding.
Specimens from Port Henry, New York (14), are associated with relatively sharp-crested interference ripples (Figure 10), whereas those from Perth, Ontario (8) (Figure 11), St. Hermas, Quebec (9), and Mooers, New York (12), are on smooth bedding planes. At Keeseville, New York (13), and St. Hermas, (9), one can observe that the bedding plane is not flat, but shows broad, shallow swales, like those of a modern tidal flat. The type slab from Perth in Ottawa, and those from Mooers in the New York State Museum and the Pratt Museum are large enough to further confirm a slight irregularity of the surface over which Climactichnites moved.

In Missouri, "Near the close of Lamotte deposition the area was inundated by an Upper Cambrian sea, resulting in contemporaneous deposition of alluvial and shallow marine sediments" (Houseknecht and Ethridge, 1978:585). More 
specifically, Climactichnites occurs above a fluvial channel deposit, indicating that "the tracks were probably formed in the washover or sandstone flat environment of the transgressive sequence" (Houseknecht, 1975:75). Along the Halls Creek tributary of the Black River in Wisconsin (3), Climactichnites occurs in the Mount Simon Sandstone $3 \mathrm{~m}$ above the base of the Precambrian in an outcrop "dominated by channel and low-angle truncation surfaces paved with claystone interclasts, large-scale tabular sets of cross-strata, and reactivation surfaces" (Driese, Byers, and Dott, 1981:371). We are not aware of any other localities where the beds containing this fossil have been studied in detail by sedimentologists.

An indication of drying conditions associated with Climactichnites is provided by desiccation cracks which we found in float pieces in the local quarry at Perth (8). More direct evidence is provided by the outcrop at St. Hermas (9) where desiccation cracks cut across a trail of Climactichnites. Another line of evidence is provided by sand holes, formed by air escaping from the sediment (Emery, 1945). Slabs from Robinson Creek along the Black River in Wisconsin (3) show a large number of such pits and craters (Figure 12). These structures were observed at St. Hermas (9) (Figure 13), and on the type slab from Perth (8) (Figure 14); they were seen at one level in Battersea quarry (7). These air hole structures penetrate the trails and developed subsequent to them in the St. Hermas, Perth, and Robinson Creek examples. Less well developed pits and craters have been observed within trails from other localities, but are more difficult to document with photographs.

Emery and Foster (1948) noted that the relative fluctuation of the water table on a beach lags behind the tidal cycle. Presumably, waves from an incoming tide of low amplitude would break on a subaerial beach and drive air upward to form these structures. If the beach gradient was appropriate, there might be sufficient time for such air holes to harden before being covered; on a modern high-energy Atlantic Ocean beach they are ephemeral. Admittedly, considerable argument surrounds the question of whether such pits could also be formed by raindrop impressions; in the examples we have observed, this seems unlikely. Regardless of whether these holes are formed by air escape from below, or water drops from above,

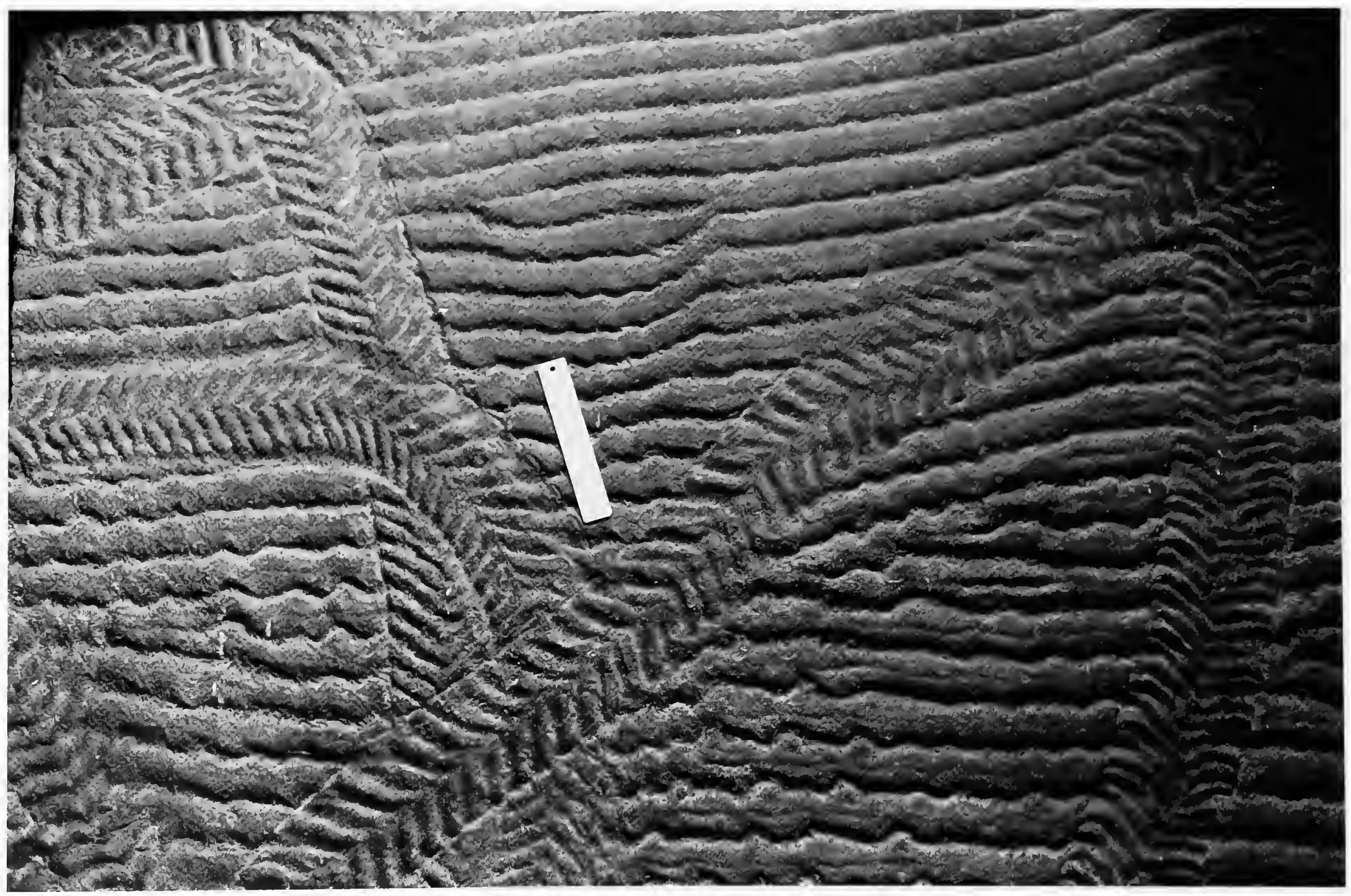

FIGURE 10.- Sharp-crested asymmetrical interference ripples cut by trails of Climactichnites on a slab of Potsdam Sandstone from Port Henry, New York (14). This is the lower surface of the overlying bed-a sole marking - so the surface relief is reversed. Scale is indicated by a $15 \mathrm{~cm}$ ruler. NYSM unnumbered. 


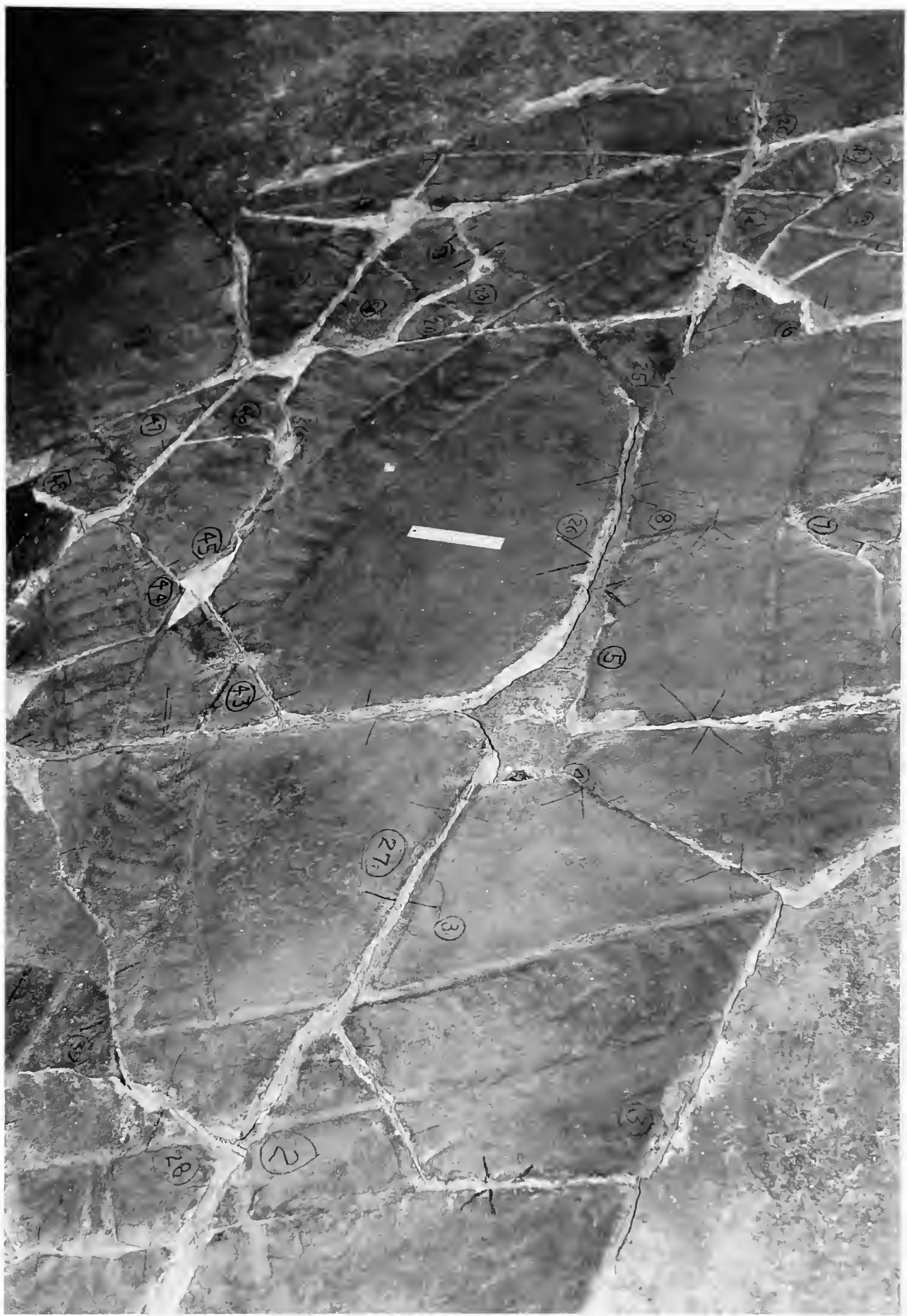

FIGURE 11.-A portion of the type slab from Perth, Ontario (8), temporarily reassembled, showing the smooth surface of the sandstone. This is the same orientation as Figure 18 showing the entire surface. This is a sole marking, so the surface relief is reversed. Scale is indicated by a $15 \mathrm{~cm}$ ruler. GSC 6299 . 


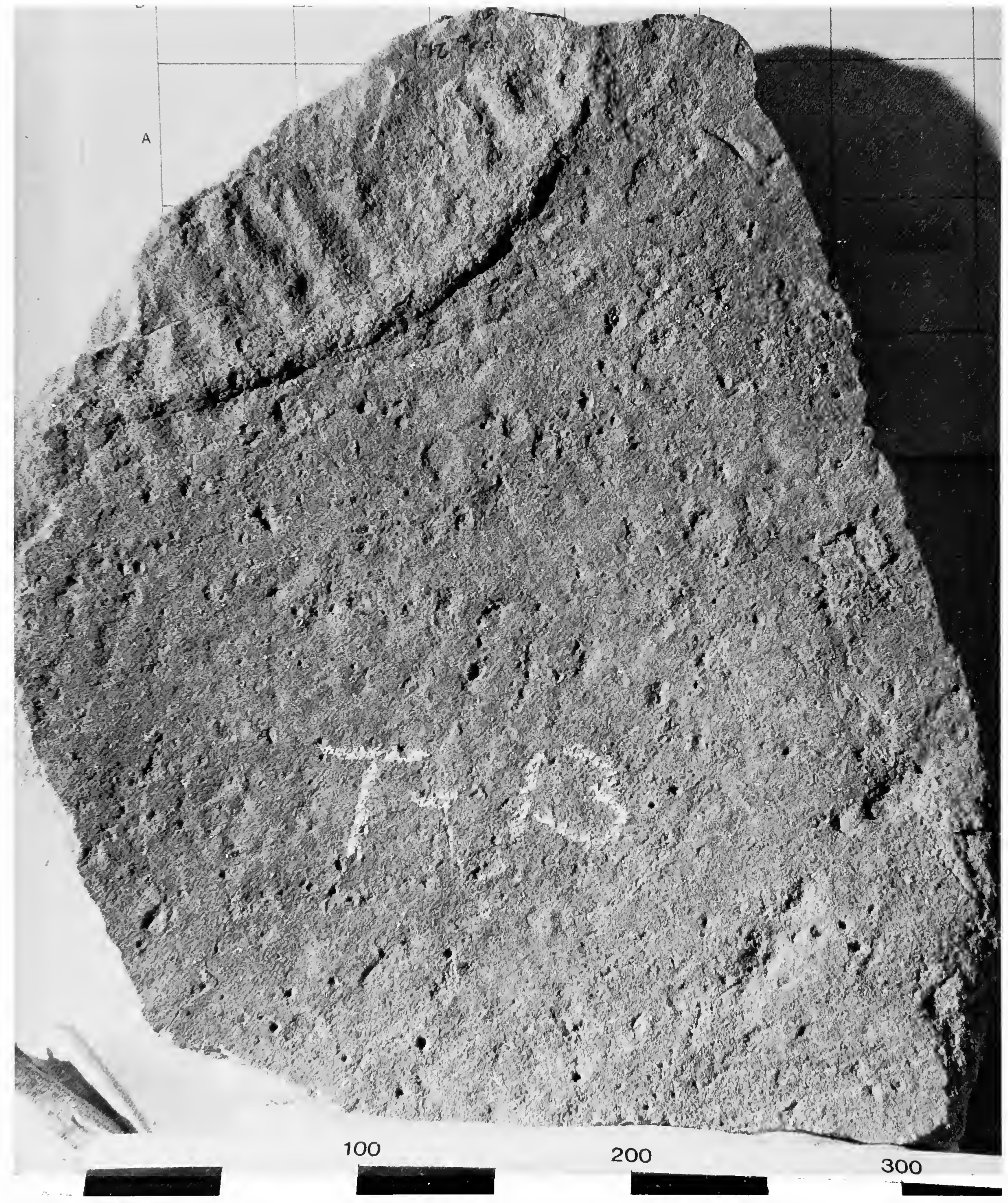

FIGURE 12.-An incomplete Climactichnites trail above and numerous air hole pits and mounds below, on a slab of Mount Simon Sandstone from Polly Falls, Black River Falls, Wisconsin (3). Photograph courtesy of Dr. B.R. Erickson, Science Museum of Minnesota, St. Paul, Minnesota. Scale in millimeters. SMM-P unnumbered. 
they are strong indicators of a surface which was not covered with water when they were formed.

From these observations, we conclude that Climactichnites made its trail on subaerial sandflats. During the time it crawled, the sand was damp, but not saturated with water, for the trail is constructed in large measure of molded sand. When the animal moved forward, the trail was exposed to subaerial drying.

In such a setting, the effect of wind driven waves could have been locally profound. As a consequence of a variety of factors, including minor changes in water depth, slight irregularities on the bottom, differential sorting of the sand grains, changes in salinity, and capillary action, we envision an environment in which the water content of the sand could vary from spot to spot. The rheologic features of the sediment cannot be reconstructed from the sandstone matrix, but local changes may be inferred from the variation in morphology seen among adjacent trails and within a single trail.

The presence of a relatively large amount of feldspar in most outcrops yielding Climactichnites is certain. Odom, Doe, and
Dott (1976) have documented the much more common occurrence of abundant feldspar in older Paleozoic sandstones, but particularly its concentration in rocks composed of smaller grain size sediment. Grains of feldspar would be larger than hydrodynamic equivalents of quartz, but not to any appreciable degree. The presence of feldspar, even in abundance, would not likely significantly modify the capillary features of a sand deposit. Time did not permit any study of composition and grain size of sediment and of associated trail width. We can therefore only make the generalization that because many Climactichnites occur in feldspar-rich sandstones, many of these animals probably crawled on fine-grained sand beaches, which in tum might indicate quiet water conditions. However, these trails do occur in coarser-grained sandstones.

Classically, the Late Cambrian sheet sands were considered as shallow marine beach deposits, but restudy by a generation of sedimentologists has shown that a variety of environments are represented in these beds. They range from terrestrial, through fluvial, to marine. It is readily apparent that our

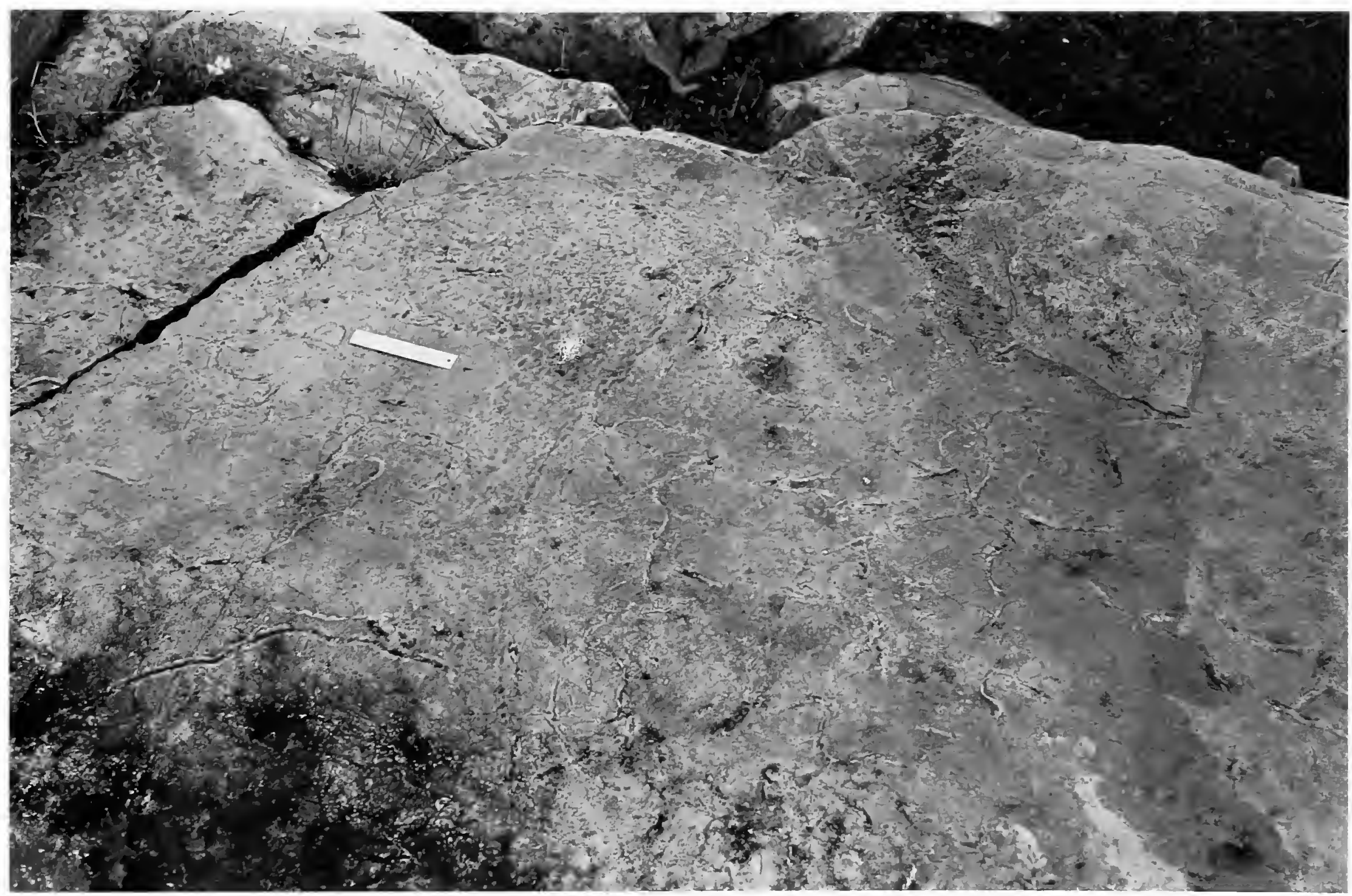

FIGURE 13.-A bedding plane of the Cairnside Formation at St. Hermas, Quebec (9). The right half of the view shows clearly numerous desiccation cracks, several of which cut a Climactichnites trail further to the right. At the left are more desiccation cracks and another convoluted trail, shown in more detail in Figure 39. Although they are difficult to see, Protichnites tracks are near the center of the field of view. Scale is indicated by a $15 \mathrm{~cm}$ ruler. 


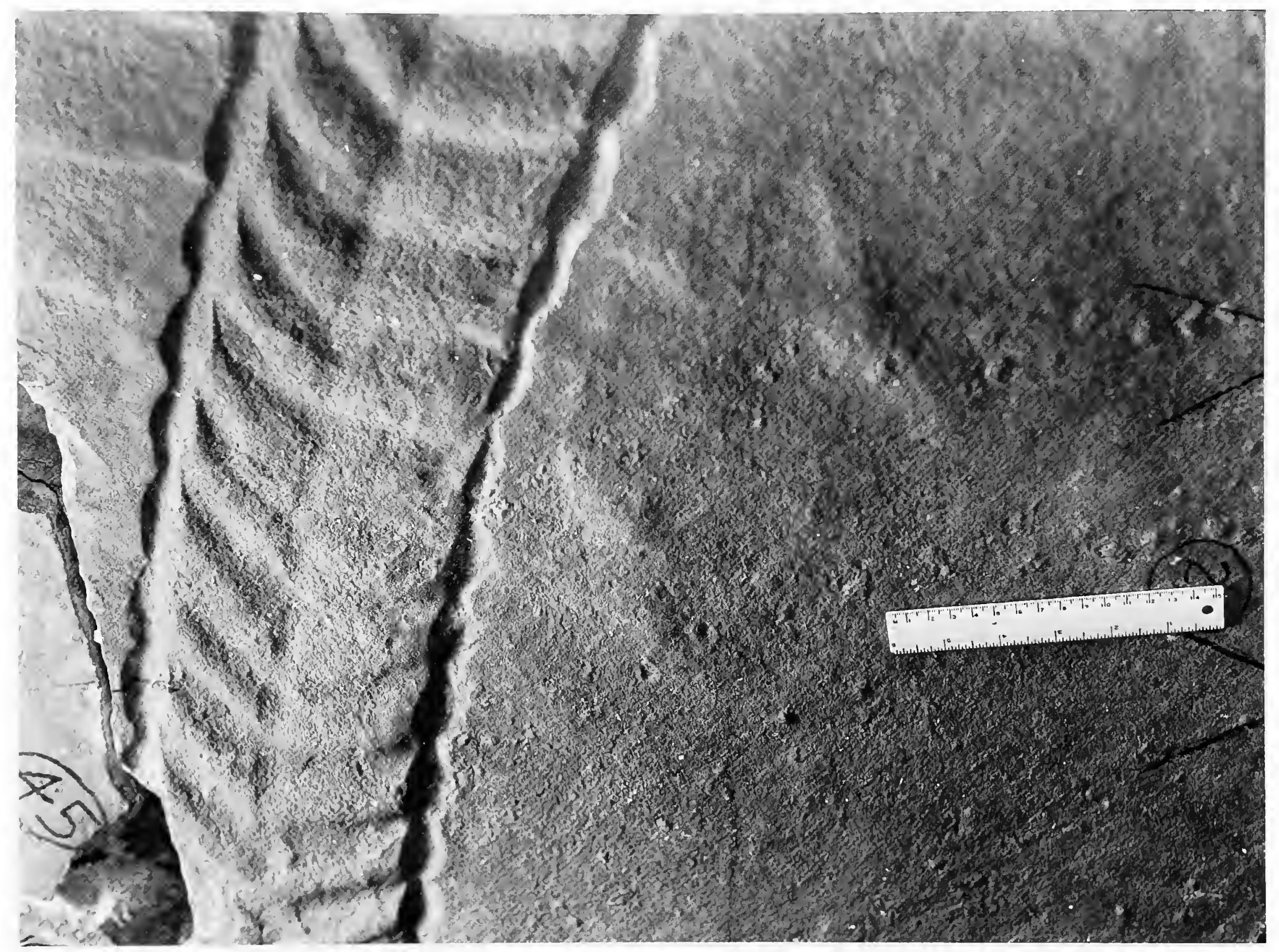

FIGURE 14.- Part of the type slab from Perth, Ontario (8), showing a portion of a trail and numerous air escape features. This is a sole marking, so the surface relief is reversed. Scale is indicated by a $15 \mathrm{~cm}$ ruler. GSC 6299 .

characterization of the environment is entirely qualitative, rather than quantitative. There are many environmental variables which we are unable to address, but by almost any standards, the changes from submarine to terrestrial posed a harsh environment for life. Perhaps the phrase "marginal marine" best indicates both the presumed exposure at low tide and the quality of life. If Climactichnites crawled on exposed sand flats, the daily temperature and ultraviolet radiation from the sun would pose major problems. To add one more speculation, a possibility for amelioration is that the animal crawled at night or during times of low ambient light rather than during sunny days.

Emery (1945:65) also noted the occasional presence of cavernous sand below the exposed beach surface. He made the suggestion that "tracks made by such an animal walking over cavernous sand may be very deep even if the animal be of relatively little weight." To the best of our knowledge this interesting point has not been pursued, but it is yet another variable to consider should a detailed sedimentological study of the environment of deposition of Climactichnites be undertaken.

\section{Systematic Paleontology}

\section{Phylum Incertae Sedis}

\section{Class, Order, and Family Unknown}

DISCUSSION.- It is the accepted practice among those paleontologists concerned primarily with fossils known only from their traces not to construct a hierarchical classification. As will be developed, we have interpreted enough detail concerning the animal to suggest that Climactichnites does not fit into any currently known phylum, living or extinct. 


\section{Genus Climactichnites Logan, 1860}

TYPE SPECIES.—Climactichnites wilsoni Logan, 1860.

DisCuSSION.-We judge that the characters of the genus and those which distinguish the type species cannot be differentiated. As a consequence, a more detailed description is given under the species.

\section{Climactichnites wilsoni Logan, 1860}

Climactichnites Wilsoni Logan, 1860:279-285; Dawson, 1890:599.

Climactichnites Fosteri Todd, 1882:280.

Climactichnites Youngi Todd, 1882:280.

Climactichnites wilsoni.-Woodworth, 1903:956-966; Clarke, 1905:18-20; Walcott, 1912:259-262; Burling, 1917:390-397; Abel, 1935:242-249; Clark and Usher, 1948:251-253.

DiAGNOSIS.-A form known only from an epirelief trail that is characteristically preserved as a ribbed band of uniform width bounded by a pair of parallel crenulated ridges, and, rarely, having an oval impression at one end of the trail.

DESCRIPTION.-The oval impression is oriented with the longer axis along the trail and has the same width as the ribbon-like portion of the trail; it is impressed and lies slightly below the level of the trail. Commonly, the upper surface of the oval impression is smooth, though it may contain a few gentle, but irregular longitudinal ridges and depressions. In exceptional preservation, closely spaced wrinkles in an arch-like configuration, are present. The proximal end of the oval impression is connected directly with the ribbon-like trail and is seldom distinct.

The ribbon-like trail is the more characteristically occurring portion of the trail and has a peculiar relief consisting of regularly alternating depressed furrows and raised bars. In plan view the pattern of bars and furrows is variable, even on the same trail, though it is approximately bilaterally symmetrical. These features contain all variants in general shape from straight transverse, through sigmoidal and arch-like, to approximately $V$-shaped. In the latter pattern, the bars may be arranged in a connected $V$ or in an alternating pattern when left and right halves are offset en echelon along the axis.

The cross-sectional profile of the bars is asymmetric, the steeper slope being away from the oval impression. In exceptional preservation, thin arch-like wrinkles are present and most prominent on the gentler slope of the bars. The distal end of the bars may be perpendicular, oblique, or sigmoidal toward the bounding parallel ridges. Again in exceptional preservation, a thickening near the juncture of bar and ridge occurs, but this seems to be a highly variable feature.

The bars and furrows are bounded by two parallel raised ridges, more or less hemicircular in cross-section, the bounding ridges being particularly prominent in large individuals. Commonly, the inner edge of each ridge is nearly straight. The outer edge also may be straight, but more characteristically is crenulated. There are slight irregularities in the width and depth of the crenulations.

All features of the trail, that is the lateral ridges, the bars and furrows, and the oval impressions, have a relatively very smooth surface when compared to the adjacent matrix.

DISCUSSION.-We have confined our synonymy to the references which provided new data on morphology, rather than those that reproduced earlier illustrations and speculated as to the form of the animal making the trail; these are discussed elsewhere. The synonym given above is taken in part from Walcott (1912:259), the only author to provide such data. Interestingly enough, Walcott did not formally use a species name in connection with discussion of specimens. He did use species names on the illustrations of new material he described, and he recognized both $C$. youngi and $C$. wilsoni at New Lisbon, Wisconsin (4).

Walcott, like earlier authors, credited the species $C$. youngi to T.C. Chamberlin, but Todd (1882:276) was quite clear that in 1879 Chamberlin gave an oral presentation and illustration of the material. In the light of this remark, under the International Rules of Zoological Nomenclature, Todd did not quote directly from a Chamberlin manuscript. Therefore, Todd is the author of $C$. youngi and $C$. fosteri. Even though Todd used both specific names "provisionally," they are still validly designated. As noted above, we have formally placed both in synonymy under $C$. wilsoni.

Although Walcott used both $C$. youngi and $C$. wilsoni in his figure captions, he gave no reason for differentiating them, and wrote "much could be written about the details of these trails, but with the reproductions based on photographs and the descriptions of the figures the student may draw his own conclusions" (Walcott, 1912:261). On the one specimen that he differentiated as C. wilsoni (Walcott, 1912, pl. 40: fig. 1), Walcott noted "the action of water forming the longitudinal furrows." If correctly interpreted, these rill-like marks cutting the bars of the trail may be yet another indication of peritidal conditions (Figure 15).

The type lot of $C$. youngi was approximately half a ton of slabs which more than a century ago were stored at Beloit College, Beloit, Wisconsin (Todd, 1882:277). The only illustration accompanying the description of this species is a cut based on a photograph of one of the slabs (Figure 16). Unfortunately, no material from this type lot or indeed any specimens of Climactichnites remain at Beloit College, nor is there any reference to them in departmental records (Dr. C. Mendelsohn, written communication, 1990). These slabs were not identified at the University of Wisconsin-Madison, or the Field Museum of Natural History, Chicago, two repositories where they might have been taken by Chamberlin after he left Beloit College. It would appear that the type lot of $C$. youngi has been discarded.

Todd (1882:279) distinguished $C$. youngi in part because it seemed to lack the paired lateral ridges of $C$. wilsoni. As noted, Walcott (1912) identified material lacking such ridges as $C$. 
wilsoni. They are also lacking on a portion of a trail associated with an oval impression (Walcott, 1912, pl. 38: fig. 1) and low and obscure on another portion of a trail (Walcott, 1912, pl. 39: fig. 2). On both these latter specimens, the furrows are sharp, but bars are absent. We suggest that bars and lateral ridges were washed away because there was insufficient time for them to harden before water level rose with the incoming tide.

Chamberlin (1883:133) thanked Reverend Young for the half ton of slabs at Beloit and added, "he has also supplied the University of Wisconsin and Dartmouth College with specimens." The slab at Madison, Wisconsin, has no locality data, but this quotation suggests that it might be from New Lisbon, Wisconsin. A slab at Dartmouth College was present but was discarded many years ago (Dr. G.D. Johnson, oral communication, 1990).

Fortunately, there is another topotype which confirms that $C$. youngi is based on a sedimentological feature. The Pratt Museum has a large triangular slab, number $68 / 1$, catalogued as being from New Lisbon, Wisconsin. No documentation has been found in the college archives for its date or collector, but an old photograph shows that this slab was on display in 1904 and presumably earlier. Because B.K. Emerson of Amherst College and T.C. Chamberlin were contemporaries, it is plausible to assume that Chamberlin sent this piece to the institution having the largest collection of trackways in the United States.

The slab is a coarse-grained iron-rich sandstone ripplemarked with low, broad, slightly asymmetrical ripples (Figure 17), crossed by seven trails. The texture and color are strikingly different from those features in Walcott's specimen and demonstrate that Climactichnites occurred on at least two different bedding planes at New Lisbon, not unlike the occurrence at the Northern Stone Company quarry (5). None of the lateral ridges are crenulated and we attribute this in part to larger grain size. Although all the trails show lateral ridges at one point or another, one trail changes dramatically from a $C$.

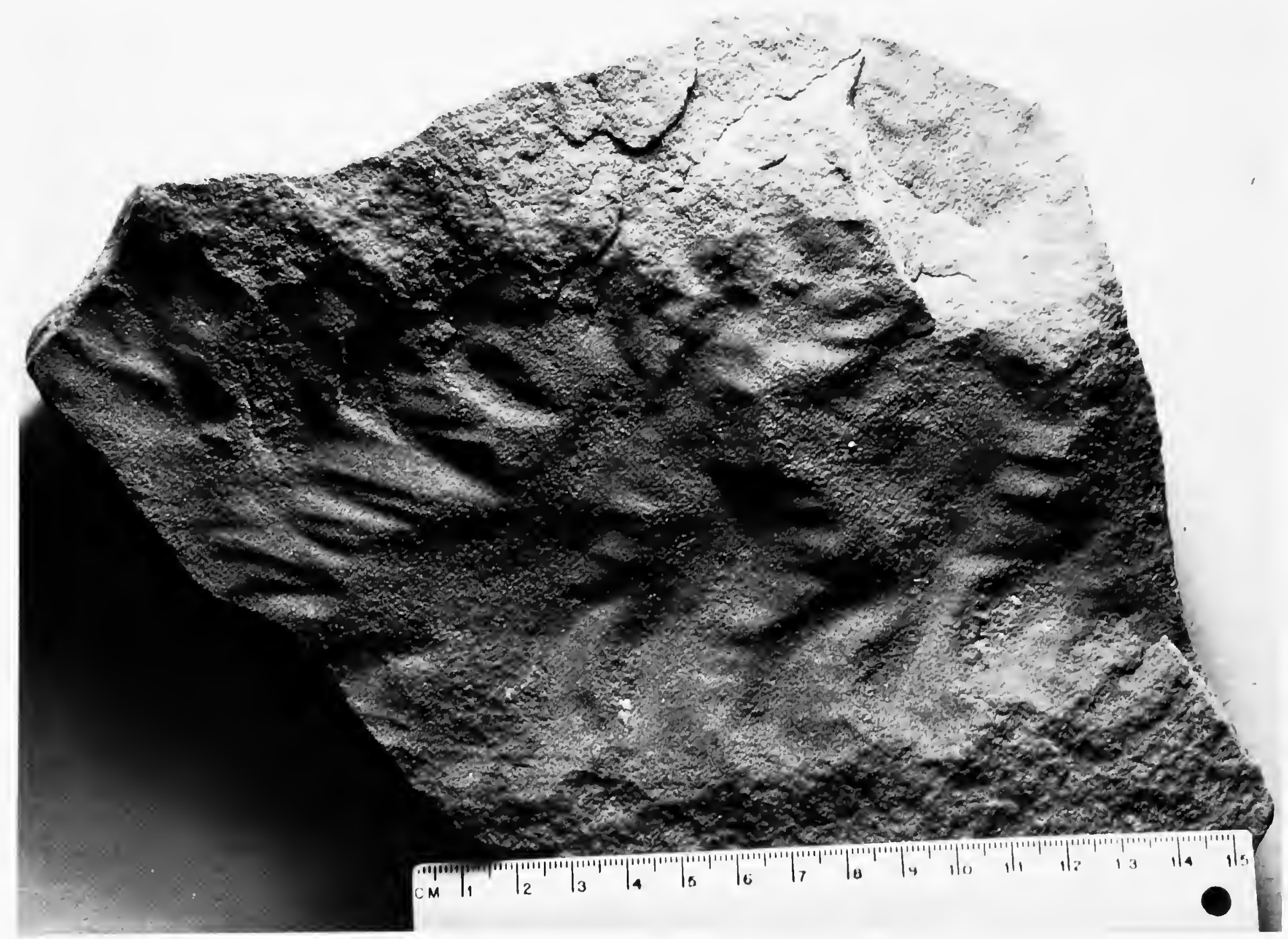

FIGURE 15.-A specimen, probably from the Galesville Sandstone, from New Lisbon, Wisconsin (4), illustrated by Walcoll (1912, pl. 40: fig. 1) as C. wilsoni. The specimen is a sole marking so the surface relief is reversed. No lateral ridges are present and the rill-like markings cut across the bars. Scale is indicated by a $15 \mathrm{~cm}$ ruler. USNM 58547. 


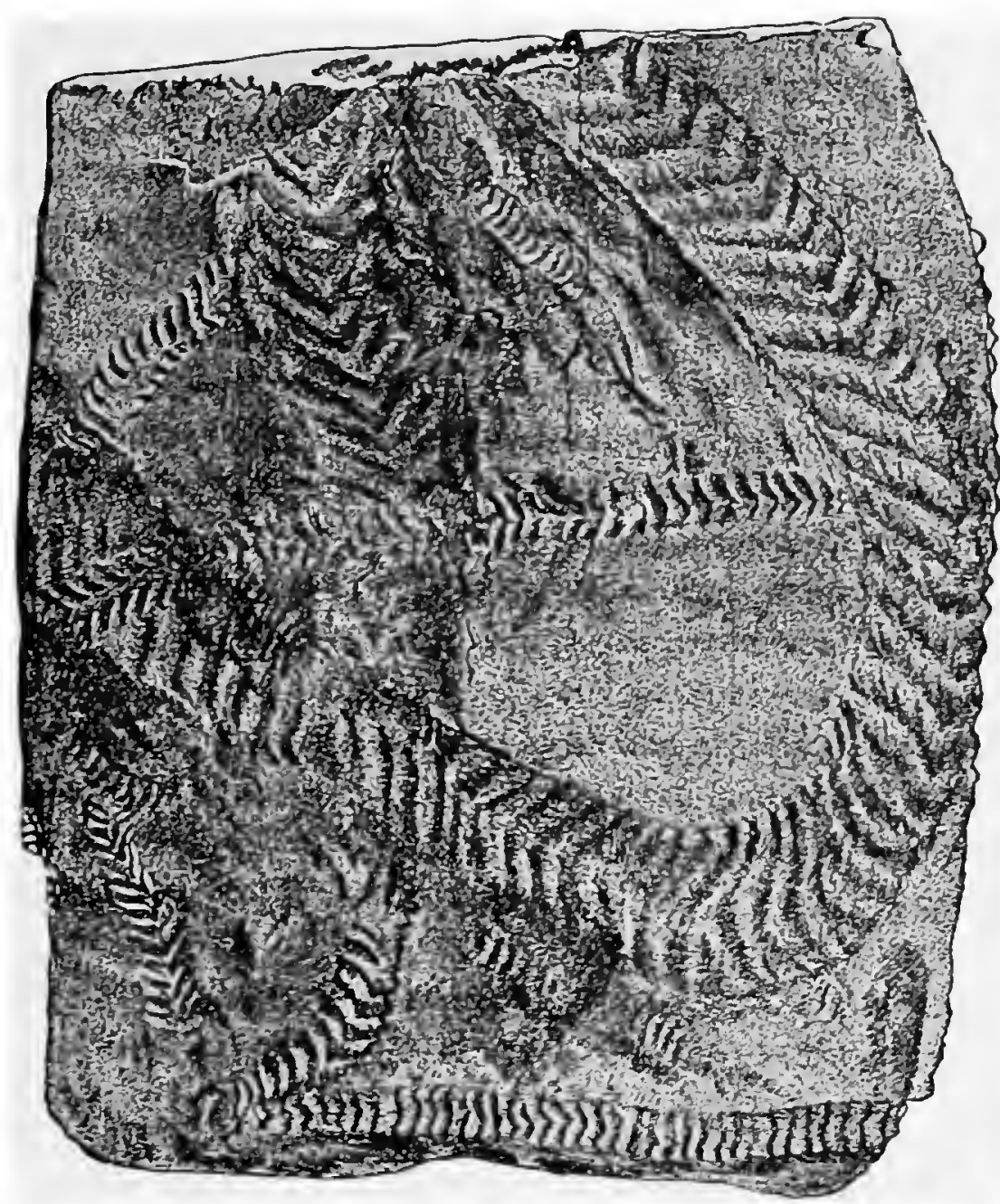

FIGURE 16.- Original illustration of $C$. youngi and, at the bottom of the illustration, $C$. fosteri, reproduced from Todd (1882:277). The caption reads "Plate 1-Fossil tracks on Potsdam Sandstone (From photograph)."

wilsoni to a $C$. youngi morphology along its length. We are thus satisfied that the presence or absence of the lateral ridges might be explained as either a sedimentological feature or as a feature of individual variation on the part of the animal, or both.

Todd (1882) also mentioned the presence of fine longitudinal markings as a point of differentiation for $C$. youngi, though these are not observable in his illustration. Presumably, such markings are like those illustrated by Walcott and reillustrated herein. The reason for preservation of such fine detail in one sandstone layer at New Lisbon, Wisconsin, is unknown, but there is no reason to assume that these features were limited to the organism which lived at that one locality. We attribute the arch-like lines to unique conditions of preservation rather than to unique morphology.

A narrow trail was tentatively designated by Todd as $C$. fosteri because it had straight bars, rather than $\mathrm{V}$-shaped ones along part of its length. This name was mentioned and reillustrated by Chamberlin (1883:132) and Dana (1895:479), but neither added new data. As will be seen on many of our illustrations, the angle of inclination of the bars to the lateral ridges may change dramatically through the preserved length of a trail. We are satisfied that only $C$. wilsoni has any biological meaning.

As to the type lot of $C$. wilsoni itself, a number of slabs of the sole surface of the overlying rock, totaling about 8 square meters, were collected in 1859 . They were assembled in plaster and used as a wall display. When the Geological Survey of Canada collections were being removed to Ottawa, "it fell with a crash, shattering the plaster casts round the specimen into fragments and breaking some of the sandstone" (Weston, 1899:135). It was reassembled and hung on the wall of the National Museum of Natural Sciences in Ottawa. After removal from that institution (Figure 18), the plaster backing again broke. The various pieces are now in the type collection of the Geological Survey of Canada and numbered GSC 6299. To avoid any future uncertainty, we designate the longest trail seen on Figure 18 as the lectotype and reproduce part of it (Figure 19) for purposes of identification. The other trails of $C$. wilsoni on this slab have the status of paralectotypes.

\section{Details of Morphology}

The formal description covers the salient morphologic features of this taxon, but, like all such descriptions, it is necessarily a constrained summary. Accordingly, we judge that a more elaborate discussion of certain aspects of the trail of Climactichnites wilsoni, combined with further illustration of specimens, will better convey our understanding of the trail maker.

TEXTURE.-When compared to the surface of the bedding planes on which they occur, the oval impressions are smooth. As an example, the oval impression illustrated by Walcott (1912) is both smoother and slightly darker in color than its matrix, even though the sand is so fine that the rock appears at first glance to be an aphanic limestone. More significantly, because there are so many more examples, the entire trail-bars, furrows, and lateral ridges (Figures 21, 22)-is quite smooth when compared to the surrounding matrix. No matter how fine the grains of the sandstone, and no matter where the specimens were collected, invariably the trail is smoother than its surroundings, even in instances of exceptionally poor preservation of the trail.

From these observations, we were lead to the view that probably the animal secreted a great deal of mucus during its trail-forming activities. Such a secretion would have the effect of lubricating the substrate and assisting the motion of the organism as it moved forward. Unless a bar and furrow were made at the extreme posterior of an animal, it was difficult to envision what would prevent these structures from being modified or even obliterated by forward movement. However, a layer of mucus covering a set of bars and furrows already formed anteriorward would allow the posterior to slide over them and causing little or no distortion.

One indirect result of mucus secretion is that this substance would bind the molded grains of sand, and protect the trail from the destructive effects of wind and incoming water. The mucus could entrap bacteria, other microorganisms, particles of organic matter, and clay-sized particles. These and the products of decay of organic matter would also serve to differentiate the 


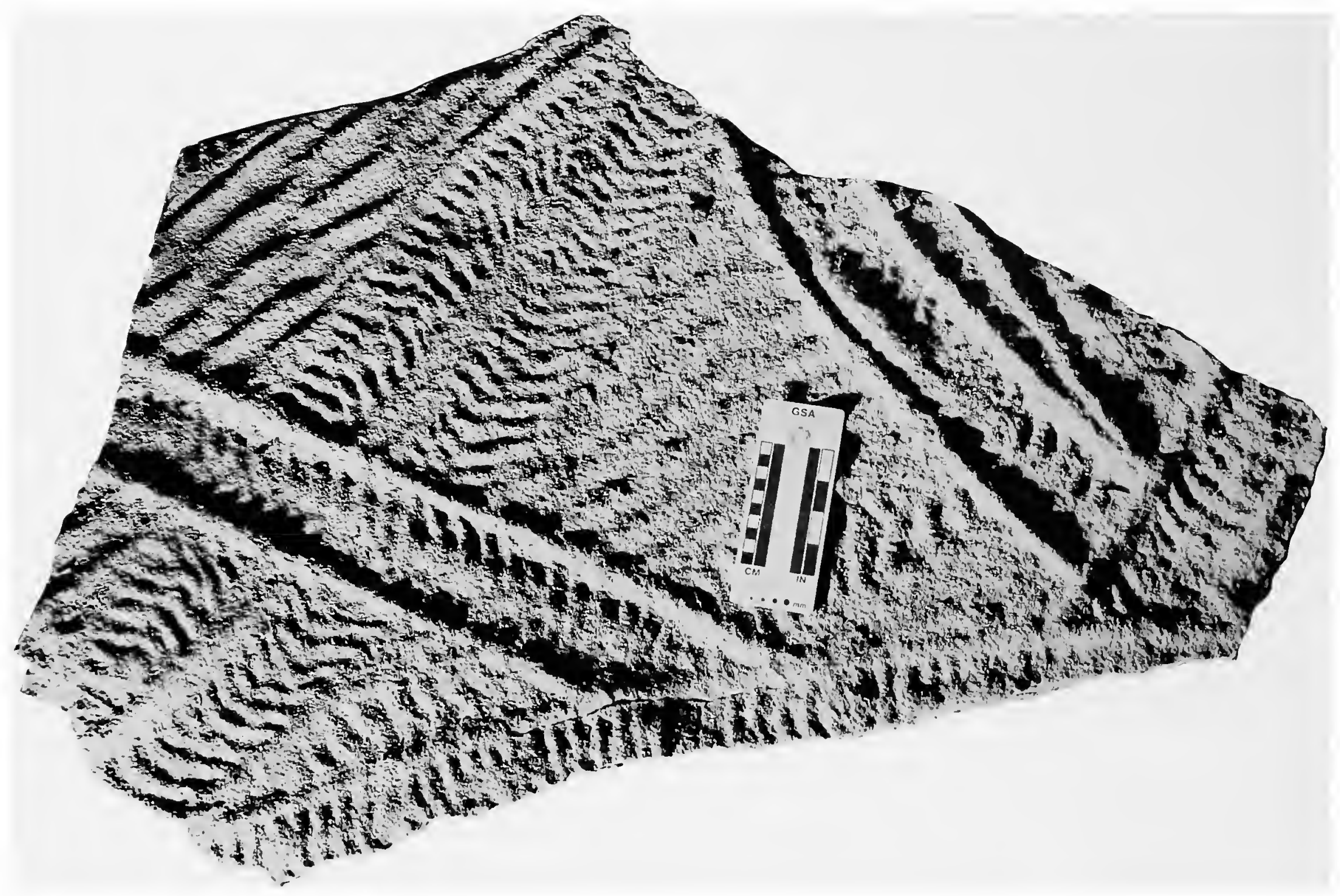

FIGURE 17.-A ripple-marked topotype slab of $C$. youngi probably from the Galesville Sandstone at New Lisbon, Wisconsin (4), showing prominent lateral ridges on several Climactichnites trails. The trail near the middle of the slab, made by an animal moving right to left, and showing prominent lateral ridges crosses two below it. The one moving toward the top of the illustration lacks the lateral ridges and is thus representative of $C$. youngi, as described. At the left of it, another animal moving in the opposite direction has a prominent lateral ridge only on the left before the point of crossing and both lateral ridges after this point. Thus, the absence of bounding lateral ridges may be a taphonomic feature. Scale is indicated by a $10 \mathrm{~cm}$ ruler. PNH 68/1.

molded sand trail from the sand matrix. The smooth or even glossy surface of the trail can be interpreted as a result of early diagenesis relative to the matrix. The mucus might have served as a horizontal barrier inhibiting circulation of pore water and thereby concentrating some compounds below the film of mucus, and, perhaps, thereby speeding lithification.

On two slabs from the Battersea quarry (7) in the collections of Queen's University, the trails are outlined in a dark purple color (Figures 23, 24), in striking contrast to the light tan matrix of the slabs (Yochelson and Fedonkin, 1991). It is unlike both the red to brown of an iron oxide and the black of a manganese oxide; such stains have been seen on some of the outcrops we have examined.

This color is confined to the sculptured sediment of the trail, specifically to the lateral ridges and to the upper part of the bars. On one lateral ridge as seen in Figure 23, the crenulations are delineated by the dark purple, supporting the interpretation that this color is not a secondary stain. We surmise that these trails were subjected to an atypical sedimentary regimen, possibly with longer than normal exposure to air, so that different chemical reactions affected these otherwise typical trails. The purple color is similar to that found in color-marked Paleozoic mollusks and brachiopods, and it may be a degradation product of a complex porphyrin. Whatever the particular cause of these color markings, they add support to our suggestion that large amounts of mucus were secreted by the animal during its movement.

OVAL IMPRESSIONS.-Partly as a consequence of the small size of the sketch produced by Clarke (1905), the impressions at one end of the trails found at Mooers, New York (12), have come to be considered asymmetrical, more or less like a kidney bean in shape (Figure 25). With each reproduction of the 


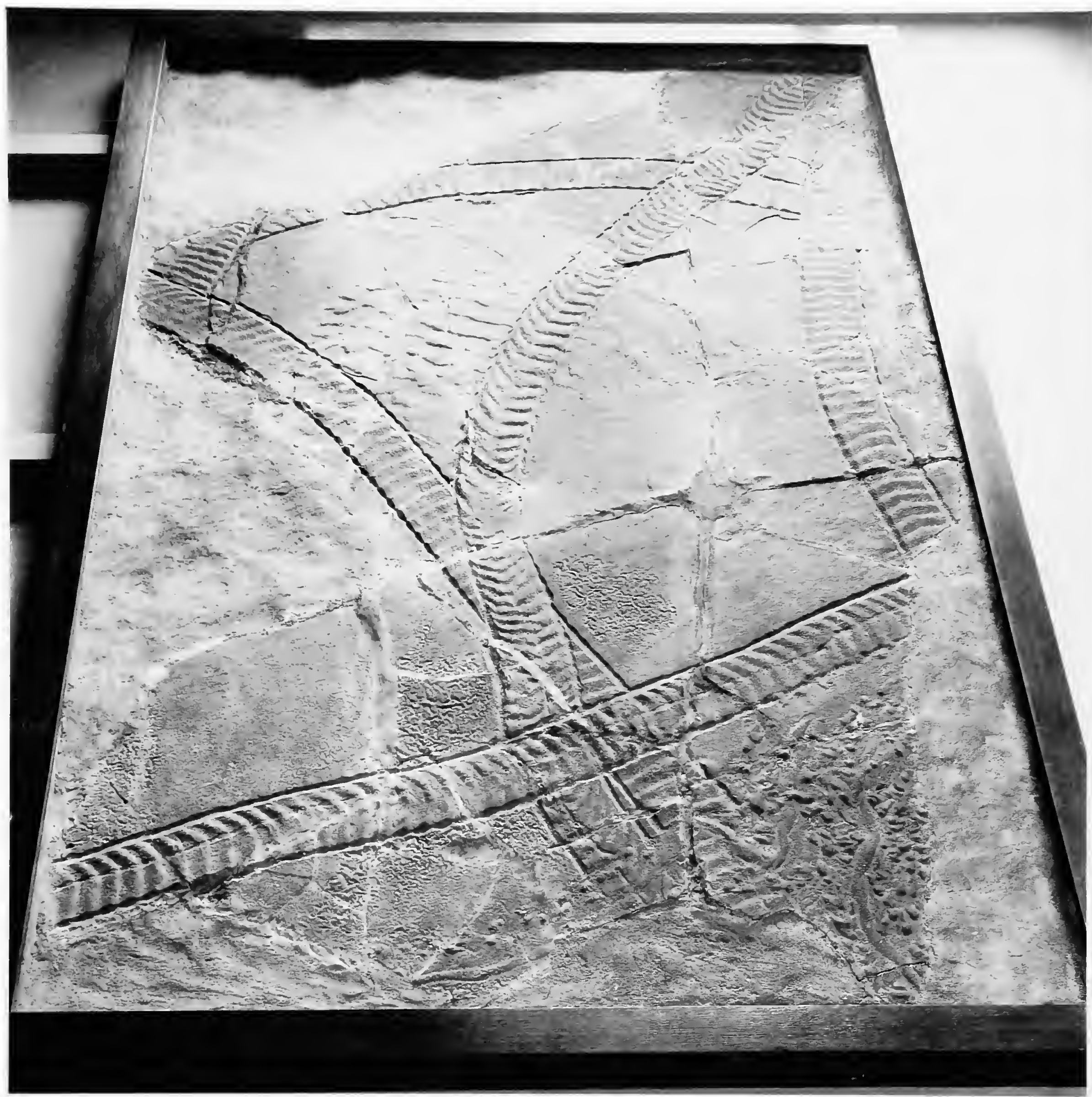

FIGURE 18. - The type slab of Climactichnites wilsoni Logan from Perth, Ontario (8), after removal from the wall of the National Science Museum in Ottawa. The surface is slightly undulatory, but is smooth except for a few low asymmetric ripples in the upper left, adjacent to the lectotype. Because this is a sole marking, all surface relief is reversed, so that the lateral ridges appear as dark depressions. The lectotype is from lower center to upper right. The irregularity in both occurrence and position of the medial marking is evident among the five trails. A meshwork of Protopaleodictyon is prominent near the lower center, just to the left of the intersection of three trails. Protichnites is prominent at the lower right. Portions of this specimen are shown in Figures 11, 14, 19, 45, 49, and 50. GSC photograph 201284B. GSC 6299. 


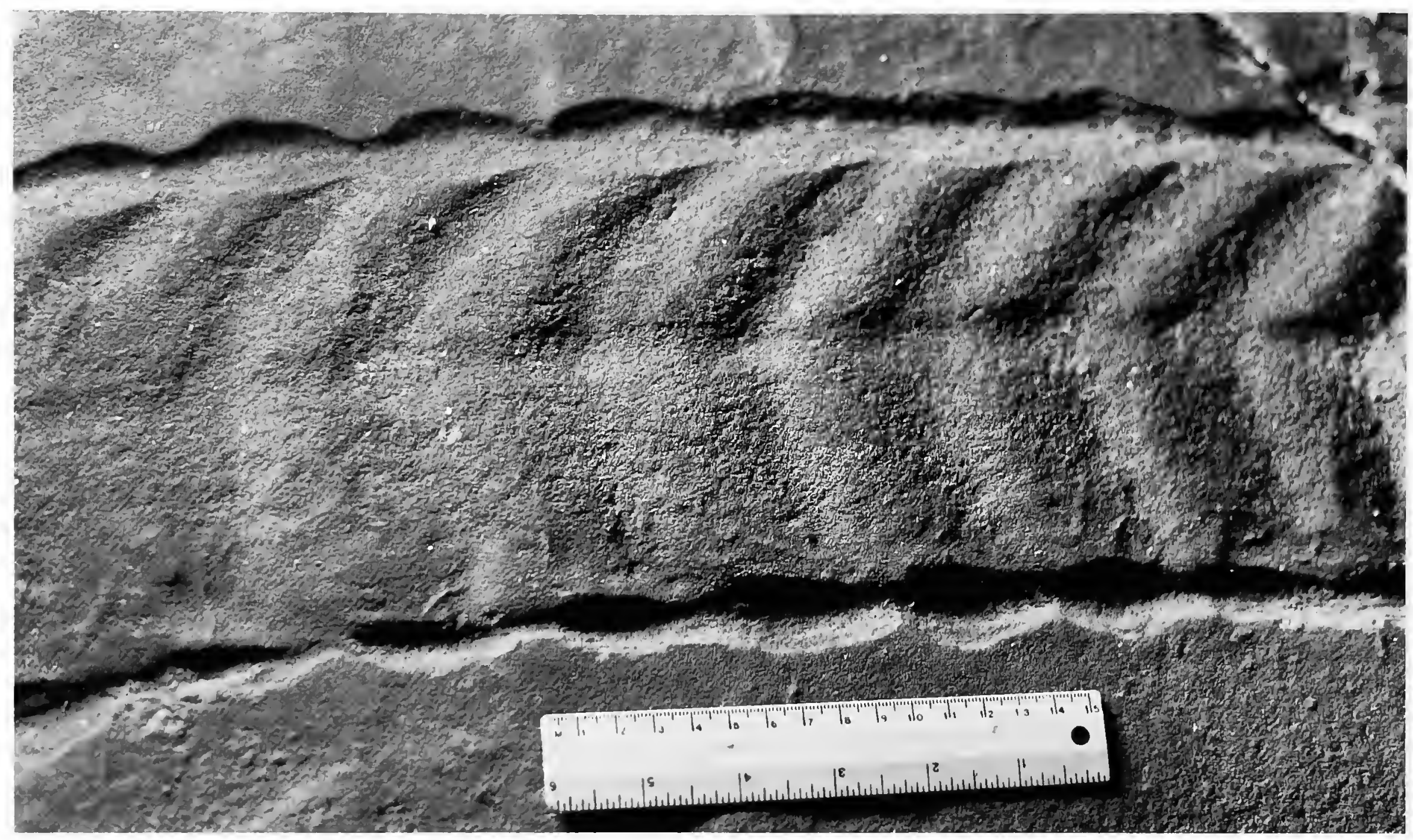

FIGURE 19.-A portion of the lectotype of $C$. wilsoni Logan, near the scale in Figure 11, showing the prominent crenulations of the lateral ridges, the asymmetrical and varying furrows and bars and a medial marking, all in negative relief on this sole marking. The orientation is rotated from Figure 18, the ripple marks on the left of that Figure are now seen above the impression. Scale is indicated by a $15 \mathrm{~cm}$ ruler. GSC 6299.

sketch, this notion has continued. In fact, the impressions are more or less bilaterally symmetrical, the pronounced asymmetry shown being an artistic artifact. Several of these features are more deeply impressed into the sediment on one side than on the other, and efforts to show this at a very small scale by shading resulted in the kidney-bean shaped rendering.

Although there is some irregularity, these impressions are rounded at one end, with sides parallel. Oval is not accurate geometrically, but is a conveniently neutral morphologic shape term to use. However, we emphasize that it is only the posterior of the marking which is well rounded. The anterior of these impressions is distinctly not oval, and is interpreted as the impression of a triangular flap which may extend forward from one side of the animal or from the other (Figure 26).

Most oval impressions are 1-3 cm deep. Invariably, they occur beneath the level of the trail, if only by less than a centimeter, as is the case with the New Lisbon, Wisconsin (4), specimen of Walcott (Figure 31). The impression may be deeper at either the anterior or posterior, and, as noted, deeper on one side than on the other (Figure 27). Seemingly, the animal moved upward from a depression to begin its trail forming activity. Depending on consistency of the sand and the precise movement, the bottom or one side of the impression may have been modified by slumping or movement of the loose sand. On at least one impression (Figure 26), there appear to be two axes of symmetry, best interpreted as an animal shifting its position; this also gives a superficial appearance of a curved shape.

On the Mooers, New York, specimens, both as represented on the plaster cast and the actual specimens in the New York State Museum, most oval bodies are associated with trails. The provenance of the slabs of New York material in the Pratt Museum (Figure 28) has not been traced, but they appear remarkably similar to the Mooers material. One oval impression is particularly noteworthy in showing one end of the impression extending as a flap-like structure, the opposing half being represented by bars and furrows (Figure 29). It is even more convincing than any of the specimens in the New York State Museum that the right and left sides of the organism could move either alternately or coordinated.

The New Lisbon, Wisconsin (4), oval impression (Figure 31) shows irregular ridge-like longitudinal bulges and furrows, confirming that the basal surface was not rigid. Similar irregularities, though not nearly so well preserved, occur on a few of the oval impressions from Mooers, New York. As may be seen on Figure 29, the flap-like anterior also shows 




FIGURE 20.-Three oval impressions from Mooers, New York (12). The matrix of the Potsdam Sandstone is very fine-grained, yet it shows more of a texture than the impressions. The clearest impression is at the right, just to the left of the missing piece of rock. It is deeper in the sediment on the right side and the anterior shows the trail beginning to the left side earlier than to the left. The same feature may be seen in the part of the impression at the bottom. The impression to the left of the scale suggests that the animal shifted position and that a ridge outlining an anterior flap covered the left posterior of the first impression. Scale is indicated by a $15 \mathrm{~cm}$ ruler. GSC 6299 . NYSM unnumbered

irregularities. Overall, these suggest that the sole of the animal was covered by a tough integument, but one that had some flexibility, and that there was at least as much flexibility, if not more, at the anterior.

Along the Chippewa River at Eau Claire, Wisconsin (2), we examined a large slab showing several trails, including an $\mathrm{S}$-shaped one. One end of this $\mathbf{S}$ appears to be the impression of an oval body (Figure 30). It shows few details, but if our interpretation is correct, this is another locality for the oval impressions.

Oval impressions thus are of two general forms. The single remarkably well preserved individual from New Lisbon (4) is a faithful replica of the sole of the animal. It shows both wrinkles of the integument and, as discussed below, fine detail on the integument. The impressions from New York are much less well-preserved and represent impressions modified partially by slumping as the animal moved upward from its shelter within the sand.

ARCHED LINES.--The excellent oval impression from New Lisbon, Wisconsin (4), illustrated by Walcott (1912) and by Burling (1917), is preserved as both part and counterpart (Figure 31). On both surfaces, it shows a series of fine, closely spaced arch-like wrinkles, having the same curvature as the posterior end of the impression. As illustrated by Walcott and Burling and reillustrated herein, the arched lines can also be seen crossing bars and furrows; they are more prominent on the gentle (distal) slope of the bars (Figure 32) than elsewhere on the trail.

Two slabs in the Museum of Comparative Zoology, Harvard University, also show these delicate arched lines. These slabs 




FIGURE 21.-Five trails of Climactichnites on part of a slab of Potsdam Sandstone from Port Henry, New York (14), on a bedding plane bearing numerous interference ripple marks; this is a sole marking, so surface relief is reversed. The trails are smoother than the matrix. Near the center of the slab the trails proceed in opposite directions. Scale is indicated by a $15 \mathrm{~cm}$ ruler. MPM $27629 \mathrm{~b}$. 
appear to be similar to the New Lisbon specimens, but their provenance is unknown. None of the other specimens we have examined is well enough preserved to show these features.

PROXIMAL STRUCTURE.-On about half a dozen of the oval impressions from Mooers, New York (12), we observed a circular structure, slightly raised, near the anterior end of the impression (Figure 33). The newly discovered oval impression along the Chippewa River (2), alluded to above, shows a slight elevation in the same area. However, the slab at the Pratt Museum (Figure 28) shows them both in the oval impressions and elsewhere on the slab. Presumably, these are "sand volcanoes" formed by incoming water forcing air and sediment upward; slightly greater consolidation of the sand below the animal may account these features being relatively more common within the impressions. No such large mounds are known to cut any of the trails we have examined.

There is, however, another feature in the oval impressions, which is not easily explained as a sedimentary structure. On the Beauharnois, Quebec (10), slab at the National Museum of Natural History, three concentric rings are present on an incomplete oval impression (Figure 34). Two other examples are known of circular features which are centrally located on the trails. On a slab from Port Henry, New York (14), in the American Museum of Natural History, medial circular areas occur on a trail; these have a more roughened texture than surrounding bars and furrows (Figure 35). On another slab from the same locality in the Milwaukee Public Museum, one clear oval impression may be seen (Figure 36). On another trail on this same large slab, two, centrally located, small cones are present.

Overall Features of THE TRail.-One of the novel features of Climactichnites is the constant width of any individual trail (Figure 37). Regardless of whether the trail is straight, curved, or slightly sigmoidal, the lateral ridges remain separated by the same distance. The examples of trails crossing over themselves, sketched by Clark and Usher (1948) (Figure 38) show a remarkably small radius of curvature. We have confirmed this by finding a specimen at St. Hermas (8) which crossed its own trail (Figure 39). The small radius of turning is impressive and suggests that the animal did not stretch out significantly when moving. The oval impressions made while

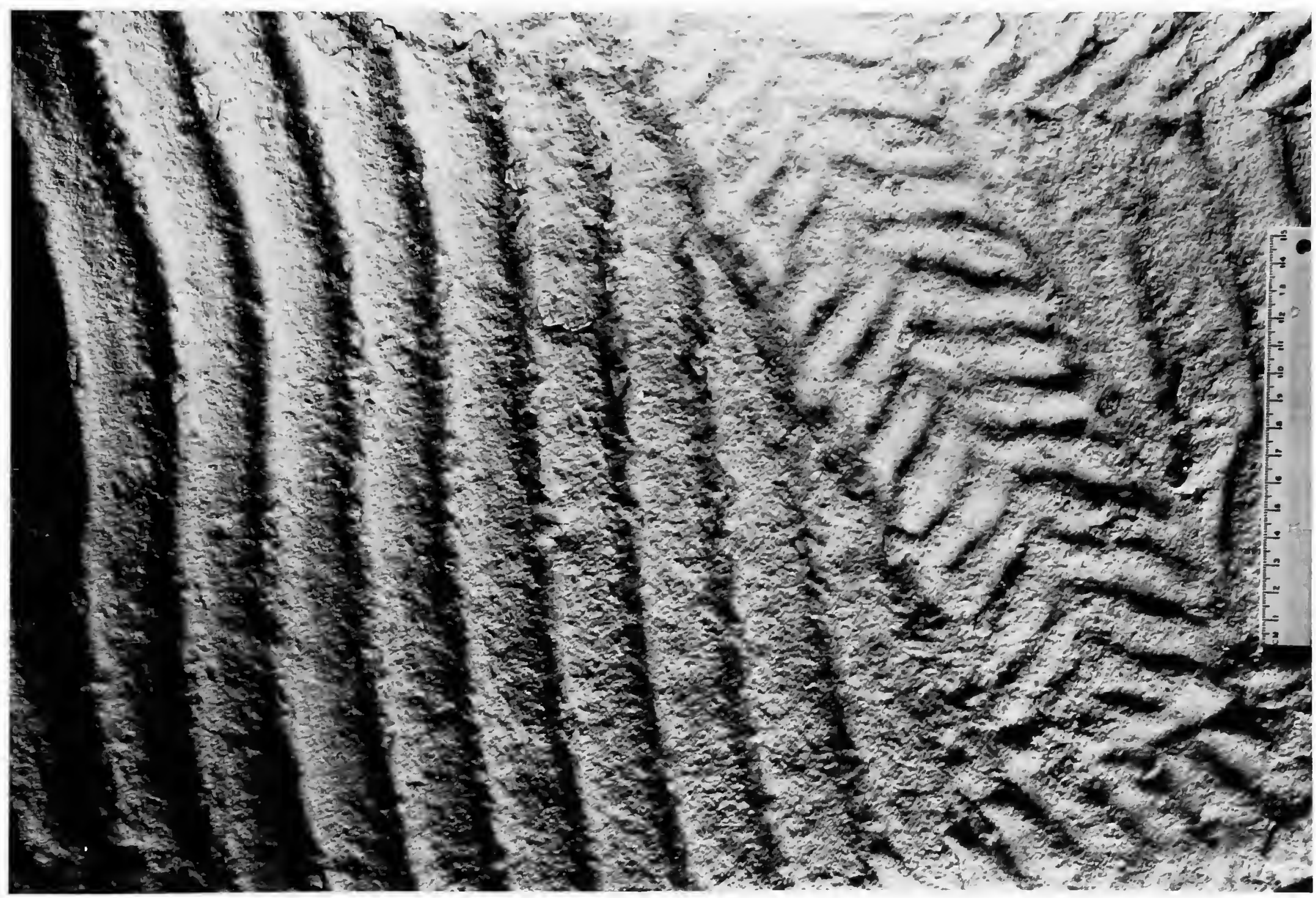

FIGURE 22.--Latex replica of portions of three trails and of ripple marks on a slab from Port Henry, New York (14), showing the smooth bars and furrows and the coarser texture of the ripples. The longest trail was made by an animal moving toward the lower right. Scale is indicated by a $15 \mathrm{~cm}$ ruler. USNM unnumbered. 


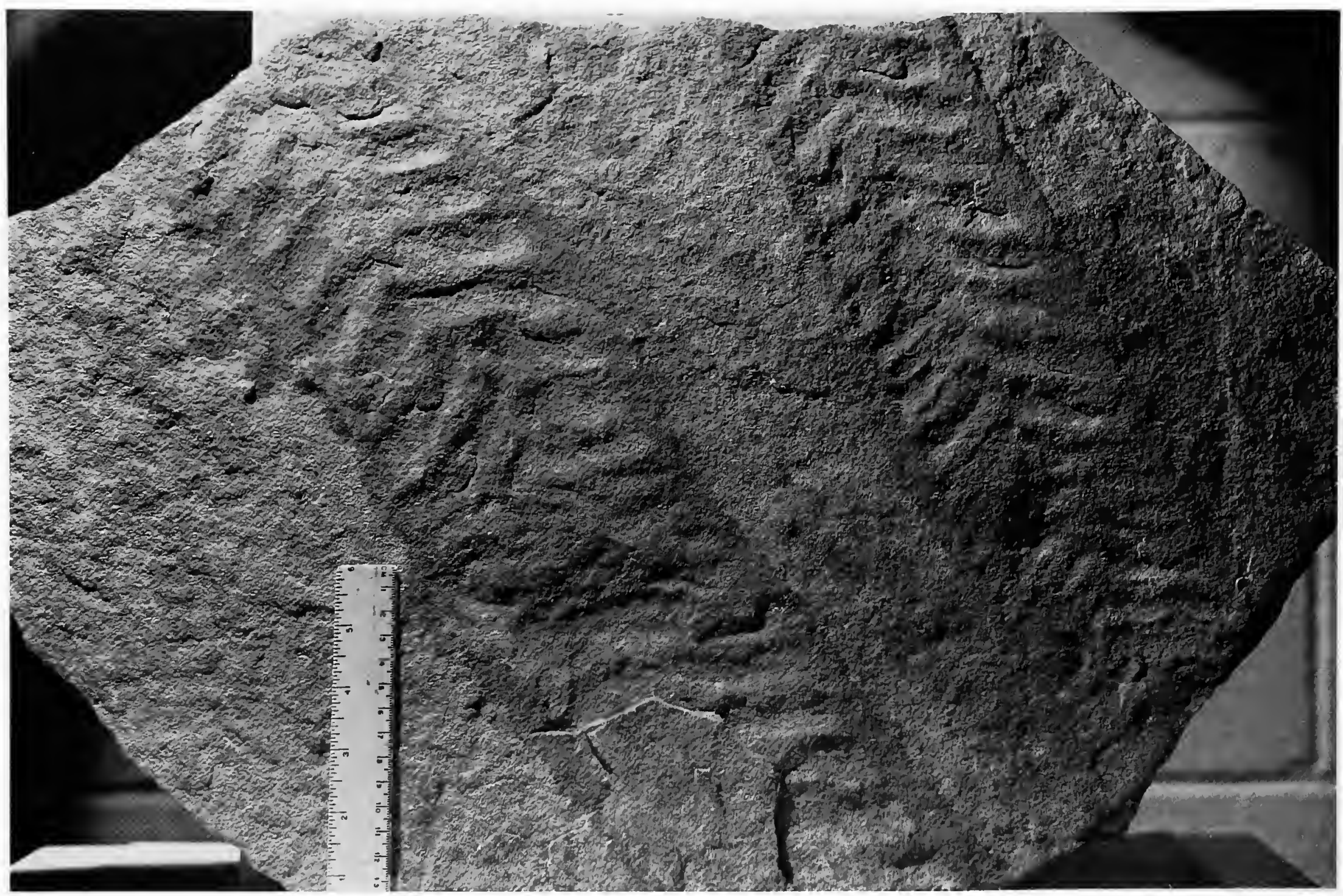

FIGURE 23.-Slab from Battersea, Ontario (7), showing two trails outlined by a distinct darker color, with similar color on the top of a few of the bars. The matrix of the slab is a brownish yellow and the color on the specimen is a dark purple. Scale is indicated by a $15 \mathrm{~cm}$ ruler. Miller Museum 2380.

the animal was at rest may also accurately reflect the approximate size of the moving animal.

On the many slabs that we have examined, we have seen no evidence of a preferred direction of movement. The large assemblage sketched by Clarke (1905) (Figure 40) suggests some directionality, but even here some animals moved in an opposite direction, and a few are at an oblique angle to the majority. The slabs collected by Dr. B.R. Erickson likewise show randomness in the direction of movement (Figure 40).

On some slabs, trails indicating one direction of movement are parallel to those showing the opposite direction of movement (Figure 41). We have considered the possibility that Climactichnites was proceeding in a meandering pattern, the most characteristic pattern among grazing trails. The common Precambrian to Recent trace fossil Helminthoida has a trail about $1.5 \mathrm{~mm}$ wide and has a meander range varying from about $10-50 \mathrm{~cm}$. If the same proportionality of meandering were applied to Climactichnites, meanders in the range of about 4-40 m might be expected. Most slabs are not sufficiently large to confirm or refute the maximum figure. However, the surface exposed at Au Sable Chasm (13), the scattered trails along the Chippewa River (2), the type slab from Perth (7), and the sketch of Clarke of the Mooers outcrops (12) show sufficient area to suggest that a rigid meandering behavior is extremely unlikely.

The trails have a superficial appearance of loose material which has been pushed forward. On a ripple-marked surface, the trail passes through a ripple crest as though it pushed forward like a snowplow or a bulldozer; similarly when one trails crosses another there is minimal lateral disturbance to the underlying trail. However, Climactichnites differs fundamentally from either of these mechanical comparisons in that the central area is not smooth, but bears the bars and furrows, which give the ladder-like appearance. Comparison of the trail to a rope ladder lying on the ground is an even better analogy.

LATERAL RIDGES. - The trails are bounded by prominent parallel lateral ridges, raised above the bedding plane, though these are not always preserved. Characteristically, the lateral ridges are higher than the bars which lie between them. There is a general size relationship in that the wider the trail, the larger and the higher the ridges. On smaller specimens, ridges are 


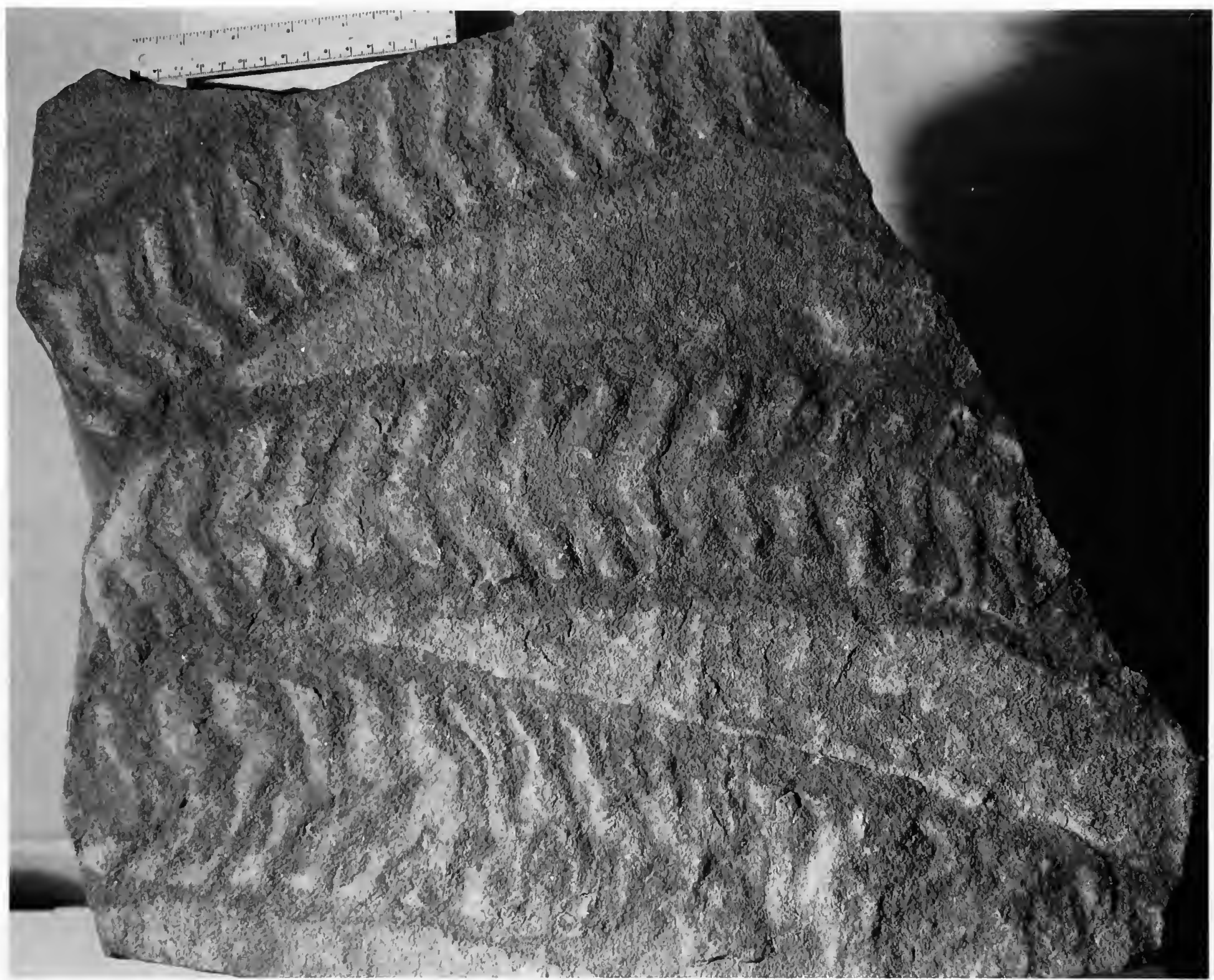

FIGURE 24.-Slab from Battersea, Ontario (7), showing three trails outlined by a distinct color. Because this is a sole marking, the surface relief is reversed and the dark color on the bars occurs in depressions, accentuated by the low oblique light; a color illustration of this slab has been published (Yochelson and Fedonkin, 1991). Scale is indicated by a $15 \mathrm{~cm}$ ruler. Miller Museum 2381 .

nearly hemispherical in cross section, where not compressed, but on very large specimens they are slightly higher than wide, where not compressed.

The inner face of the lateral ridge is more uniform than the outer face, but in some examples the ridge may be narrower adjacent to a bar. The outer face of the ridge may be even, but far more commonly, on well-preserved specimens, it is crenulated (Figures 42,43). There appears to be no correlation between height and width of ridges and presence or absence of such crenulation. There is also individual variation along the length of some trails in the presence of nearly uniformly spaced crenulations; crenulations may disappear and then reappear in less than a meter.
The crenulations tend to be spaced almost equally along a lateral ridge, though there is some variation in the distance between these indentations. On at least some specimens, the deepest part of the crenulation coincides with the top of a bar. Not unexpectedly, the crenulations are most prominent on the largest specimens, but on well preserved specimens where the lateral ridges are as narrow as $5 \mathrm{~cm}$, we have observed faint indentations on the outer faces of the ridges. It is possible that the presence or absence of crenulations is related to the amount of pore water in the damp sand. This relationship would, in effect, control the amount of source material available for the ridges, as would the ability of the individual animal to move and compress loose sediment. 


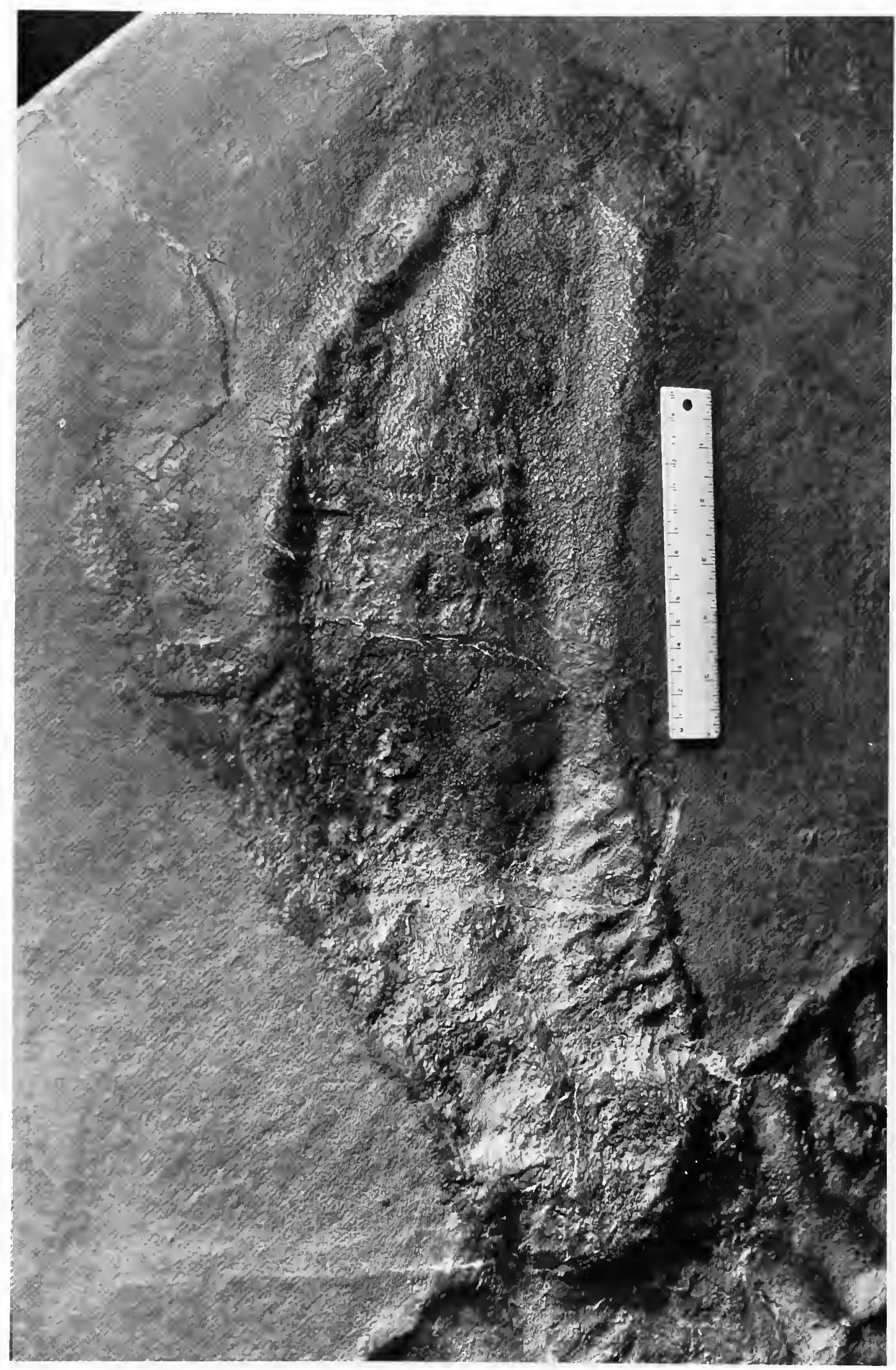

FIGURE 25.-Part of plaster cast of slab from Mooers, New York (12). The impression is not kidney-bean shaped, though several interpretations are possible. The preferred one is that an animal settled at nearly a right angle to the trail in the lower right and began to move toward it. A rim of sand indicates the animal stopped just after intersecting the earlier trail. Later, another animal settled at a slight angle to the first, partially obliterating the lower impression. This one faced toward the top of the photograph and its impression is deeper toward the left. Slight movement formed a ridge to the left side and a sand slide occurred to the right. The irregular ridge in the upper left reflects an anterior flap. Scale is indicated by a $15 \mathrm{~cm}$ ruler. NYSM public display. 
On some specimens both lateral ridges and bars are absent. Rarely traces of bars may be seen without the lateral ridges, but there are no examples of lateral ridges retained and medial bars absent. Of the specimens which lack lateral ridges, the one which Walcott illustrated as $C$. young $i$ is an excellent example (Figure 44).

BARS AND FURROWS.-Between the lateral ridges, elongate depressions and elongate ridges are present. The term "bar" is used for these inner ridges to avoid confusion with the continuous bounding ridges.

The furrows are narrow depressions nearly parallel-sided throughout most of their length, tapering to a point toward the center of the trail and rounded near the ridge. Commonly these depression are straight, but they may be gently arcuate. They may be as deep as $1 \mathrm{~cm}$ in exceptionally large specimens. The furrows are inclined at an acute angle to the adjacent lateral ridge; few examples of furrows at right angles to a ridge are known. Typically, one end of the furrow nearly touches a lateral ridge and a distinct, central non-furrowed area of the bedding plane separates the two rows of furrows.

The bars are raised and, like the furrows, are inclined to the lateral ridges. They are longer than the furrows and extend medially to the axis of bilateral symmetry. If bars from either side touch, there is a medial irregularity.

One important feature of the individual bars is their consistent asymmetry, as seen in profile along the length of the trail, being steeper on the forward (distal) side. The bars are more strikingly asymmetrical than the furrows and, in general, the larger the bar, the greater the asymmetry. Although it is almost impossible to make any observations in the third dimension, one exceptionally large paralectotype is broken along several laminations in the sandstone, revealing inclined structure at three levels (Figure 45). Such internal structure would not be seen if the trail were the result of the animal plowing forward. This suggests to us that the bars are at least in part built up and have a structure like miniature sand dunes.

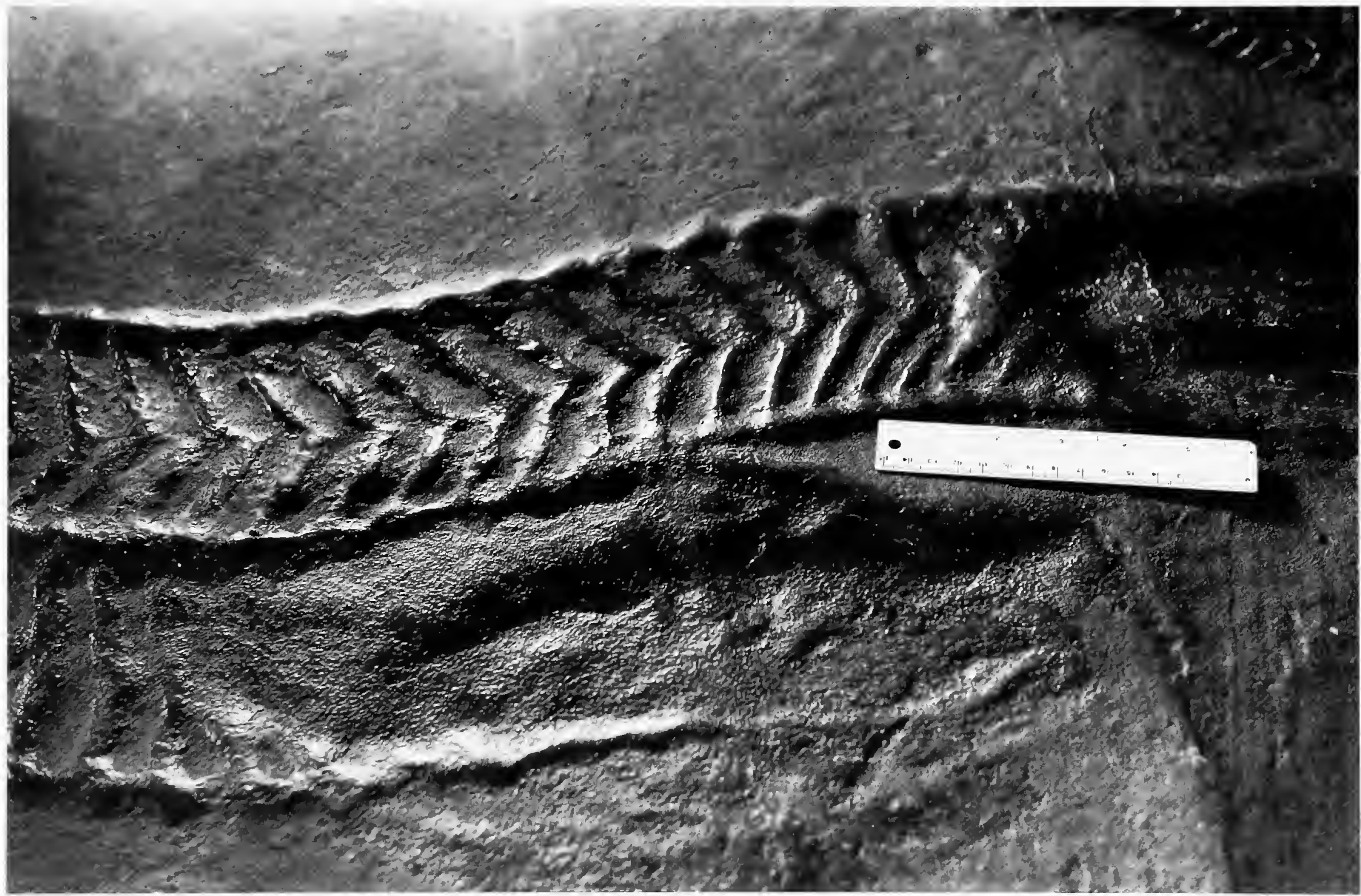

FIGURE 26.- Another part of the same plaster cast showing, below the scale, an oval impression leading into a trail. Within the impression the sediment surface has been modified and the right side of the impression is lower than that to the left. The trail begins sooner on the left side than on the right and supports the notion of an anterior flap on the right side. Another trail, above, also begins at a depression at the right side of the photograph. This has an angular anterior and bars appear on the right and left for about five centimeters before they become continuous between the bounding lateral ridges. The lateral ridges are crenulated after the animal left the oval impression. Both impressions are deeper than the trails. Scale is indicated by a $15 \mathrm{~cm}$ ruler. NYSM public display. 


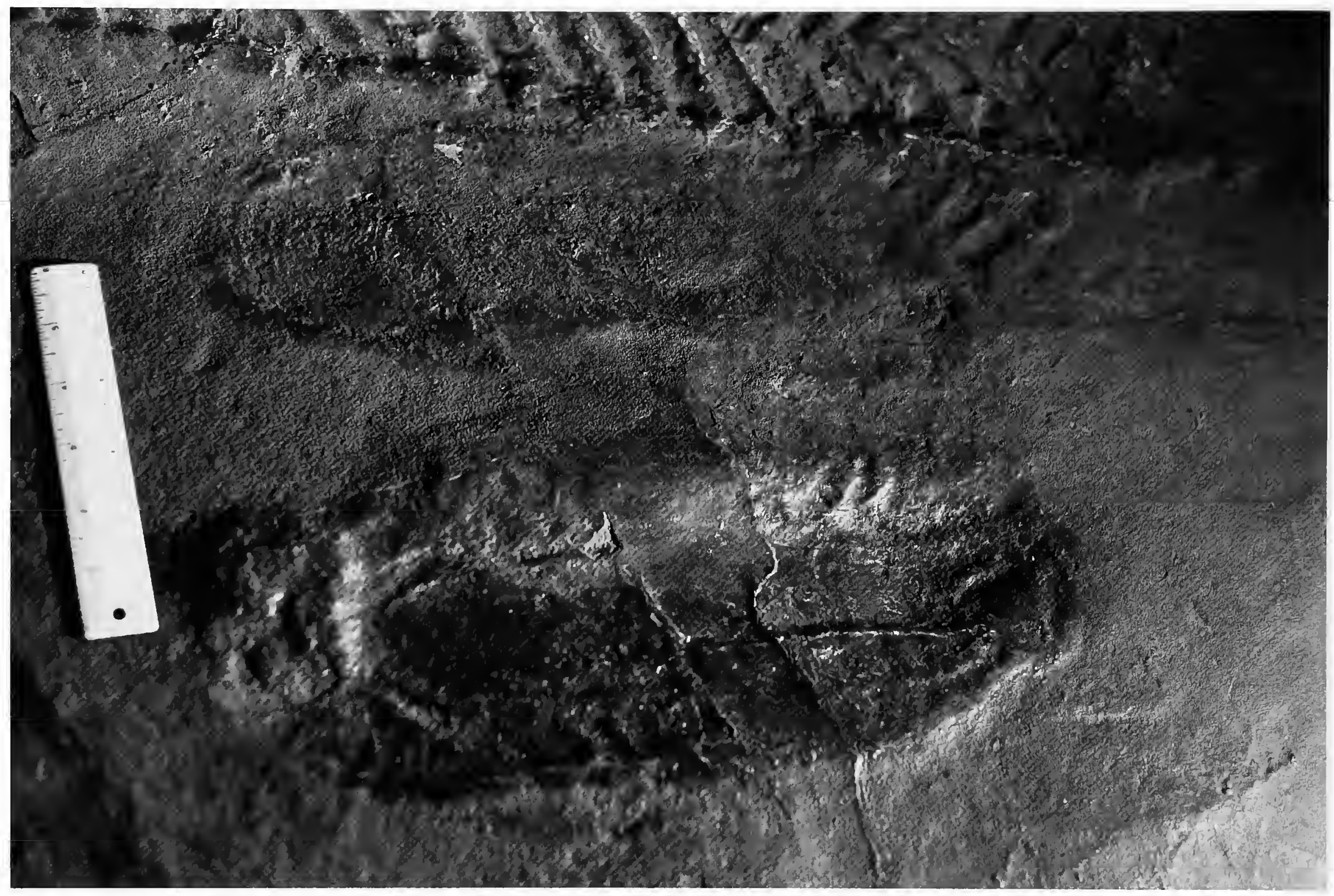

FIGURE 27.- Another portion of this same plaster cast showing two impressions. The one at the top adjacent to the trail is hardly impressed into the surface. The trail extending from it is obscure, but there is a suggestion that it begins on the left and that a flap extended forward on the right. The impression below is more deeply impressed, but less so on the right side at the lower part of the photograph. Scale is indicated by a $15 \mathrm{~cm}$ ruler. NYSM public display.

In addition to the internal structure of the dune-like bars seen on the type slab, several smaller specimens from the Northern Stone Company quarry (5) display inclination of layers on the sawn surface of bars, though not clearly enough to reproduce photographically; we have no material of a large trail which may be sectioned. These observations demonstrate that the trail is a surface phenomenon. In spite of the difficulty of compacting sand, an animal traveling over the surface by some sort of undulatory motion might-at least in theory-press the sand down into furrows. Even though pressure on the surface might result in forming a ridge, it would never result in a ridge having internal dune-like structure near the top.

Even though Climactichnites is conventionally depicted as showing uniform $V$-shaped bars (Figures 21,22 ), in fact this form is quite rare. Individual arms of the $V$ may be offset (Figure 46). Local asymmetry may also occur with a bar emplaced at irregular intervals along one side of a trail (Figure 47). Rarely the bars and furrows may be straight across at right angles to the bounding lateral ridges (Figure 42), more commonly they are at an acute angle to the bounding ridges, and in some examples they are highly irregular (Figure 48). On other trails the bars may be gently arched or may show greater curvature locally (Figure 49). Some bar and furrow systems are sigmoidal (Figure 50).

The amount of individual variation evident in the trails is remarkable. In addition to its unique morphology, in this feature of great variability, the trail of Climactichnites is unlike any other fossil trail we have examined. It is theoretically possible that the variation in trails represents more than one activity, for example conventionally feeding with locomotion, and rarely only locomotion. We know of no way to test such a hypothesis, but it is possible that sigmoidal trails which emphasize movement by one side of the animal (Figure 43) represent rapid locomotion.

Despite our best efforts, we have been unable to develop any correlation between width of trail and inclination of the bars and furrows to the lateral ridges. On one slab in particular (Figure 51), we have noted that areas of incomplete bar 


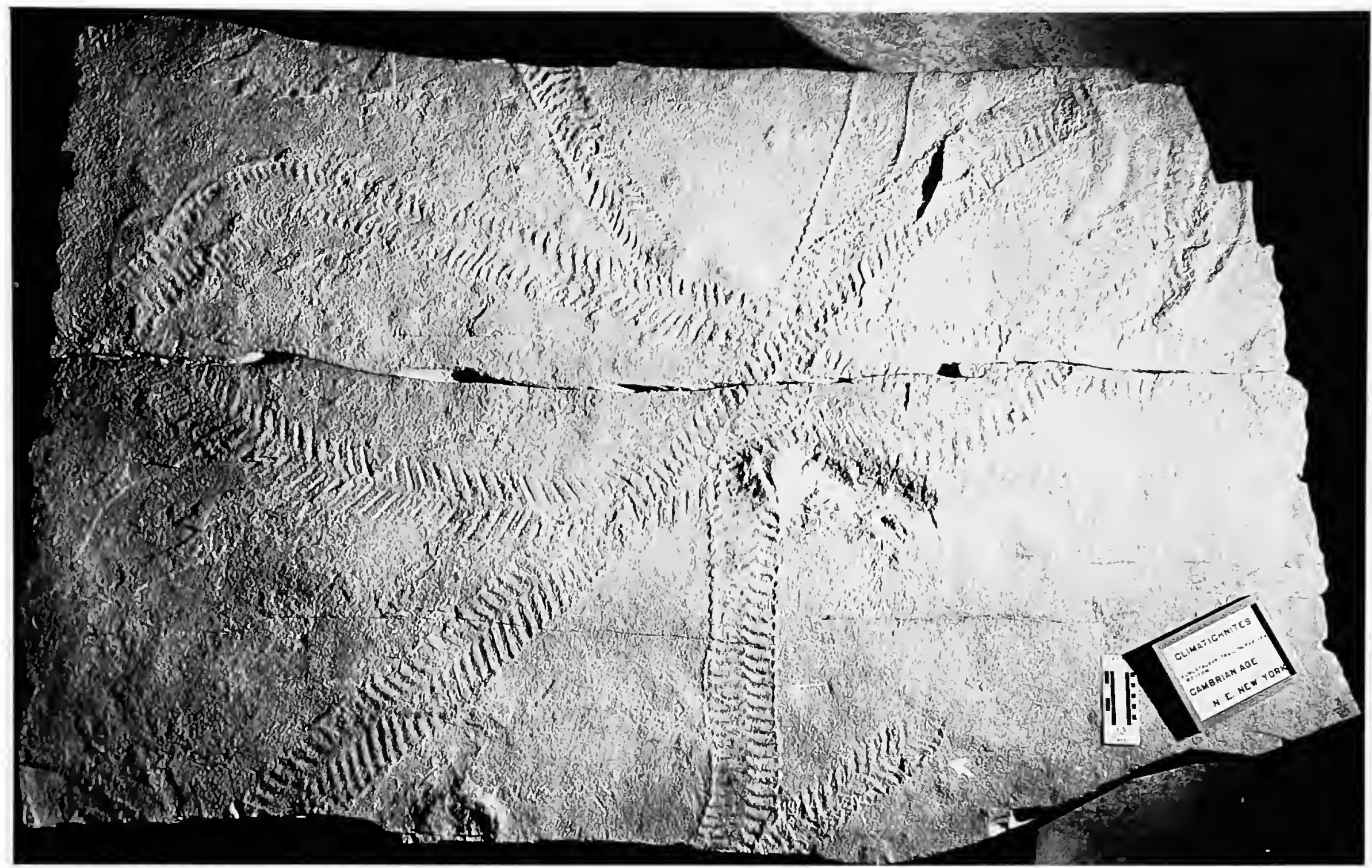

FIGURE 28.-Two slabs of the Potsdam Sandstone from "N.E. New York," possibly from Mocers, New York (12). An oval impression is present at the upper right and a second, broken off, occurs at the top of the slab. Sand mounds or "volcanoes" are present on the slab, which probably formed when incoming water forced air upward. Portions of this specimens are shown in Figures 29,53, and 54. Scale is indicated by a $10 \mathrm{~cm}$ ruler. PNH $98 / 1$.

formation and asymmetry of several trails coincide. This observation suggests to us that the degree of moisture in the sand may have had a profound effect on details of the trail. It is as though these animals crossed an area of wet sand.

Another feature is the loss of lateral ridges and bars even though detail in the furrows is retained (Figure 52). The key to interpreting this peculiarity was found on the two matching large slabs in the Pratt Museum (Figure 28). Unfortunately the number on these slabs is not listed in the museum catalogue and the accompanying label gives only the general information of northeastem New York. However, the slabs bear oval impressions along with the trails and, in color and texture, they are similar to the material from Mooers, New York. Because John M. Clarke was a student of Prof. B.K. Emerson of Amherst, it is reasonable to assume that he permitted Amherst College to remove material from his temporary quarry.

Some trails preserved on these slabs have no trace of lateral ridges or bars (Figure 53); the furrows which do remain serve to delineate the trail. The most logical interpretation is that these incomplete trails were formed later than adjacent complete ones, and there was not sufficient time for them to harden before incoming water washed away the ridges and bars which rose above the surface. This interpretation of the loss of ridges and bars emphasizes the importance of a secretion in hardening the trails.

Two of the trails which lack lateral ridges and bars on the large slabs in the Pratt Museum show other curious features (Figure 28). The furrows become shorter so that the medial area is undisturbed. They also become shorter and cease abruptly (Figure 54).

MEDIAL RIDGE.-On some specimens (Figures 18, 55) a low ridge may overlie some of the bars and furrows. This feature varies in presence or absence among the trails observed and on long trails may be seen to start and to stop along the length of the trail; neither the beginning or end of the ridge is prominent. This feature varies in position between the lateral ridges along a trail and also varies in its prominence (Figure 56).

\section{Abundance and Size Distribution of Trails}

Where it occurs, Climactichnites is both widespread and abundant. For example, in the lower level of the Northem Stone 


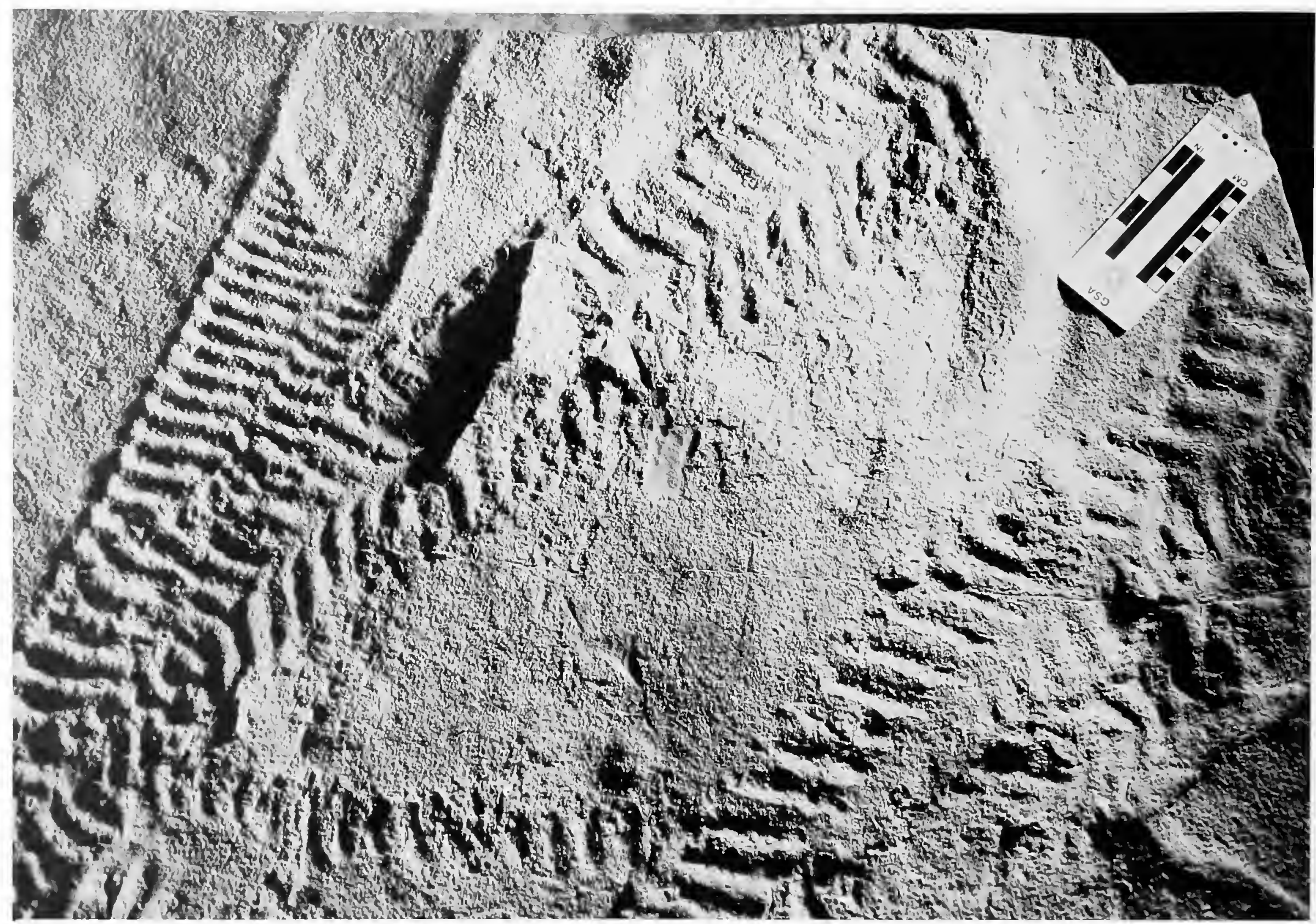

FIGURE 29.-Upper right quadrant of the slab shown in Figure 28. The oblique anterior of the impression at the upper right is clear; the rounded posterior is broken away. Irregularities just behind the oblique ridge suggest that this anterior portion was relatively flexible. The scale partially obscures another oval impression. At the far left and lower center, sand mounds occur. Scale is indicated by a $10 \mathrm{~cm}$ ruler. PNH 98/1.

Company quarry, Wisconsin (5), we counted in excess of 50 trails in an area of approximately 400 square feet; one modest-sized slab from this quarry shows six trails (Figure 46). Along the Chippewa River in Eau Claire (2), we saw approximately 50-60 trails in scattered outcrops along less than a kilometer of river bank; no doubt many more would have been found if the water level were lower and the outcrop continuous. More than two dozen occur on a slab collected by Dr. B.R. Erickson along the Black River (3) (Figure 40, bottom).

Nearly a dozen trails occur on the type slab from Perth, Ontario (8) (Figure 18), and more than that are seen on the display material from Beauharnois (10) in the National Museum of Natural History (Frontispiece). Although the collection at Queen's University contains only two slabs, there is anecdotal information of a large number of trails on slabs from the Battersea quarry (7) which were subsequently paved over; one of the remaining slabs bears three trails (Figure 24).
At Melocheville, Quebec (10), Clark and Usher (1948) reported many trails on the quarry floor. Clarke (1905) sketched nearly two dozen in about 300 square feet of outcrop at Mooers, New York (12) (Figure 40, top). Near Alexandria Bay, (11), a $15 \times$ $30 \mathrm{~cm}$ slab shows eight trails. At Au Sable Chasm (13) we estimate at least 25 trails in an area of about 100 square feet. A piece about five feet square in the New York State Museum from Port Henry (14) contains more than a dozen large trails. In light of both the broad geographic distribution and local abundance of these trails, the notion that Climactichnites is a "chance occurrence" of a rare pelagic animal swept inland by abnormal conditions, such as a great storm or tsunami, is untenable.

Despite limited information available from the outcrops, we are left with the impression that Climactichnites was more abundant on the sand flats on which oscillation ripples had formed than it was on the smoother surfaces. Another observation, supported by more data, but still qualitative, is the 


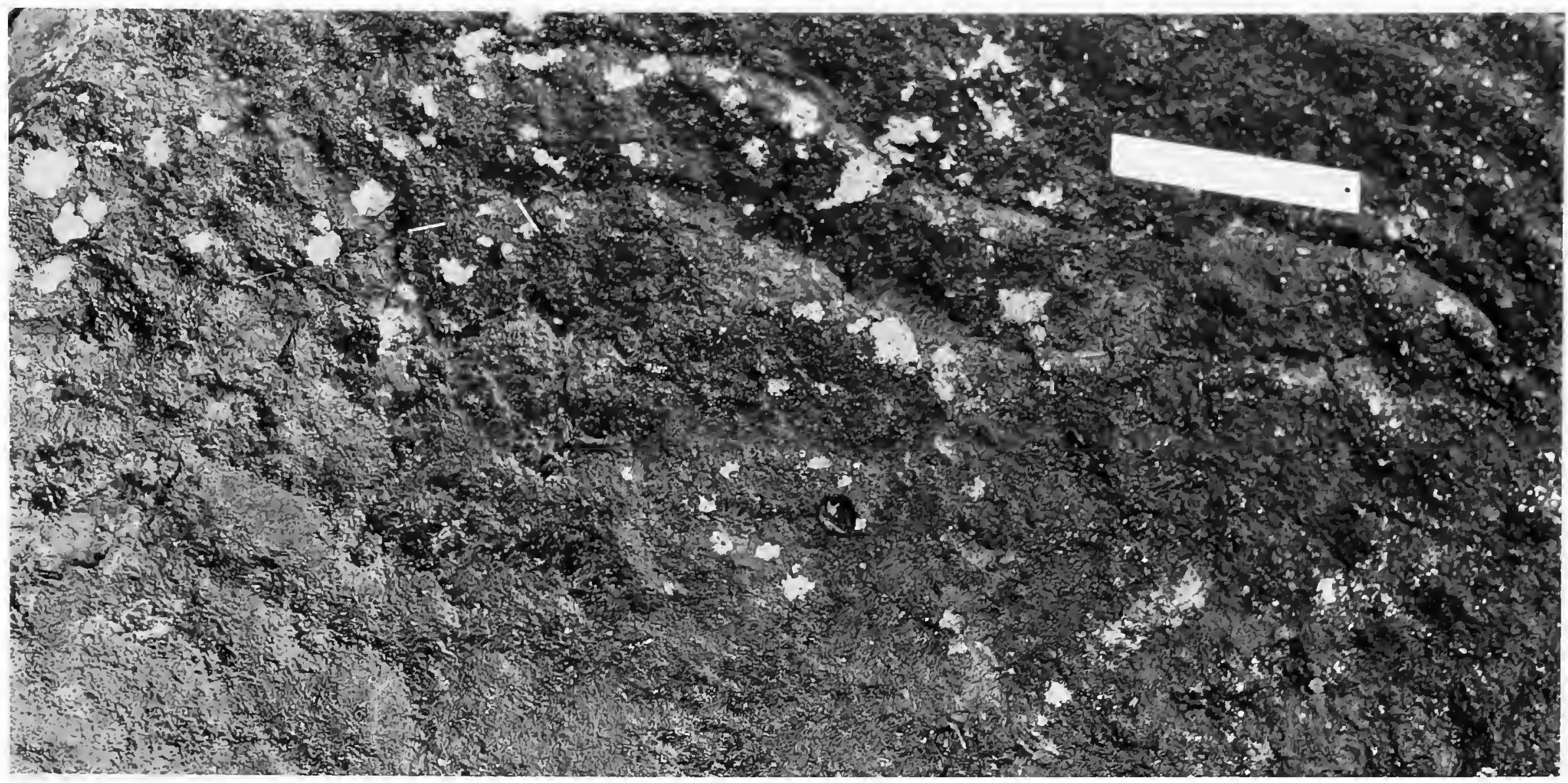

FIGURE 30.- Surface of a loose block of Mount Simon Sandstone on west side of Chippewa River, just below the dam at Eau Claire, Wisconsin (2). The ridges below the scale outline the posterior of an oval impression. The animal then presumably crawled toward the left forming a sigmoidal trail. Scale is indicated by a $15 \mathrm{~cm}$ ruler.

limited size range of trails at any one locality. Small trails in the range of $6-8 \mathrm{~cm}$ in width are known only from the lower level of the Northern Stone Company quarry (5). Medium-sized trails $(8-12 \mathrm{~cm})$ are widespread, as are large ones $(13-18 \mathrm{~cm})$, but these two general groups almost never occur on the same slab. Our interpretation is that this was directly related to the characters of the substrate, smaller animals requiring a different moisture content than the larger ones; presumably smaller animals would find it more difficult to move sand heavily saturated with water. There are a few instances in which a narrower width trail will occur with larger ones, but such distributions are exceptional.

\section{Earlier Views on the Origin of Climactichnites}

In summarizing the various views which have been proposed as to the nature of Climactichnites, it may be helpful to consider the works more or less in chronological order rather than by the group of organisms to which they suggested the trail maker belonged.

In his original description, Logan (1860:285) did not discuss locomotion. He ended his paper by noting "My naturalist friends to whom I have exhibited the specimens, appear disposed to consider the tracks those of some species of gigantic mollusk..." Notwithstanding this first published opinion, the notion of molluscan affinities did not prevail and vanished for nearly half a century, to be replaced by emphasis on various arthropods.
Jones (1862a) suggested that this fossil was a collapsed burrow, or gallery track, of a crustacean moving below the sand surface. The same year (Dawson, 1862) noted the error of this supposition, pointing out that the fossil was a surface trail. That comment was ancillary to experiments Dawson conducted with a living Limulus crawling on a beach. Because the Potsdam Sandstone was an ancient rock and living Limulus a "primitive" animal, there was considerable logic behind this early experiment in the "actuopalaeontologie" of a trace fossil. Dawson observed that under different conditions of subaerial and littoral depth, and thus sand moisture, Limulus produced markings similar to either Protichnites or Climactichnites.

"The supposition in regard to Climactichnites has been that it is possibly the track of a gasteropod [sic] or an annelid; but my recent observations of Limulus show that it may have been produced by a crustacean moving by a broad swimming foot, having a median notch like that in the largest pair in Limulus" (Dawson, 1862:274). Dawson went on to note that for this animal to produce the trail in question it would need more mobile and stronger swimming feet and the telson should not drag on the sediment. Further, he did mention that his living specimens produced lateral and medial furrows in the sand rather than ridges, an important difference. Jones (1862b:455) immediately recognized the significance of this difference and repeated his concept:

The great well-known North American trilobites (Paradoxides), however, whose bodies exactly fit in width to Climactichnital and Protichnidal trails of Canada, and whose abiding place was really the muddy-sea bottom on the 
geological horizon of the Potsdam sandstone, in all probability crawled over these littoral sands, just as the Limulus ... and ... it may have burrowed in them with much longer burrows than Limulus makes, and in that case the in-fallen galleries would supply the raised ridges of the Climactichnite.

Billings (1870:484-485), partly on the absence of any limulid body fossils having been found in the Potsdam Sandstone, suggested that both Climactichnites and Protichnites were formed by a large trilobite. During this time, the issue of trilobite limbs was still a point of uncertainty, and it was not until later in the decade that the presence of limbs and some of the details of their morphology was documented by Walcott. It is also helpful to recall that throughout most of the 19th century, trilobites and limulids were considered by many paleontologists to be crustaceans. Markings possibly made by trilobites on the bottom were a concern in trying to determine something of the life habits of these animals.

In his classic textbook, Zittel (1881-1885:591) did not provide any illustration of Climactichnites. He allotted the genus only a phrase in mentioning several forms from the Potsdam that might be evidence of early limulids or eurypterids. Nicholson and Lydeckker (1889:525) followed Dawson's views in their textbook.
In his compendium of North American fossils, Miller (1889:538-539) placed Climactichnites under Crustacea, but was cautious enough to note: "It may not be the track of a Crustacean." Lesley (1890) reproduced the drawings which Hall in turn had reproduced from Logan's original work. Lesley (1890:1192) added nothing new, but he nicely paraphrased Hall's view:

...that the animal seems to have had no free moveable limbs, or otherwise very short ones, without the sharp appendages belonging to Limulus; and that the only reason for calling the tracks crustaceans is our ignorance of the existence at that time of any larger creatures than Trilobites and one Limuloid.

Nearly three decades after his original investigation, Dawson returned to the theme of Limulus as a present-day model for Climactichnites. In his will, Sir William Logan left funds to pay for the replacing of fossils which had been removed from Montreal when the Geological Survey of Canada was transferred to Ottawa. As a consequence, the Redpath Museum hired Richardson to collect, and obtained a single large piece of sandstone from Perth. This new material may have inspired Dawson, who emphasized trilobite burrowing structures, now generally placed in Rusophycus and Cruziana, as germane to

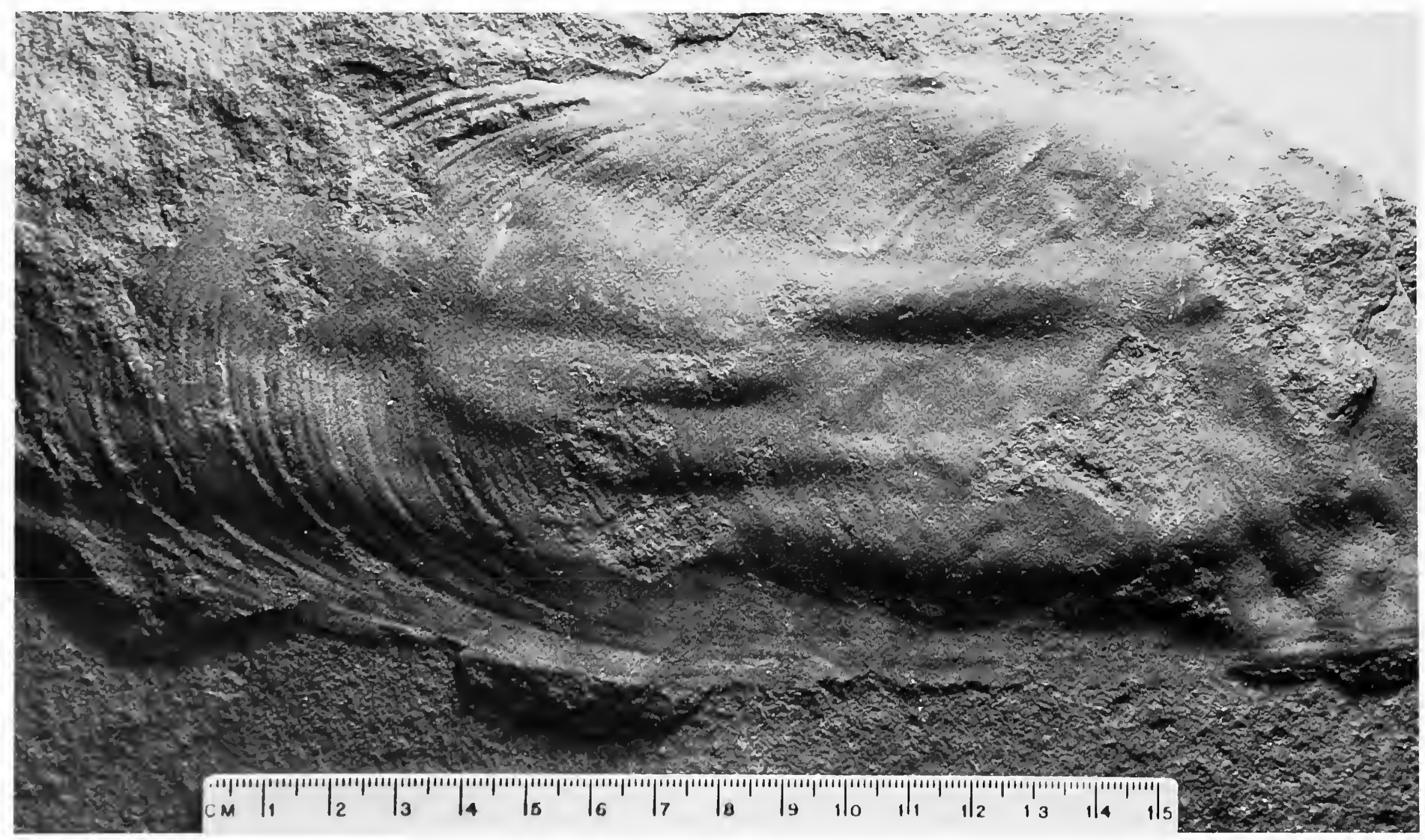

FIGURE 31.-Counterpart (sole marking) of specimen probably from the Galesville Sandstone at New Lisbon, Wisconsin (4), illustrated by Walcott (1912) as C. youngi, showing the impression of the base of an oval impression; compare with Figure 44 . The fine arched lines cross the irregular elongate ridges and furrows. The slightly coarser arched lines near the top right may mark the first stages of trail formation. The matrix is exceedingly fine, but as in other examples, the impression is smoother than the matrix. Scale is indicated by a 15 cm ruler. USNM 58544. 


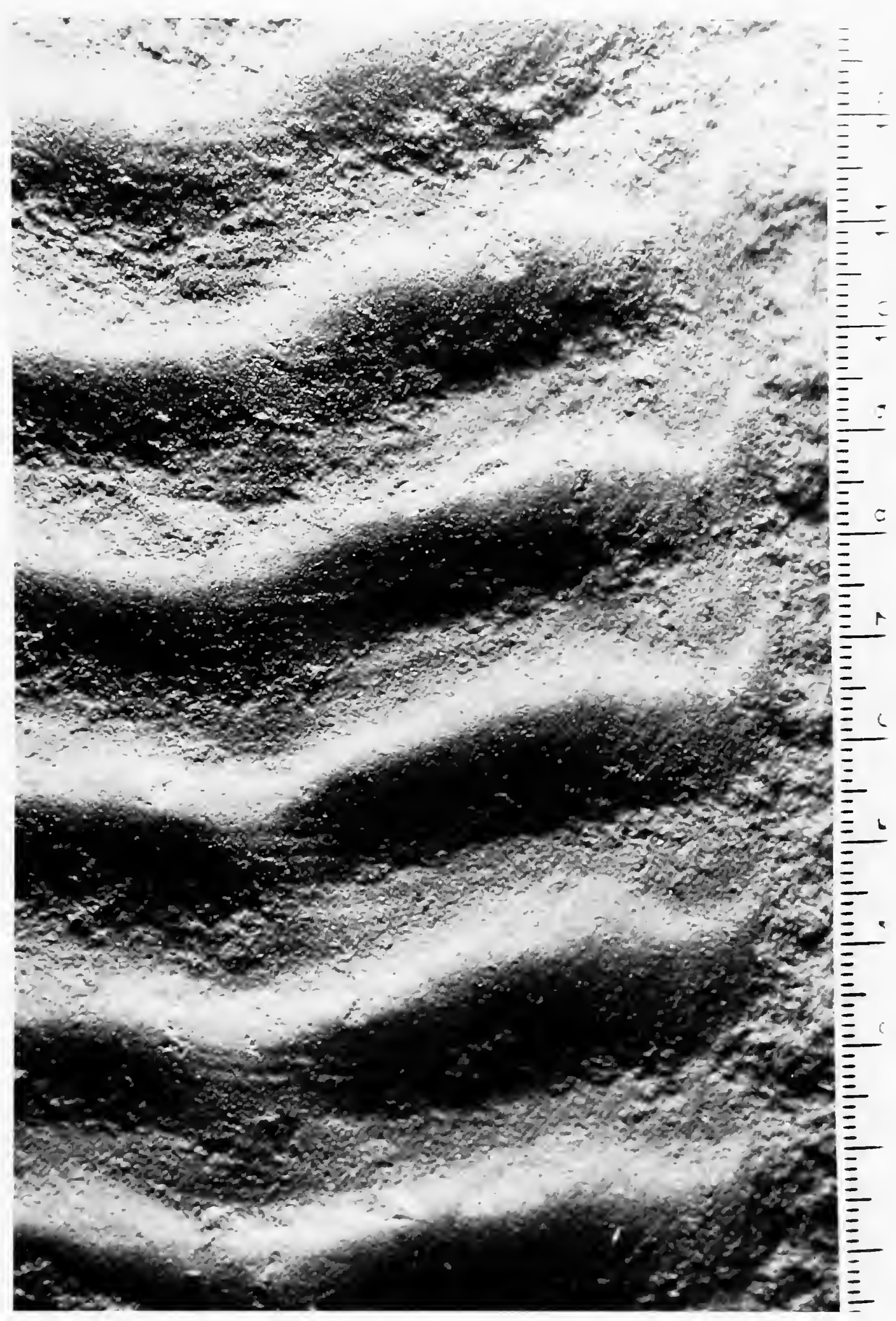

FIGURE 32.-Detail of a portion of a slab probably from the Galesville Sandstone at New Lisbon, Wisconsin (4), shown in Figure 51. This was illustrated by Walcott (1912, pl. 39: fig. 2) as C. youngi, and reillustrated by Burling (1917). Although Burling corrected the direction of movement, neither he nor Walcott noted that the lateral bounding ridges are not present. The arched lines are preserved on the gentle (distal) slope of the bars, and not on the steep (proximal) slope. Even though no lateral ridges are present, the sharp prong-like edge adjacent to them is evident on the right side and is comparable to the same feature in Figure 43. Scale in centimeters. USNM 58545. 


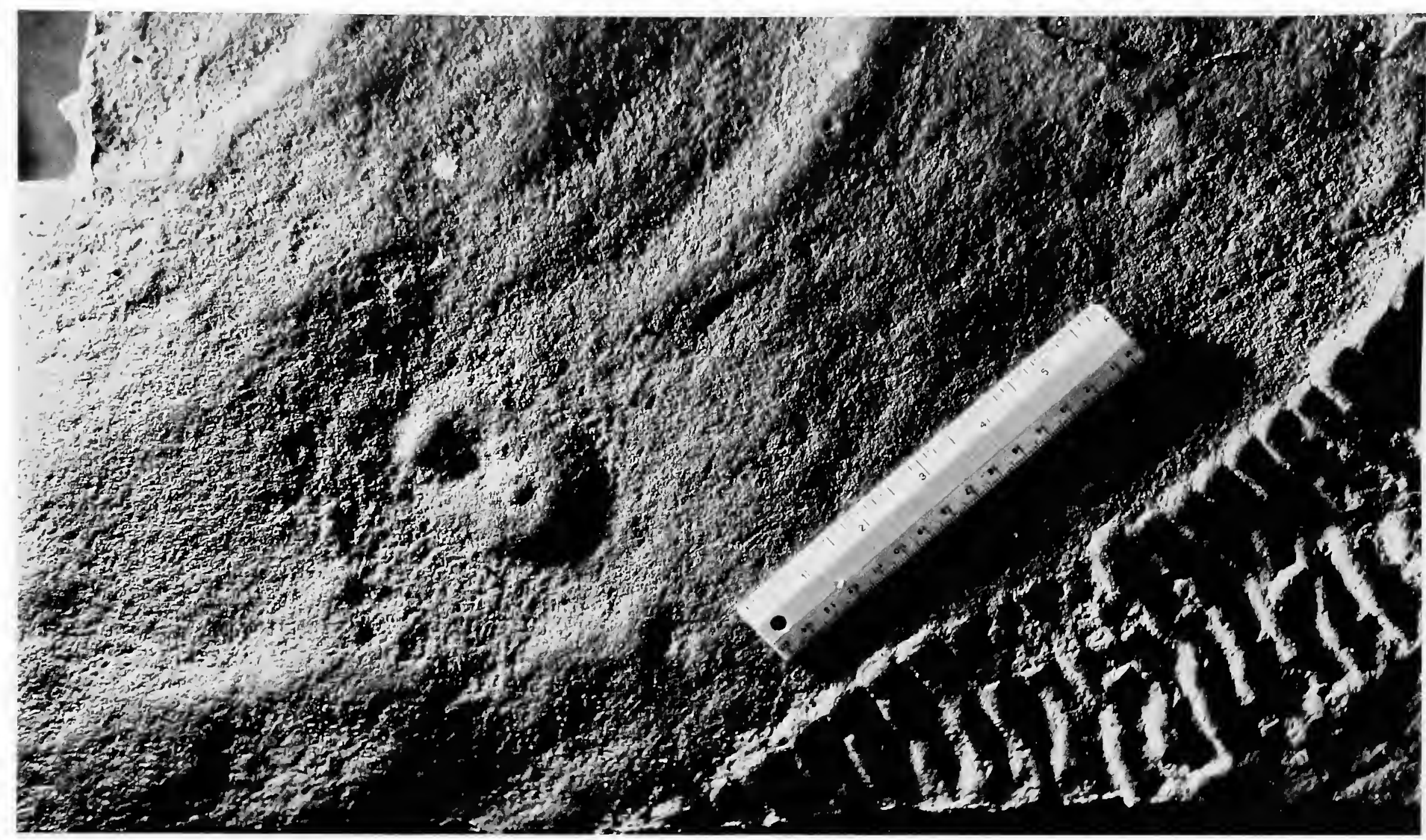

FIGURE 33.-Two oval impressions, separated by a ridge, and a portion of a trail from Mooers, New York (12). A "sand volcano" or sand mound is on the compacted surface of the impressions. Scale is indicated by a $15 \mathrm{~cm}$ ruler. NYSM unnumbered.

the issue of the Potsdam Sandstone trail maker (Dawson, 1890:601).

From all the phenomena attending the Potsdam Climactichnites, I am now inclined to regard them as of this nature, and as implying the existence of a large Crustacean with a truncated tail divided into two moveable lobes. This would account for the ridge sometimes dividing the furrows and transverse ridges, and for its change in position from side to side of the mesial line, -also for the interrupted ridge on each side of the trail, which would be the natural result of the successive strokes of a flat organ, -and for the appearance presented when the tracks turn abruptly.

The large topotype slab (Figure 55) was illustrated by him, and with that length of trail material available to him, he therefore should have had a better notion of the large degree of individual variation both among trails and along a single trail. In this paper, Dawson's earlier published "may" became a certainty, and his comment that crawling Limulus produced furrows in the substrate simply disappeared.

Like Nicholson and Lydeckker, Dana mentioned Climactichnites in several editions of his textbook, and in the final edition, he (Dana, 1895:479) reproduced reduced sketches of all three named species. In a previous sentence, he had mentioned large specimens of the trilobite Dicellocephalus. "The track. . .from Perth. . has been referred to a large Trilobite, on the view that the limbs of the species were natatory....The partial natatory character of the limbs has recently been established...." By this, Dana was referring to the then new discoveries of the limbs of Triarthrus becki Green at Rome, New York. Dana presumably assumed that the movement of the swimming limbs of a trilobite could form a trail when it scurried along the bottom.

Packard, a specialist on living arthropods, reinforced the interpretation of this fossil as that of an arthropod by simple repetition (Packard, 1900:65).

Logan's Climactichnites wilsoni, six and a half inches wide and thirteen feet long, also from the Potsdam sandstone, which Dana suggested may have been made by a large trilobite, seems to be such. There is an interrupted median furrow; the oblique furrows probably were made by the legs, and the lateral furrow bounding the track is much like that made by the cheeks or sides of the head of Limulus.

Again furrows and ridges were confused probably because this zoologist was not familiar with the concept of impressions on the bottom of overlying beds, as Logan had illustrated, and was further misled by Dawson's comments.

Gratacap (1901:89) suggested that: "Climactichnites and Protichnites may all be the repant impressions of broad ringed worms." He gave no further information at the time to support this novel interpretation and seemingly never elaborated on it.

Woodworth (1903) provided an important addition to the 


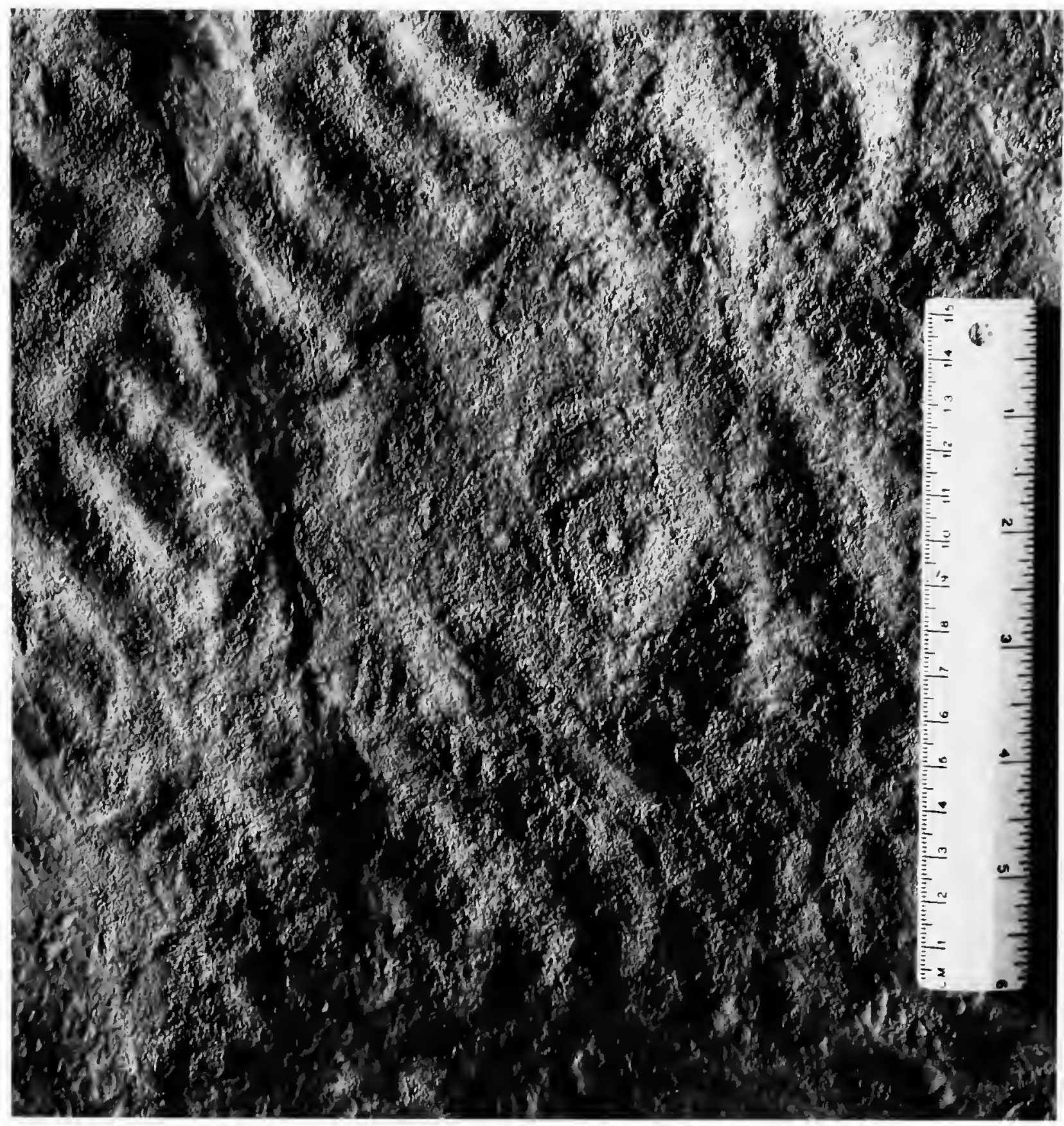

FIGURE 34.-Three concentric markings on an incomplete oval impression, cut off above and below by trails, from Beauhar nois, Quebec (10). The area below the scale in this view having a different texture is restored in plaster to simulate ripple marks. The area illustrated is near the center of the Frontispiece. Scale is indicated by a $15 \mathrm{~cm}$ ruler. USNM public display.

morphology of Climactichnites with his discovery of an oval impression at one end of some of the trails (see Figure 40, top). In another piece of experimental ichnology he pushed a small board through sand to simulate the trail. He concluded that arthropod limbs, including the specialized organs of limulids and eurypterids, were incapable of producing the trail of this fossil.

Following the suggestion of a Professor Walter Faxon, Woodworth then proposed polyplacophoran mollusks as the putative trail formers, probably influenced in part by the shape of the oval impressions (Woodworth, 1903:965).

The mantle of the Chiton extends beyond the shells; they have a powerful foot for attachment to rock surfaces; though habitually attached to rock surfaces, they can crawl very slowly over sand; they can roll themselves up into a ball as did many trilobites; the retractile forward hitching movements of the foot of a large Chiton, moving inch by inch, might have given rise to smoothened, cross-ridged trails known as Climactichnites; and the sedentary animal with retracted foot, the terminal impressions seen at Mooers. No other existing form seems so readily capable of producing the assemblage of phenomena. But it is equally possible that some large sea slugs of the order Aplacophora may have produced the trails and the terminal impressions, though the modem representatives of these primitive gastropods are not littoral animals. Further than the suggestion of a molluscan origin for these terminal impressions and the connected trails, it does not seem possible at present to seek definite conclusions.

This return to a molluscan comparison was ignored, for Limulus and its allies were considered as putative trail makers by Hitchcock and Patten (1908:382) in an abstract; no subsequent publication was produced. Hitchcock was one of the sons of Edward Hitchcock and may have seen the plaster casts of Logan's type lot in the Pratt Museum; Patten devoted his life to the study of Limulus. The abdominal gill plates of eurypterids were considered by them as an appropriate morphology for forming the bars in the Climactichnites trail. The writers referred to a slab installed in the Butterworth 


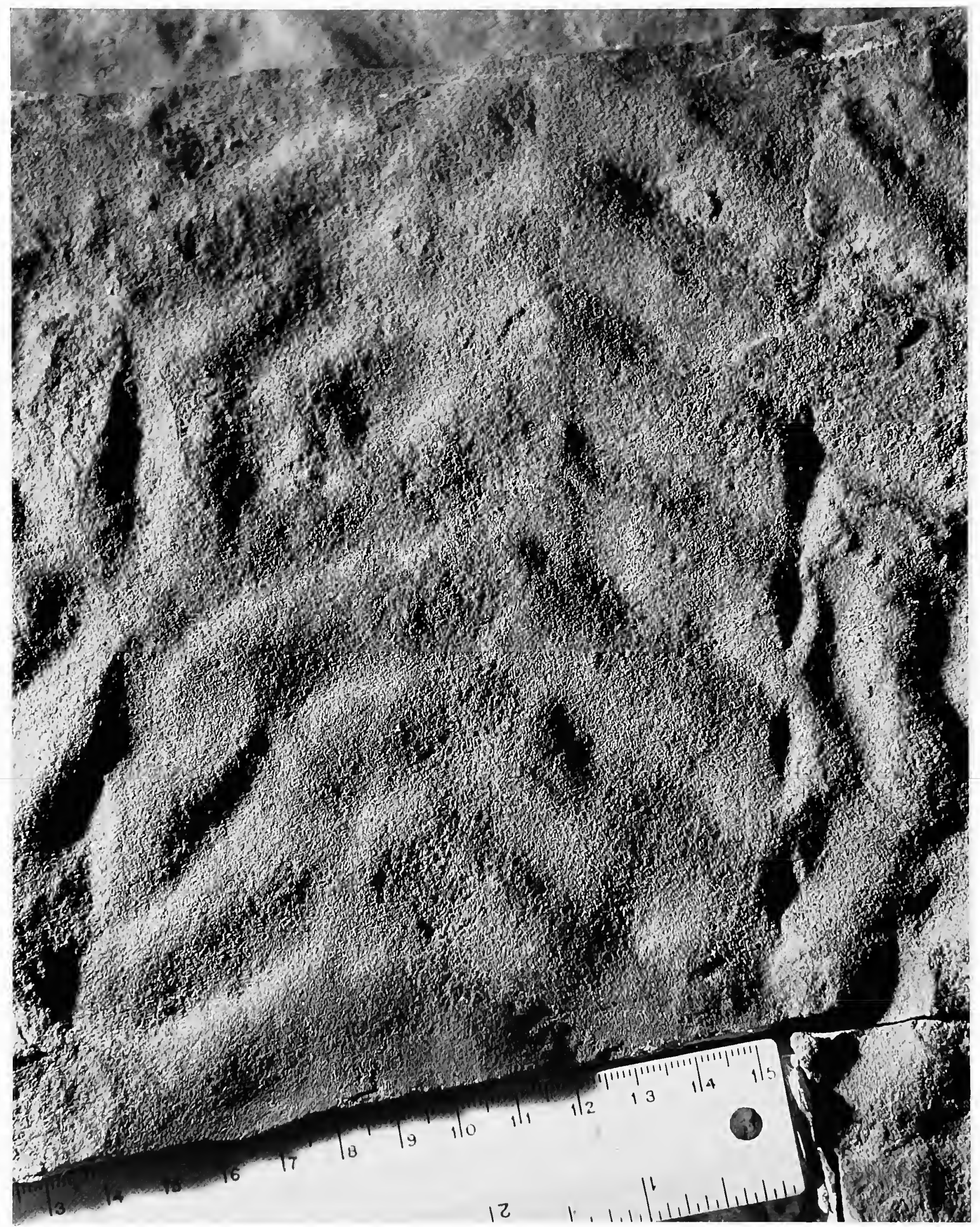

FIGURE 35.-Four circular slightly roughened areas in the central part of a trail from the Potsdam Sandstone from Port Henry, New York (14). This is a sole marking, so the surface relief is reversed; the prominent crenulations of the lateral ridge seen to the right side of the trail are accentuated by shadows in the depression. Scale is in centimeters. AMNH unnumbered. 
Museum and indicated that the trail began at a depression and rose through the sand, as in the manner of a modern Limulus.

After considerable investigation, we have found that the Butterworth Museum was at Dartmouth College in New Hampshire. Chamberlin (1883:133, footnote) noted that the Reverend A.A. Young obtained about half a ton of slabs bearing Climactichnites for Beloit College, and "He also supplied the University of Wisconsin and Dartmouth College with specimens." It is likely that the depression mentioned by Hitchcock and Patten was an oval impression, as illustrated by Walcott (1912) from New Lisbon, Wisconsin (4) (Figure 44). Unfortunately, the Butterworth Museum has been dismantled and the slab or slabs mentioned in the abstract no longer exist (Dr. G.D. Johnson, oral communication, 1991). According to Dr. Johnson, inquiry to a retired faculty member who was an undergraduate at Dartmouth brought a recollection of many slabs of dinosaur tracks on the walls, but nothing of Climactichnites.

In an extended footnote, Clarke and Ruedemann (1912:8586) repeated with favor much of the short abstract of Hitchcock and Patten. They suggested that the Cambrian eurypterid Strabops would have been capable of making the trail, and they were the first authors to specifically consider eurypterids as putative trail formers for Climactichnites. Against this view, they cited the direction of movement suggested by Woodworth (1903), toward the oval, as being unlike the habits of Limulus and therefore opposed to this interpretation. With the reinterpretation by Burling (1917) as to the direction of movement, that concern vanished. Nevertheless, this footnote was essentially the last significant mention of arthropods-be they crustaceans, eurypterids, limulids, or trilobites-in connection with Climactichnites.

In their textbook, Grabau and Shimer (1910:89) described $C$. wilsoni but did not illustrate it. They remarked: "The trail has been generally recognized as that of some crustacean. It may have been made by some unknown terrestrial or semiterrestrial animal." They referred to the work of Woodworth (1903) but, notwithstanding that, the genus was placed in their chapter on Phylum Annulosa, under Class Annelida, Order Polychatea, Suborder Errantia, and in the final section titled "doubtful

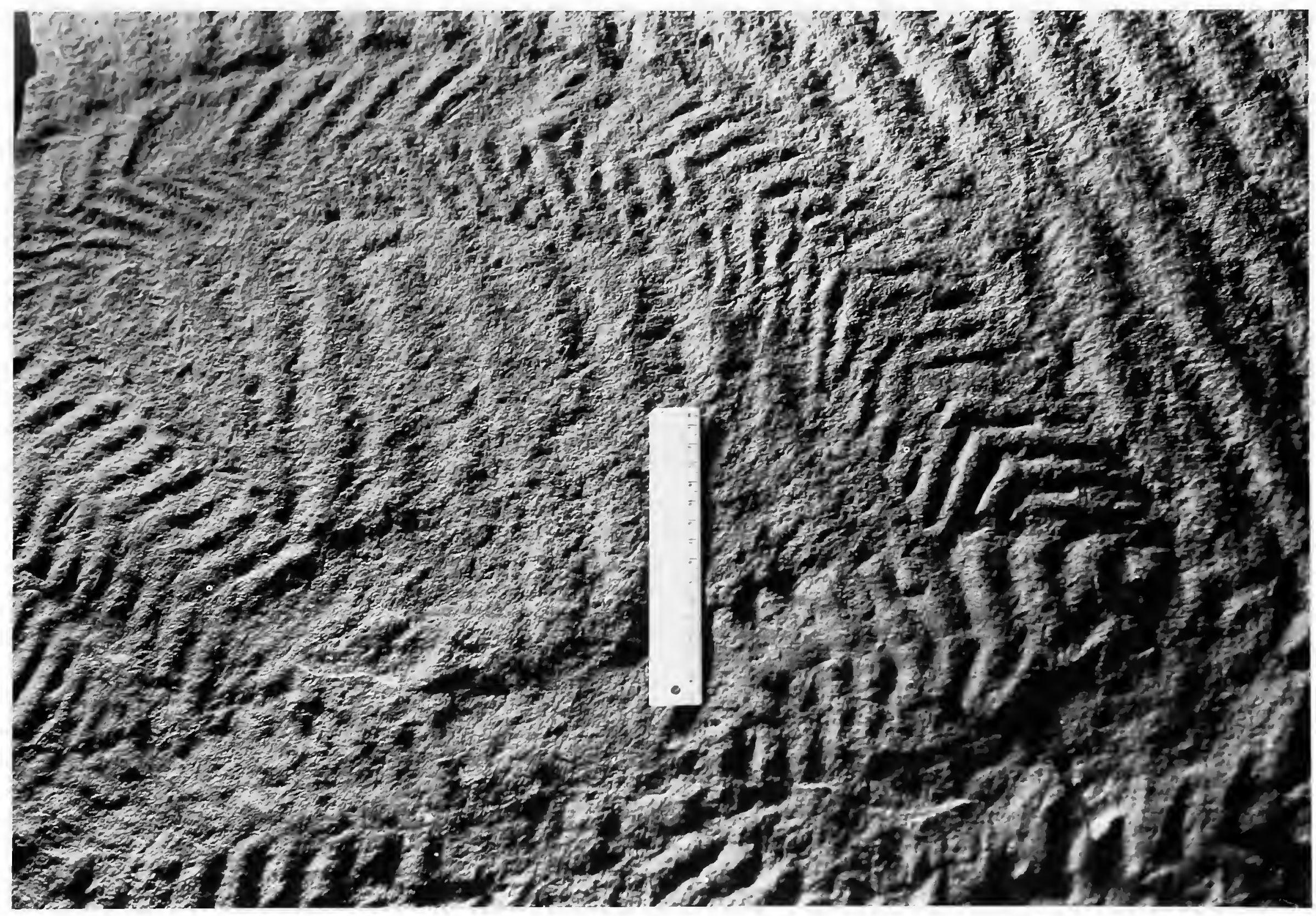

Figure 36.-Portion of a slab of Potsdam Sandstone from Port Henry, New York (14). In spite of the reversal of surface relief on this sole marking, the circular area in the curved trail above and to the right of the scale is similar to that shown in Figure 34. Scale is indicated by a $15 \mathrm{~cm}$ ruler. MPM 28389. 
affinities." Discussion of a possible crustacean among the worms is a bit strange, but on the other hand, their mention of a terrestrial animal was perceptive.

In a footnote to his study of Cambrian merostomes, Raasch (1939:7, footnote) effectively ruled those animals out as related to Climactichnites; he did not suggest any group as related to the trail maker.

There is of course a vast disparity of age between the Wisconsin Climactichnites and Aglaspis barrandi, the former being below the earliest Upper Cambrian fauna, the latter in the latest. There are, however, abundant merostome fragments in places in the earliest fauna, the Cedaria fauna of the Eau Claire division, but this lies still more than 100 feet above the horizon of the trails. Conversely, where merostomes are abundant, no trails of Climactichnites or Protichnites types have been observed.

The same year that eurypterids were suggested as the putative trail former, Walcott (1912) described Climactichnites specimens from New Lisbon, Wisconsin (4). He refuted the chiton hypothesis put forth by Woodworth (1903) and suggested that the trail of Climactichnites might have been made by the movement of some large annelid worm (Walcott, 1912:201).
Among the Burgess shale forms there is a large Chaetopod worm (Pollingeria grandis), a crushed specimen of which has a length of $13 \mathrm{~cm}$, width $7 \mathrm{~cm}$. The larger scales found in the same layer of shale indicate that some individuals attained near twice that size. Such an annelid would have had sufficient size, weight and strength to make the Climactichnites trails. Among recent annelid species of the Aphroditidae attain a large size and some have a shallow water habitat and crawl about on the wet sand between tides.

Seemingly the concept of worm origin for this trail was independently arrived at by Walcott, for he did not give a reference to the comments by Grabau and Shimer (1910). In the textbook by Zittel (1913:142), Climactichnites trails are not illustrated and are mentioned as "of uncertain origin but may be those of some large crustacean." A long footnote gives a comprehensive review of the literature, including the 1912 paper by Walcott. More or less like the classification given in the Grabau and Shimer textbook, although Zittel suggested Climactichnites was a crustacean, it was inexplicably placed in Phylum Vermes, Class Gephyrea.

After his analysis of the details of the trail and the direction of movement from the oval impression, Burling (1917:397) did not suggest any assignment to phylum. He concluded that data

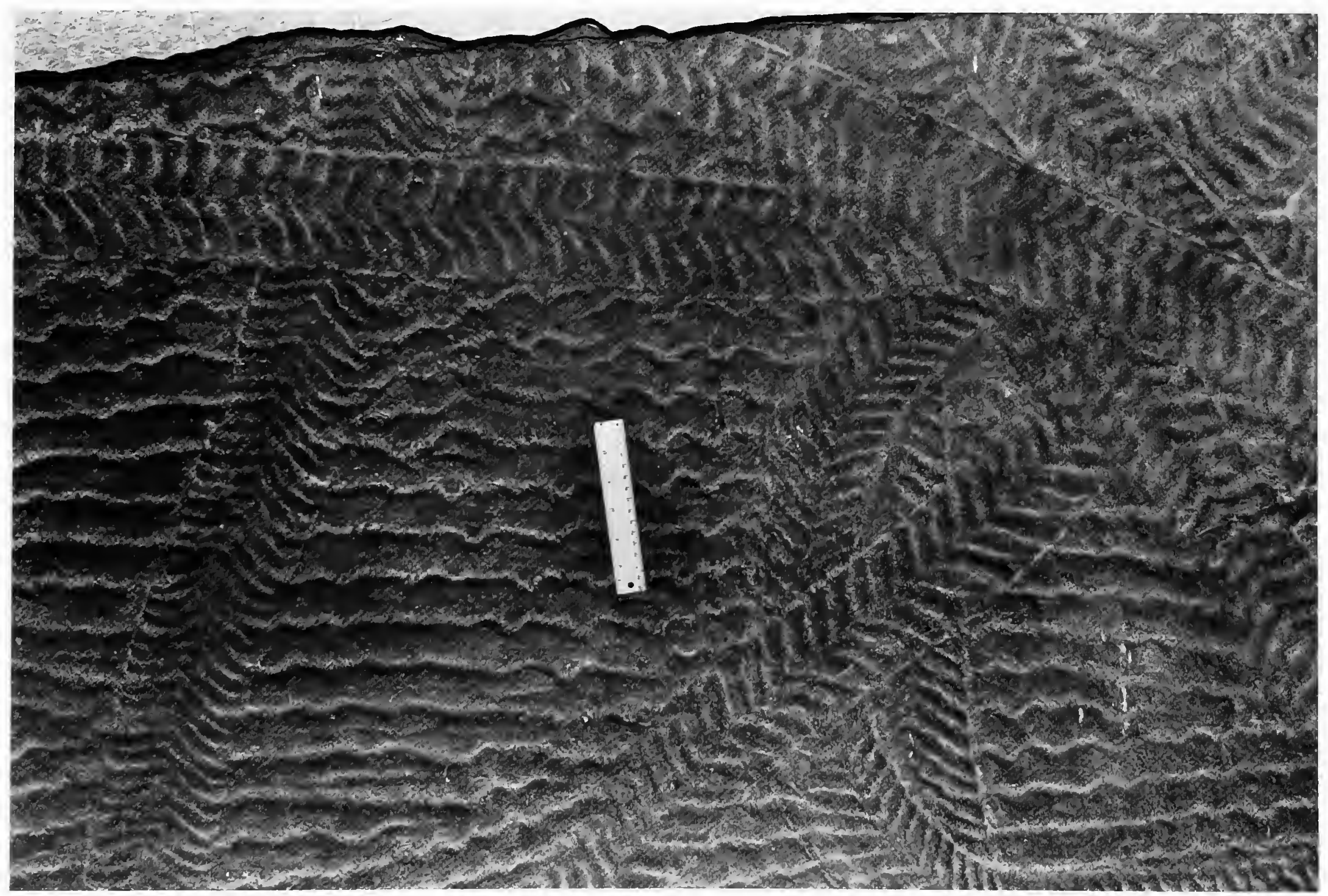

FIGURE 37.-Trails on a slab of Potsdam Sandstone from Port Henry, New York (14), showing no directionality. The troughs of interference ripples are standing in strong relief on this sole marking; the irregularities in the ripple marks may represent another later current direction. Scale is indicated by a $15 \mathrm{~cm}$ ruler. NYSM unnumbered. 
were sufficient to emphasize "that Climactichnites was made by the snail-like creep of a flexible slug-like animal which was frequently stranded at low tide, but was able to swim in waters of the full tide, have passed the stage of guess-work and border on the real."

Based on observations he made of living gastropods crawling, Raymond (1922:111) returned to the original idea published by Logan: "Climactichnites is essentially the same sort of trail made by Littorina...." Raymond referred to the work of Woodworth (1903) and Walcott (1912) but apparently was unaware of that by Burling (1917). He pointed out that the trail of a Littorina may bear transverse ridges which are directed forward as in the Walcott material, quite unaware that this orientation was reversed.

In 1925, Abel (1935:242) visited Albany, New York, and examined the trails collected from Mooers, New York; he was the first to publish a photograph of one of those oval markings. As a most unexpected piece of humor in his work, he noted a story attributed to R. Ruedemann that the local farmers considered the oval impression at the start of the trail to be a mark of the footprint of Christ stepping on a serpent, an imaginative folk legend. He then considered in some detail the various notions which had been put forth as to the animal which may have formed the Climactichnites trails. Not only did he then decide that Climactichnites was of molluscan origin, like Raymond (1922), he was firm in his opinion that the trail formed by movement of a gastropod. Indeed, he suggested a shell-less opisthobranch, though he was aware of some of the problems in this interpretation.

Shimer and Shrock (1944:799) reproduced Clarke's sketch of 1905, but mixed the figure caption with that of Protichnites, adding a minor bit of confusion. They covered the various possibilities as to origin in writing: "This trail may be that of an extinct crustacean, mollusk, or annelid worm, or possibly some other extinct Cambrian organism." In confirming the direction of movement interpreted by Burling, Clark and Usher (1948) did not contribute any opinion as the kind of animal which made the trail.

A description of Climactichnites was given by Häntzchel (1962:W-188) in the "Treatise on Invertebrate Paleontology" wherein he suggested that the trail was: "Probably formed by mollusks, arthropods, or worms." This was in the Treatise tradition of mentioning all opinions, but remaining neutral. Subsequently, an excellent brief general account of the salient literature was prepared by Malz (1968) in which he attributed

FIGURE 38.-Sketches reproduced from Clark and Usher (1948:252, 253) of trails crossing over themselves on the quarry floor at Melocheville, Quebec (10). Top: The caption for the smaller (upper) figure is "Figure 2. Climactichnites wilsoni Logan, a normal size trail showing the relationship between the $V$-shaped markings and the direction of progression." Bottom: The caption for the lower is "Figure 1. Climactichnites wilsoni Logan. A narrow trail showing by two intersections the direction of progression, and also the oval body at the beginning of the trail."
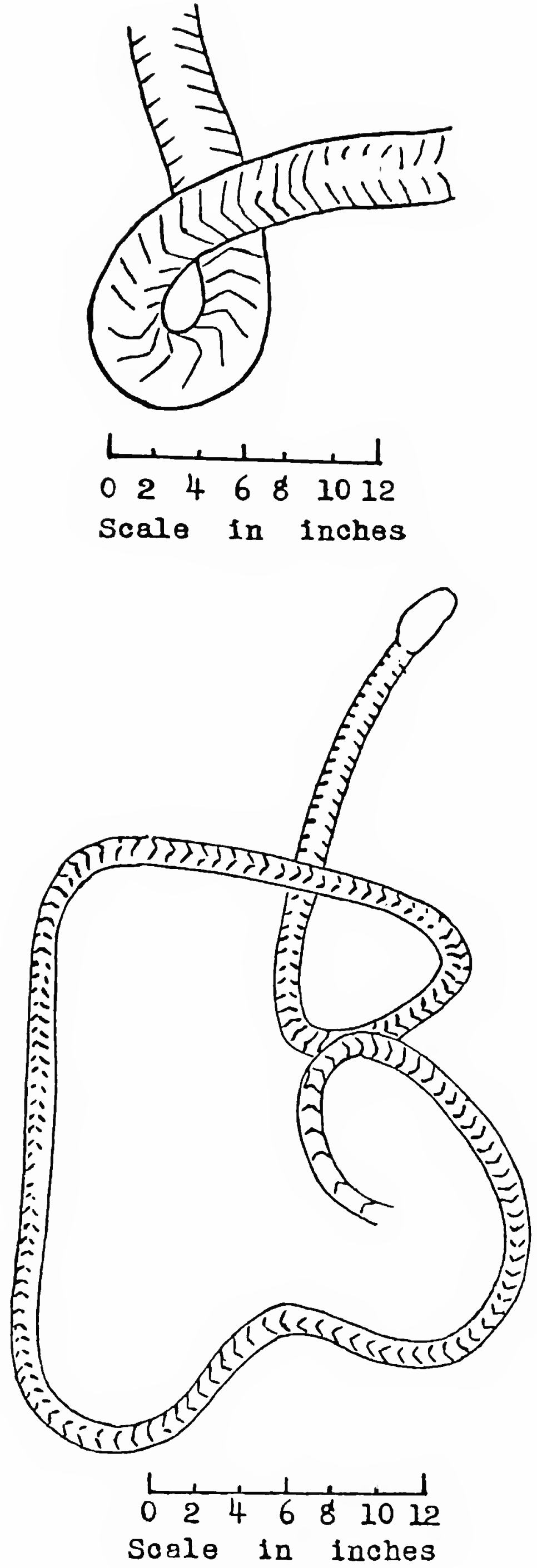
Climactichnites to an unknown animal. Malz reproduced the earlier illustrations of Clarke (1905) and Walcott (1912) and in the captions recognized two species of the genus.

In his revision of the "Treatise," Häntzschel (1975:W-52) added to his 1962 comment and considered this fossil to be the "crawling trail of unknown producer...." He then listed all the various possibilities for relationship which had been proposed in the literature. He reproduced Clarke's sketch and two of Walcott's figures from the summary by Malz, thereby once again recognizing more than one species within the genus.

The molluscan hypothesis has reappeared more recently. Runnegar et al. (1979:1382) ascribed the trail to an "aplacophoran sea slug or an animal resembling Matthevia." No data was given to support this statement.

Since the late 1950s, the study of trace fossils has advanced dramatically and paleoichnology is now a recognized specialty within paleontology. Many forms of ichnofossils have been used for paleoecological and stratigraphic interpretations. Some trace fossils have even gained the status of index fossils in correlation or as key indices for interpreting certain paleoenvironments. Notwithstanding all this activity, Climactichnites, the largest and most spectacular trace fossil in the Cambrian, has remained something of a myth, a name that many workers have heard of, but few have seen examples of, let alone studied.

\section{Comments on Earlier Hypotheses of Origin}

Most of the suggestions as to the nature of the animal capable of making a trail like that of Climactichnites may be characterized as grouping around arthropods, "worms," or mollusks. However, there were other ideas expressed in the



FIGURE 39.-A bedding plane in the Cairnside Formation at St. Hermas, Quebec (9), showing a trail of Climactichnites crossing over itself; the orientation is slightly different from Figure 13. Numerous desiccation cracks occur, best seen to the lower left of the scale. Scale is indicated by a $15 \mathrm{~cm}$ ruler. 

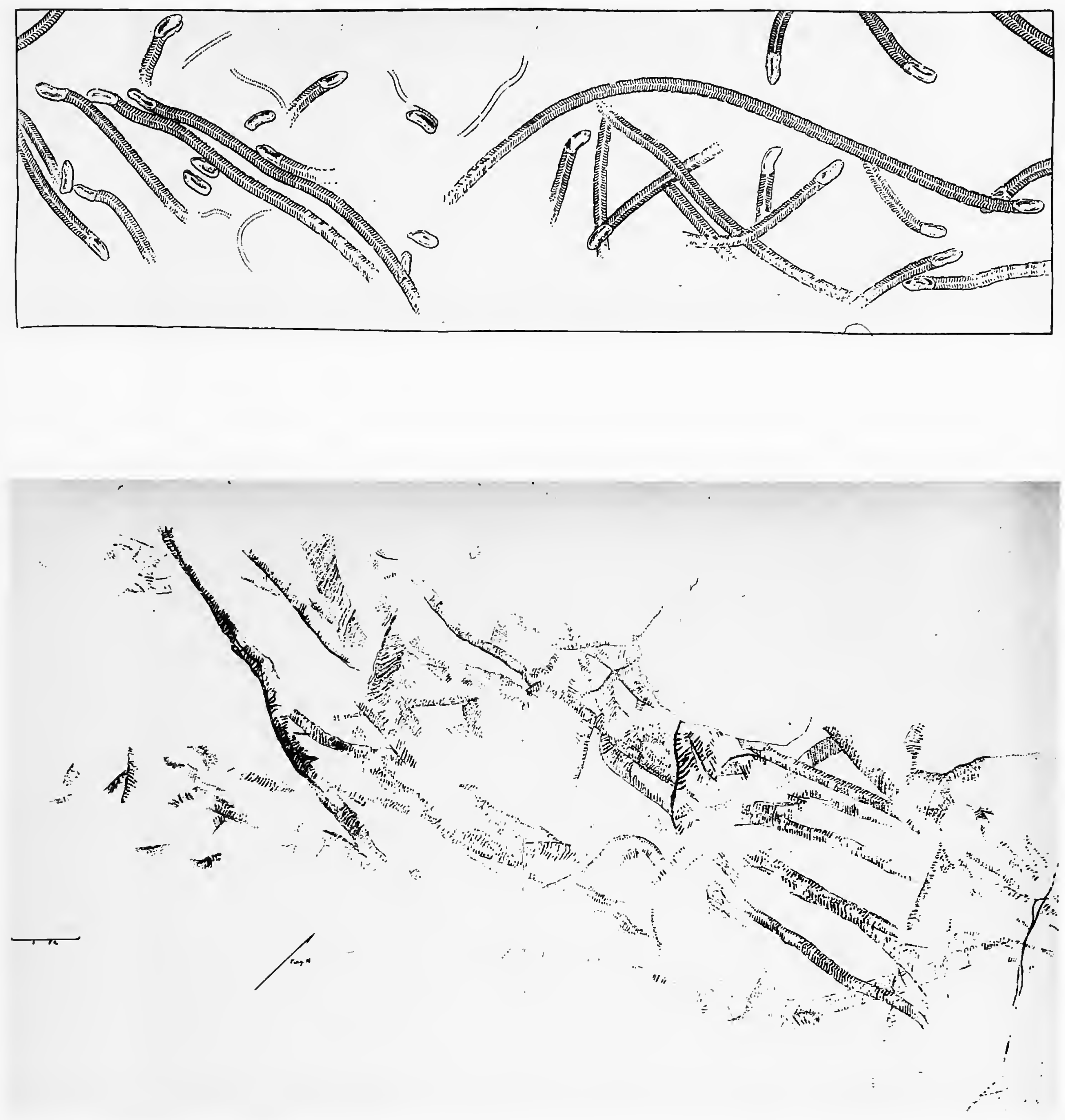

FIGURE 40.-Top: Sketch of the exposure at Mooers, New York (11), from Clarke (1905, pl. 3) "Trails on Potsdam sandstone, Bidwell's Crossing, Clinton co. Sketch made before removal." Clark reproduced the sketch at about $1 / 28$ th natural size; it is here reduced to about $1 / 45$ th natural size. The occurrence of two oval impressions side by side toward the left suggests that the left one-third of this area is that which is cast in plaster and on display in the New York State Museum. A similar plaster cast in the Brooklyn Museum was illustrated by Burling (1917) but is no longer extant. Bottom: Sketch of the exposure at Polly Falls, on the Black River, near Black River Falls, Wisconsin (3), prior to its removal, at about $1 / 35$ th natural size. Unpublished sketch courtesy of Dr. B.R. Erickson, Science Museum of Minnesota. 


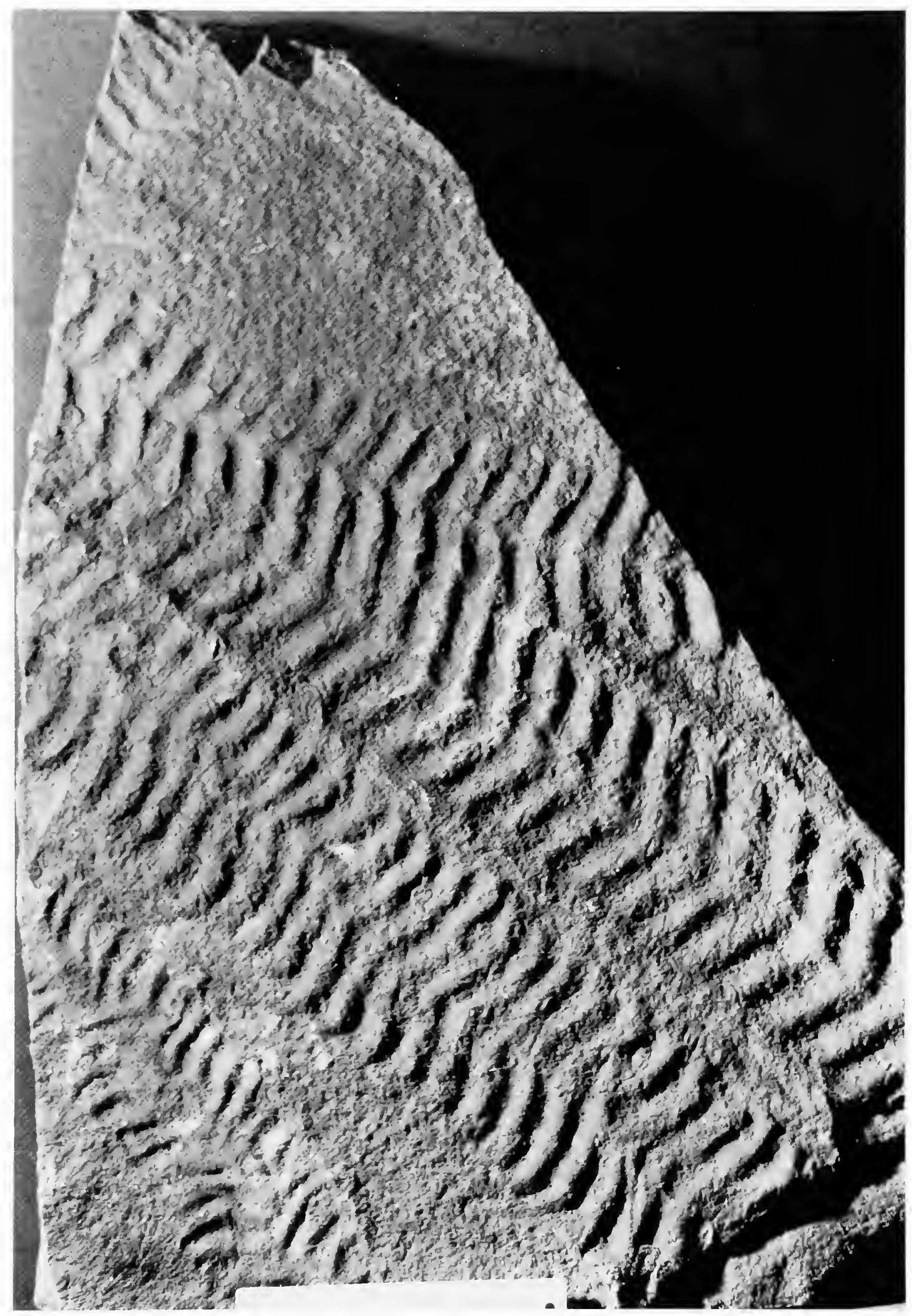

FIGURE 41.-Two large trails which moved in opposite directions on a small slab of Potsdam Sandstone from Port Henry, New York (14). The upper is intersected and partially obliterated by another trail made by an animal moving toward the right, the same direction as that which made the lower trail. The trail at the lower left lacks lateral ridges. Unlike other specimens from Port Henry, this is the bedding plane surface. Scale is indicated by a $15 \mathrm{~cm}$ ruler. MPM 27629a, on public display. 




FIGURE 42.-A topotype slab from Perth, Ontario (8), showing strong crenulations. This is a sole marking, so the surface relief is reversed, and the crenulations on the right side are obscured by matrix remaining in the depression. The bars are strikingly sinusoidal. Scale is indicated by a $15 \mathrm{~cm}$ ruler. ROM 22171. 


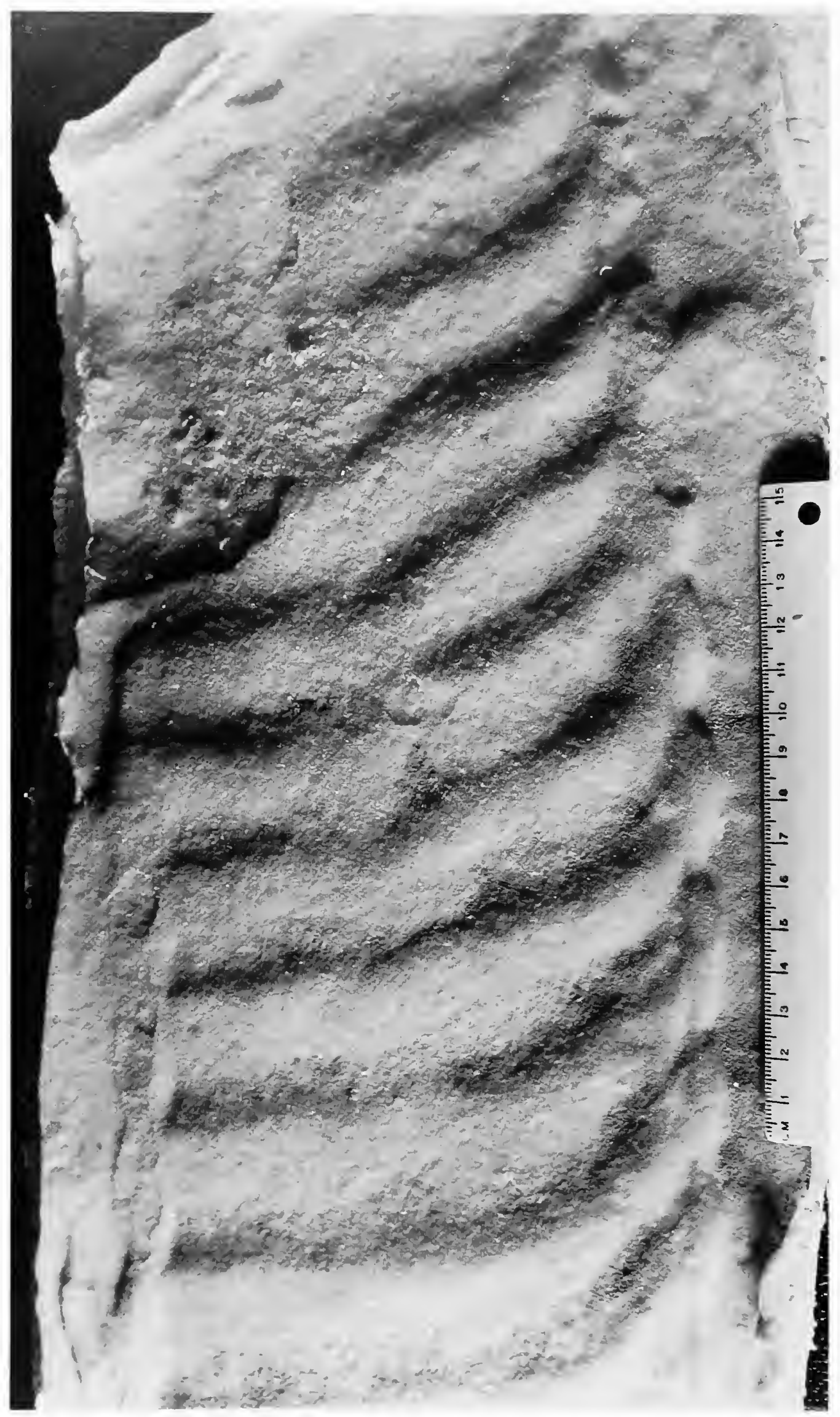

FIGURE 43.-Latex impression of part of the same specimen shown in Figure 42. Just to the left of the scale, the forward prong-like extensions of the bars adjacent to the lateral ridge are similar to those on the trail from New Lisbon, Wisconsin (4), shown in Figure 32, which lacks the lateral ridges. Scale is indicated by a $15 \mathrm{~cm}$ ruler. ROM 22171. 


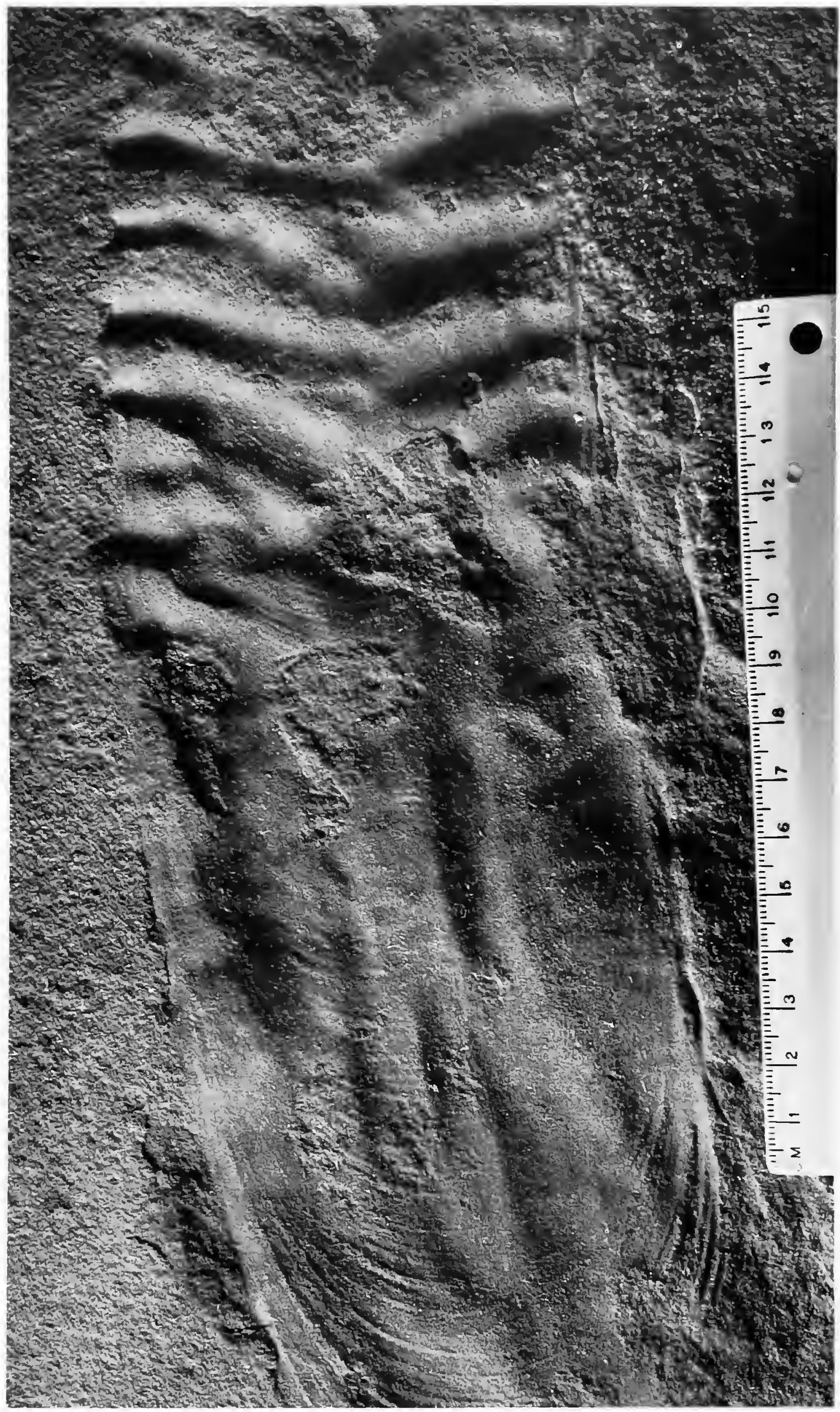

FIGURE 44.- Oval impression and part of a trail probably from the Galesville Sandstone at New Lisbon, Wisconsin (4), figured by Walcott (1912, pl. 38: fig. 1) as C. youngi; Figure 31 is the counterpart of the oval impression. The irregularities on the base of the impression are as clearly shown as on the counterpart. The trail seemingly begins on the left, the right side possibly being smooth under an anterior flap. Major irregularity in the depth of furrows at the start of the trail is evident. Arched lines are seen both on the oval impression and part way along the trail, especially on the left side. The lateral ridges are absent, except for the faint parallel lines on the right. The bars are missing and the bedding plane surface may be traced from one side to the other between the furrows; this is particularly evident near the top of the photograph. Also, a roughed central circular marking may be seen on one of the bars. Scale is indicated by a $15 \mathrm{~cm}$ ruler. USNM 58544 . 


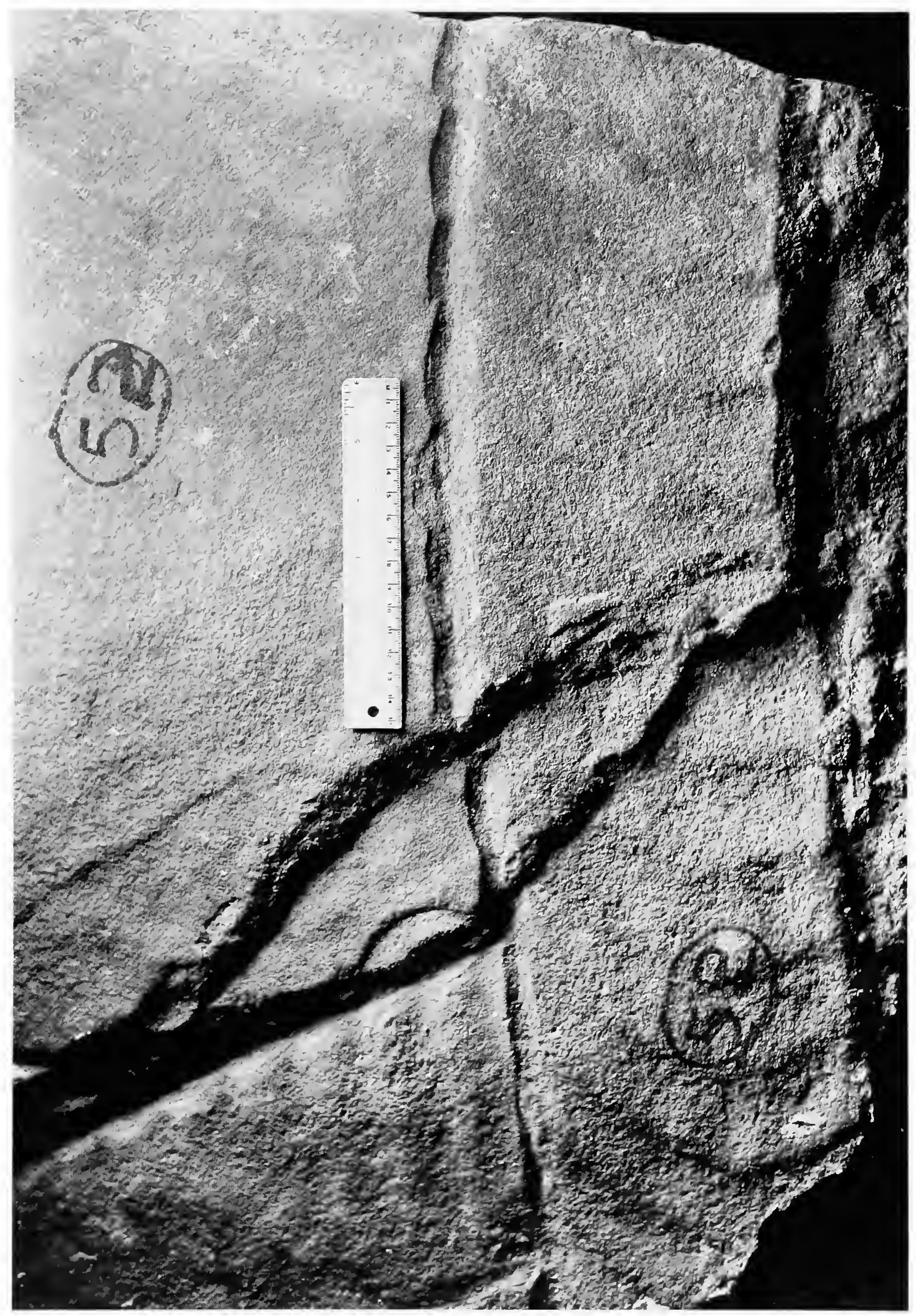

FIGURE 45.-A portion of the type slab of Climactichnites wilsoni Logan, broken at one comer; this is at the upper left of Figure 18. The number 52 at the lower right is several centimeters below the same number at the upper left. On the sole marking of the bedding plane, adjacent to the scale, on the small lower triangular piece, and on the numbered segment, the bars are evident, and these three separate layers thereby demonstrate a dune-like buildup to form the bars. Scale is indicated by a $15 \mathrm{~cm}$ ruler. GSC 6299 . 
literature. The easiest hypothesis to dismiss is that of Chapman (1877:488-489) who suggested that for Climactichnites

... an animal origin can scarcely be attributed on any rational grounds....If the impression be really a track, the animal must either have had, or been able to assume, the form of a complete sphere or cylinder with ribbed surface and it must have possessed sufficient internal force to roll itself over and over throughout a length of many feet; or otherwise the animal must have moved forward by a series of spasmodic jerks, or jumps....

His solution to the dilemma was to suggest that this fossil was not an animal, but an algal frond, a fucoid in the terminology of the day. Without commenting on the merits of this view, Chapman did not come to it abruptly, for years earlier (Chapman, 1862:189, fig. 157) he had mentioned Climactichnites and produced a small, inferior drawing of it. Today, Chapman's analogy of a rolling animal has been replaced by a rolling tire, but each assumes a regularity to the trail which does not exist.

Nathorst (1881:26, translated) was withering in his scom.

Even tracks as distinct as the Protichnites described by Owen, and Logan's Climactichnites, have not escaped attempts at being drawn into the vegetable kingdom. To Mr. E.J. Chapman belongs the honor, a doubtful one to say the least, of having made this attempt, and of course it was once more algae that had to figure as their nearest relatives.
Nathorst did not suggest any phylum assignment for Climactichnites.

The view of Jones $(1862 \mathrm{a}, \mathrm{b})$ that the trace of Climactichnites might be some sort of collapsed burrow was based on his examination of the gallery of crustaceans living at the sea shore. At the same time, his reference to trilobites leads one to think that he might also have had in mind the notion of "Bilobites"- a generic name now suppressed-, a name given to the structure formed by the excavating activity of trilobites. The shape of the trace of Climactichnites, with bars and furrows alternating though in an irregular manner but particularly the crenulations of the bounding lateral ridges, argues strongly against there being any infaunal activity associated with the animal, because it is not likely that such detail could be formed by excavation within the sediment. The faithful reproduction of fine detail on part of the structure but not on another (Figure 51) also argues against this view. The single most telling point opposed to an internal burrow interpretation is the presence of Protichnites cutting across some trails of Climactichnites (Figure 55).

Knowledge of the occurrence of Rusophycus, and other comparable structures which presumably were produced by

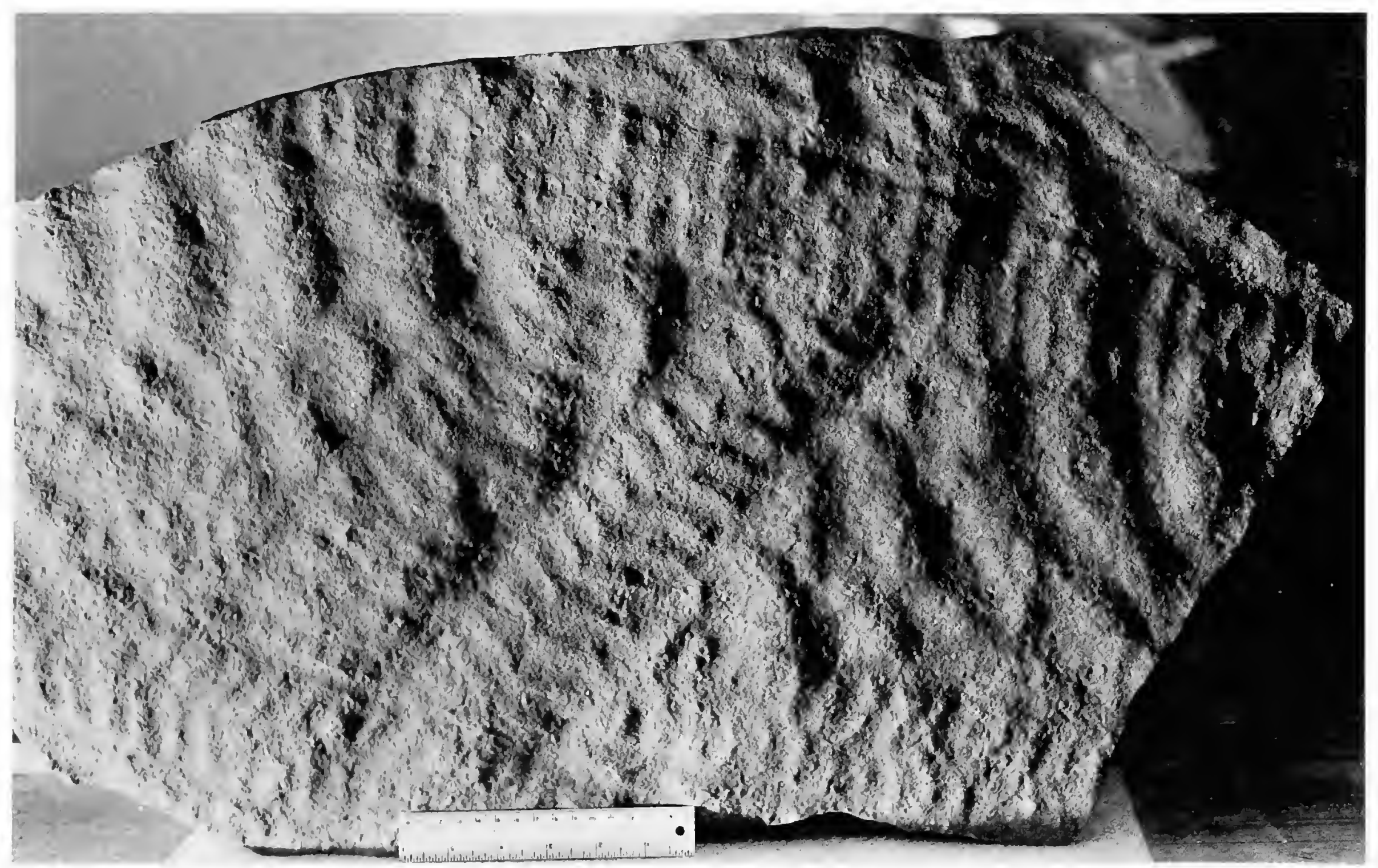

FIGURE 46.-A slab from the Northern Stone Company quarry (5), showing six trails crossing slightly asymmetric ripple marks. The diagonal trail and the one at the lower left are quite uniform. This is a sole marking so the surface relief is reversed. Scale is indicated by a $15 \mathrm{~cm}$ ruler. MPM 28388. 
trilobites, combined with the early observation made by Dawson (1862) of the movements of Limulus on the beach, formed at least part of the basis for suggesting arthropod affinities for Climactichnites. Most structures attributed to trilobite burrowing are exceedingly short compared to the length of this trail, but "Bilobites" (Cruziana of current usage) may be as long as a meter. Size also was a consideration in the various suggestions about arthropods. Most trilobites are small, but a few specimens do approach the width of a Climactichnites trail. Modern Limulus is of appropriate width and some of the eurypterids also would have qualified in this aspect.

The mutual occurrence of Climactichnites with the trail of Protichnites, which was clearly made by a limbed animal, further confused this issue and suggested arthropod affinities to some writers. However, there is no relationship between Protichnites and Climactichnites other than local cooccurrence. To go to an ancillary point, the telson of limulids forms a drag mark impressed in the sediment; a limuloid-like form might well have been responsible for the trail of some of the species assigned to Protichnites. In contrast, a median marking is not a consistent feature of Climactichnites, and where it is present, it forms a ridge, not a furrow.

Recently, a colleague observing our work in progress suggested that Anomalocaris from the Burgess Shale should be considered as the trail maker. This fossil, which may be an arthropod, has a relatively large size and paddle-like appendages, as well as a circular anterior mouth, all features which could aid in trail formation. On the other hand, it is currently interpreted as a predatory swimming form (Briggs, 1991:139). We do not consider the difference in time between Middle and Upper Cambrian as significant a bar to this interpretation as the difference between the deeper water muds and the exposed sands in which these two different fossils are preserved. We are unable to visualize how Anomalocaris might have produced a trail like that of Climactichnites, assuming that it crawled, for no part of its morphology seems to be capable of producing crenulated lateral ridges. The morphology of Anomalocaris has been dramatically reinterpreted several times during the years

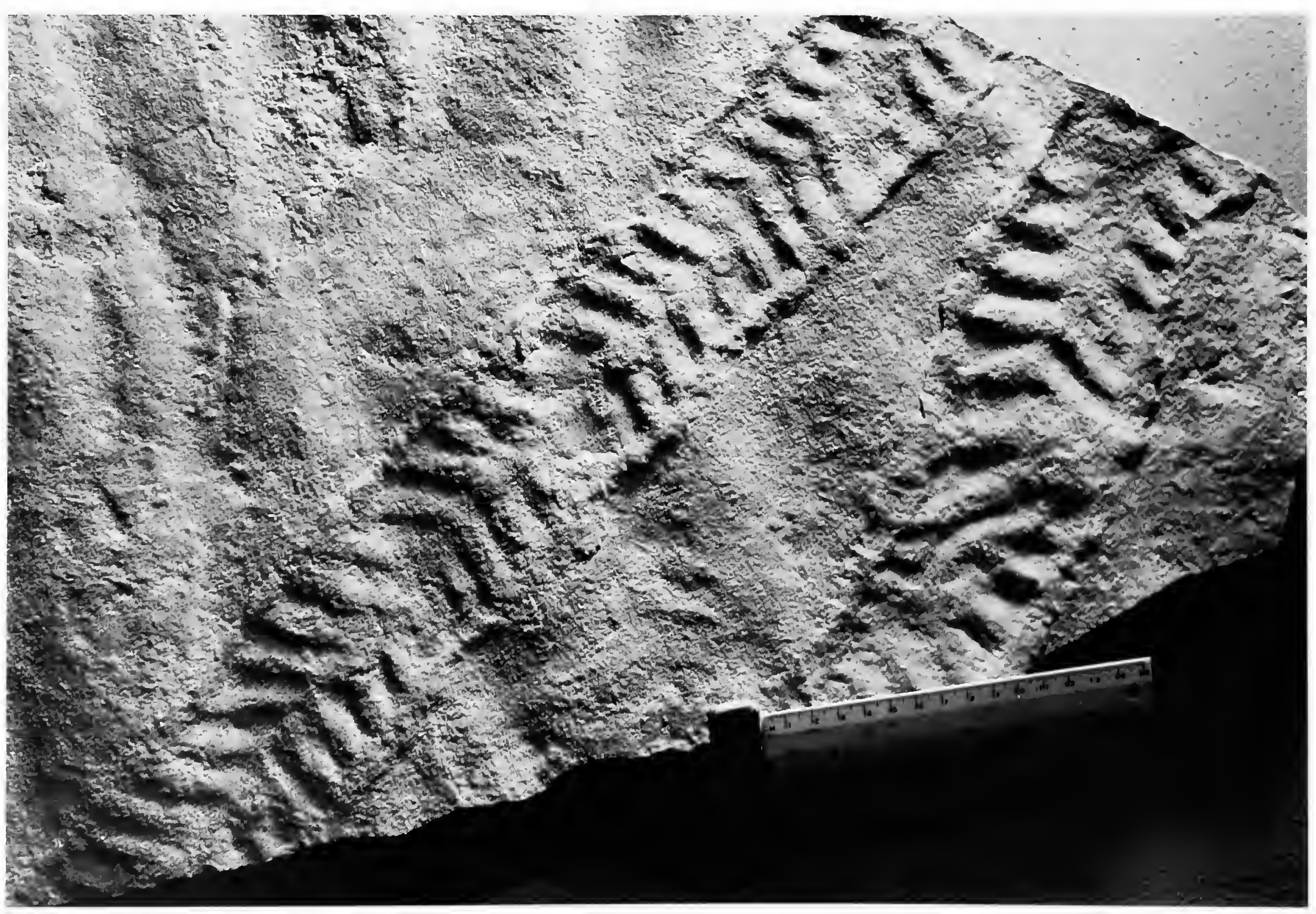

FIGURE 47.-Part of a ripple-marked slab, provenance unknown, but possibly from New Lisbon, Wisconsin (4) (compare with Figure 17). At the lower left, an offset of $V_{s}$ and an intercalated extra half bar are shown. At the right, above the scale, the trail is quite irregular. Scale is indicated by a $15 \mathrm{~cm}$ ruler. Public display at Geology Museum, Department of Geology and Geophysics, University of Wisconsin, Madison, Wisconsin. 


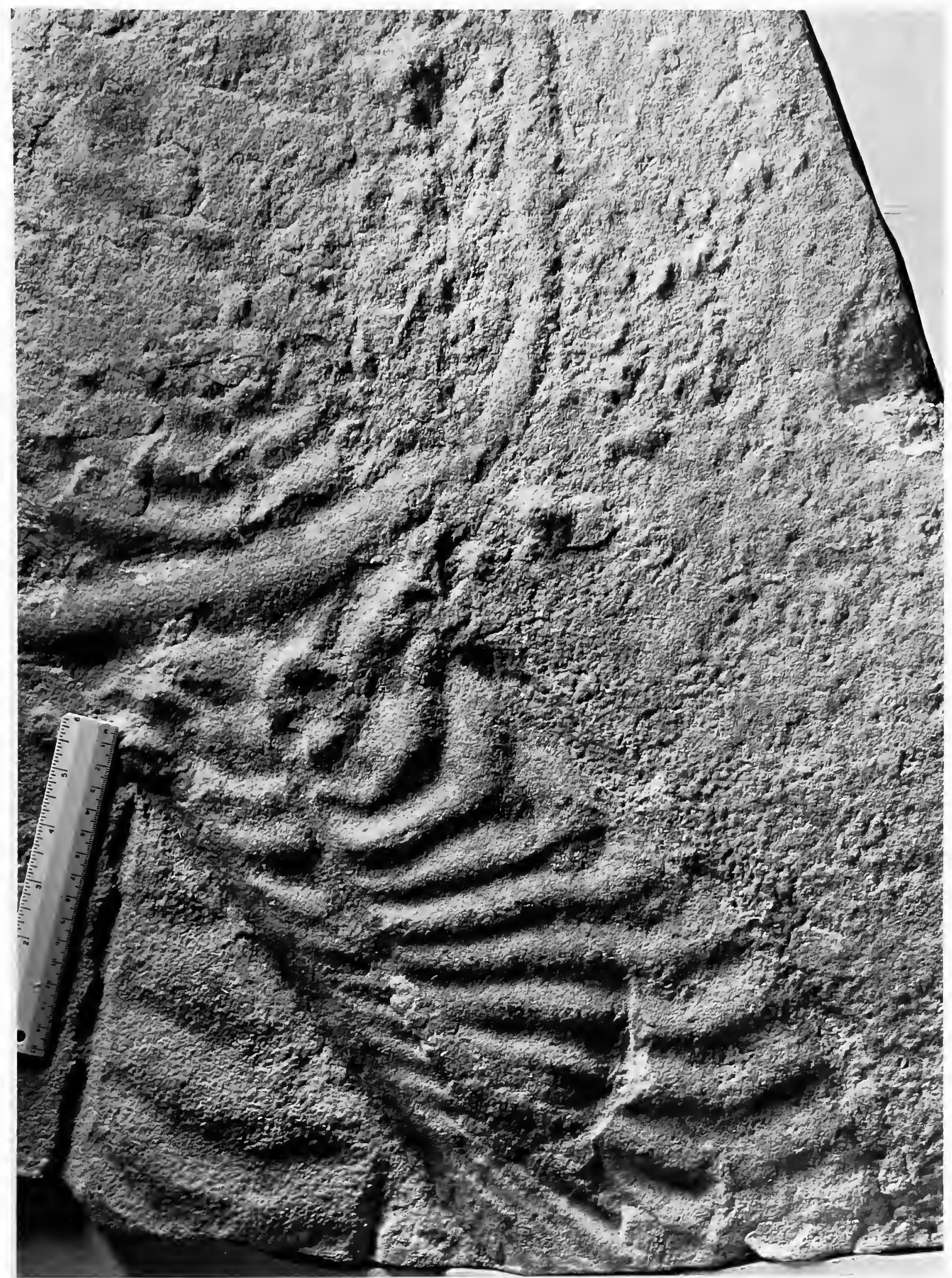

FIGURE 48.-Lower left portion of a topotype slab from Perth, Ontario (8), shown in full in Figure 55. The Climactichnites trail to the right of the scale is highly irregular. The markings above and to the right are Protichnites. This is a sole marking with the surface relief reversed. Scale is indicated by a $15 \mathrm{~cm}$ ruler. RM public display. 


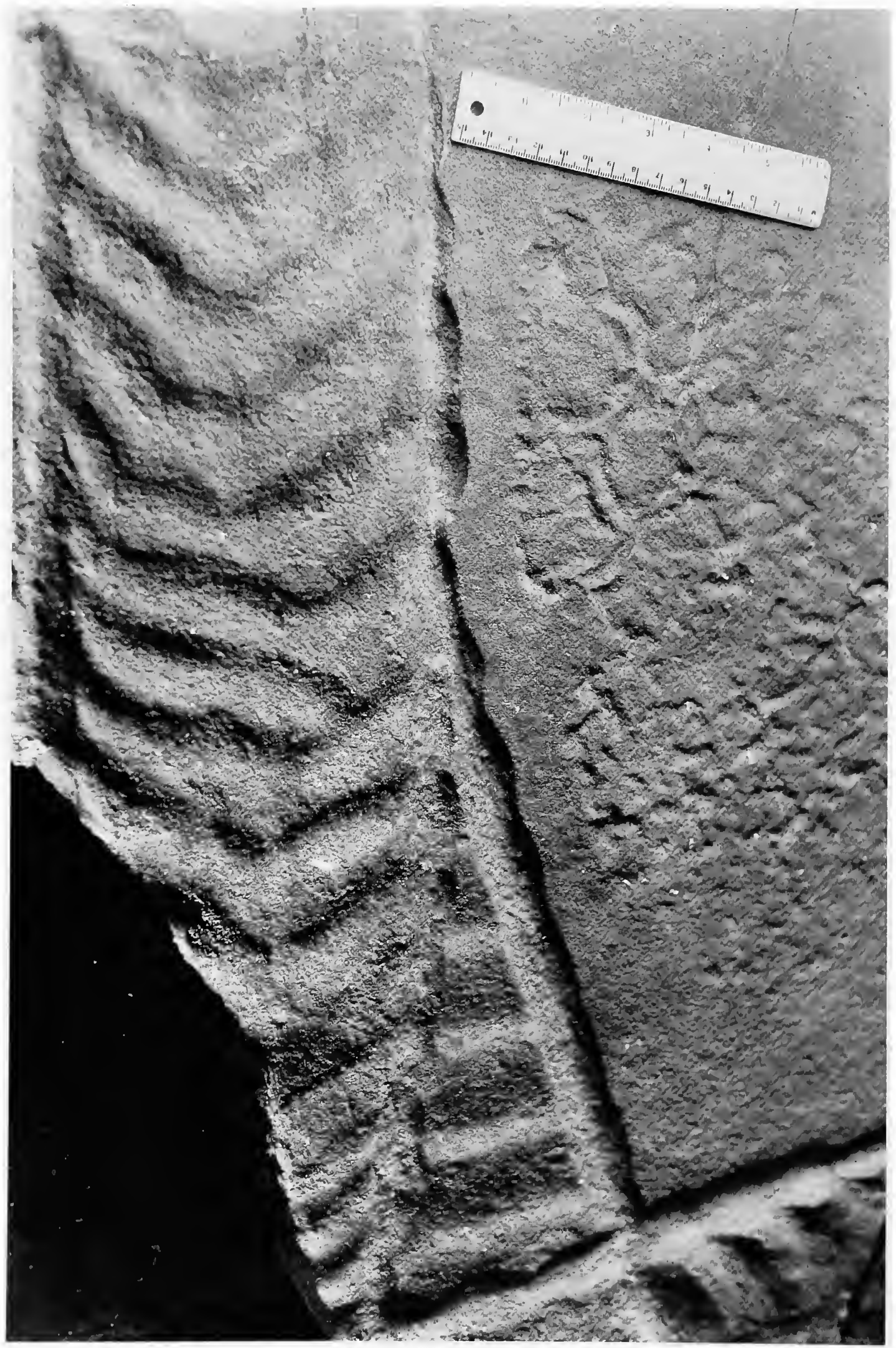

FIGURE 49.--Part of the type slab from Perth, Ontario (8), showing some variation from a wide $V$ at the top to more arcuate and irregular bars below. Although the Protopaleodictyon at the right appears in normal negative relief on this sole marking, a trick of the lighting causes the trail to simulate a positive appearance. This is part of the lectotype and is shown in the lower center of Figure 18 . Scale is indicated by a $15 \mathrm{~cm}$ ruler. GSC 6299. 


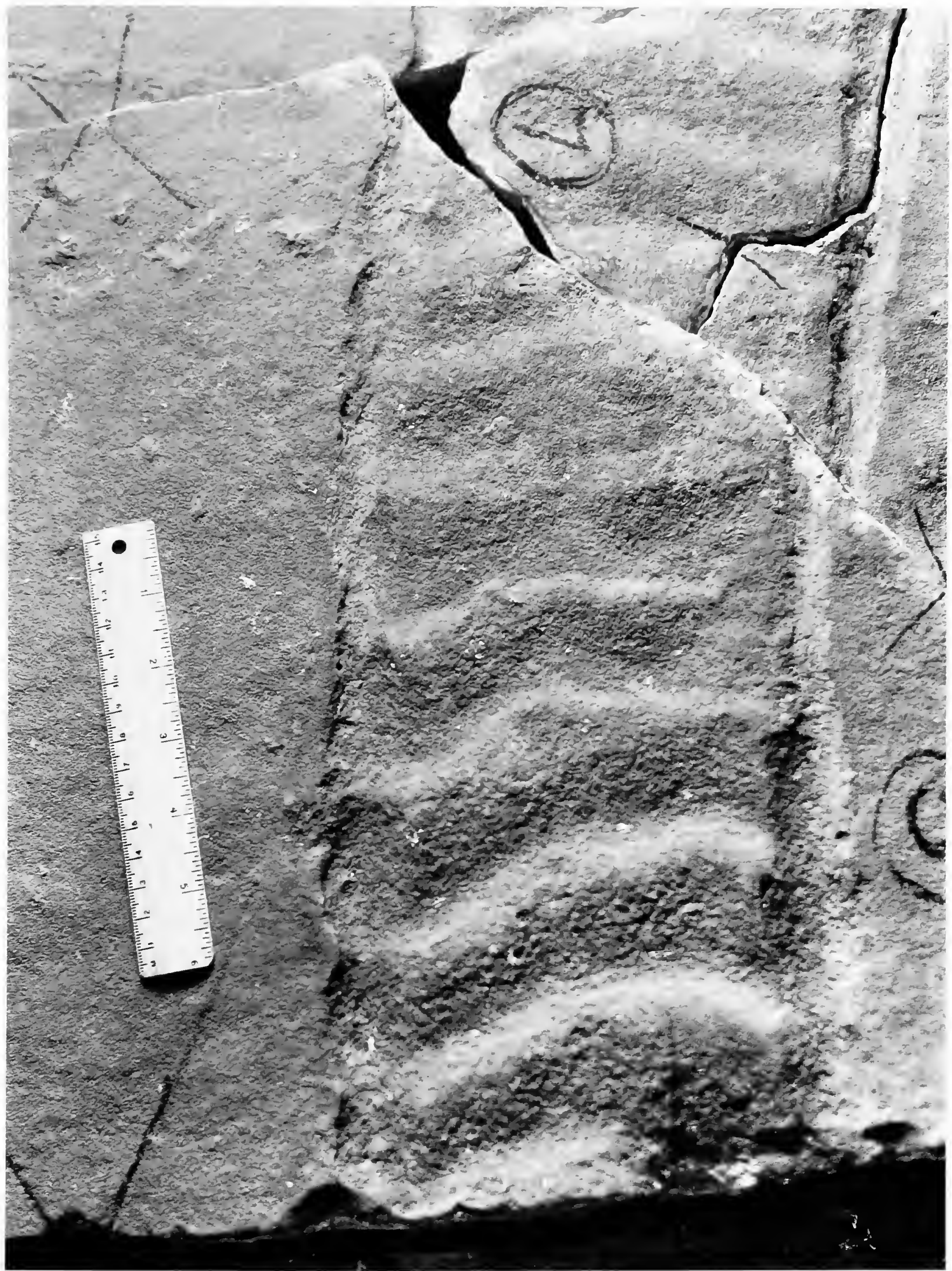

FIGURE 50.-Another part of the type slab showing uniform, irregular, and sigmoidal bars; this is a sole marking, so surface relief is reversed. At the upper left are a few tracks of Protichnites. The precise location of this slab on Figure 18 is not certain, but it may be part of the trail at the left in that view. Scale is indicated by a $15 \mathrm{~cm}$ ruler. GSC 6299. 




FIGURE 51.-A portion of a uniform Climactichnites trail probably from the Galesville Sandstone at New Lisbon, Wisconsin (4). Part of this specimen was illustrated by Walcott (1912, pl. 39: fig. 2) as C. youngi and reillustrated by Burling (1917). An enlargement of a part of this specimen is shown in Figure 32. To the left, the arch-like markings are reproduced on the gentle side of the bars, but not the steep slope. This differential occurrence would seem most unlikely if these were markings inside a collapsed burrow. The lateral ridges are not present, though parallel lines appear in approximately the position of the ridge. Scale is indicated by a $15 \mathrm{~cm}$ ruler. USNM 58545.

as various isolated parts have been linked together, but we think it unlikely that another reinterpretation will produce a Climactichnites-like form.

Even though more authors suggested arthropods of one kind or another as responsible for Climactichnites, Walcott, who probably was more familiar with the limbs of fossil arthropods and their various modifications than any other paleontologist of his day, chose to ignore this hypothesis entirely and developed a second. After questioning any molluscan attribution for the trail, he (Walcott, 1912:201) suggested that Climactichnites might have been formed by a large worm. Walcott's comments coming only three years after his discovery of the dramatic Middle Cambrian Burgess Shale fauna were necessarily colored by this incredible increase in knowledge of ancient soft-bodied fossils. Although the specimens collected from that unit are too small to match the width of larger Climactichnites, he covered this concern by mentioning that larger forms might occur in younger deposits. By noting modern shallow-water forms, he also resolved the problem of fundamentally different facies of the dark shales and the sand flat.

However, as Walcott (1912:261) wrote: "I have not seen any trace of bristles or stiff setae that occur on the parapodia of most of the Aphroditidae, but this is not unexpected in a sandstone formation." Considering the delicate features he described and illustrated on the material from New Lisbon, Wisconsin (4) (Figures 44,51), it seems difficult to reconcile the two thoughts in this sentence. Although a large, flattened, worm-like creature might have been able to make surface bars and furrows by vertical undulations of its body on damp sand, the internal dune-like structure of the bars could not be formed by simple compaction. An even greater difficulty exists in visualizing how any worm-like creature could form the crenulated lateral ridges.

The concept of "worms" certainly involves several different phyla and their collective history is surely one of the least known aspects of paleontology. Notwithstanding that, there 


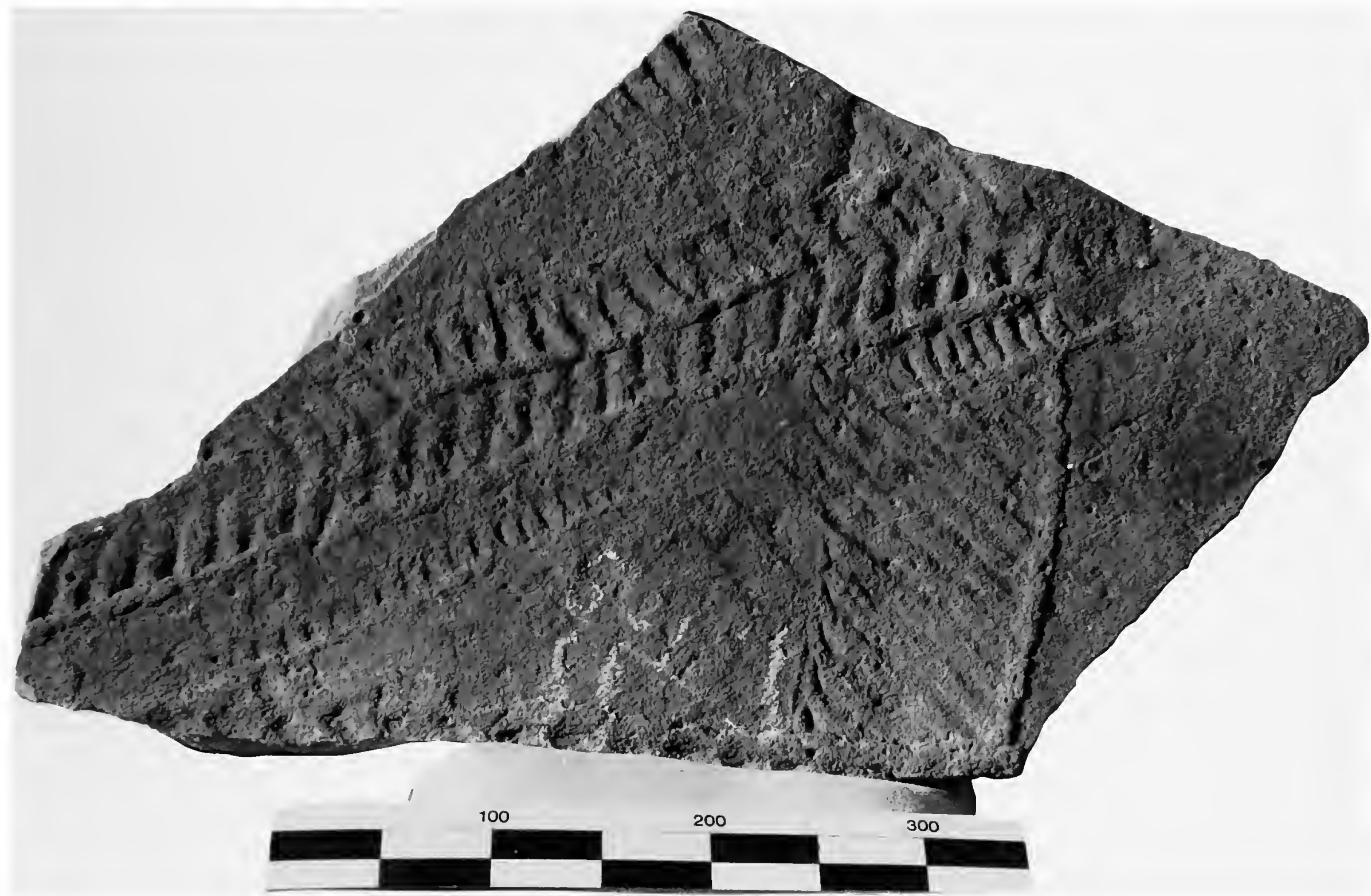

FIGURE 52.-A slab of Mount Simon Sandstone from Polly Falls on the Black River (5). Several trails show disruption near the center of the slab as though this was an area with different characteristics. The Climactichnites trail at the right is exceptionally wide. To the far right of the large trail and at the upper left some dewatering structures are present. Photograph courtesy of Dr. B.R. Erickson, Science Museum of Minnesota. Scale is in centimeters. SMM-P unnumbered.

seems to be no worm-like creature in the Burgess Shale fauna or any other comparable fauna capable of making such a trail. Without being aware of Walcott's remarks, another colleague suggested that priapulid worms should be considered as the putative trail former. Priapulid worms do occur in the Burgess Shale fauna (Conway Morris, 1977), but they are relatively small specimens. Living Echiurus burrows into sand, but does not crawl on the surface (Gislen, 1940).

Gratacap's hypothetical ringed worm likewise could not have formed the lateral crenulations, even if it had been discovered in the fossil record. The "worm" approach of Walcott has received no further support and a worm-like creature has simply been carried as one of a series of possibilities by later writers. Three-quarters of a century of investigation since the discovery of the Burgess Shale fauna has not resulted in the finding of younger soft-bodied faunas containing significantly larger worm-like animals, approaching the width of even the smallest trails of Climactichnites.

Walcott (1912:201) dismissed part of the molluscan argu- ment (the third prime historical suggestion for the placement of Climactichnites): "So far as is known to me, there is no recognized mollusk that would make such forward curving lines, and we do not know of any chiton or mollusk capable of making such an impression." Even though the lines mentioned are now known to be the result of travel in the opposite direction, the argument is still valid. Raymond (1922) reported that trails of Littorina occasionally showed an arcuate impression curved in the direction of movement; such a feature is quite rare in gastropod trails and only was seen in a few of the Littorina trails he studied.

So far as we know, Woodworth (1903) was the only author to mention polyplacophorans, or chitons, as putative trail makers. It is granted that a very large modern polyplacophoran would approximate the width of an oval impression. However, although the posterior of such an impression might simulate the outline of the foot, the anterior of a polyplacophoran foot would also be arcuate and unlike the forward projecting lateral flap occasionally impressed in the Cambrian sandstones. Further, it 


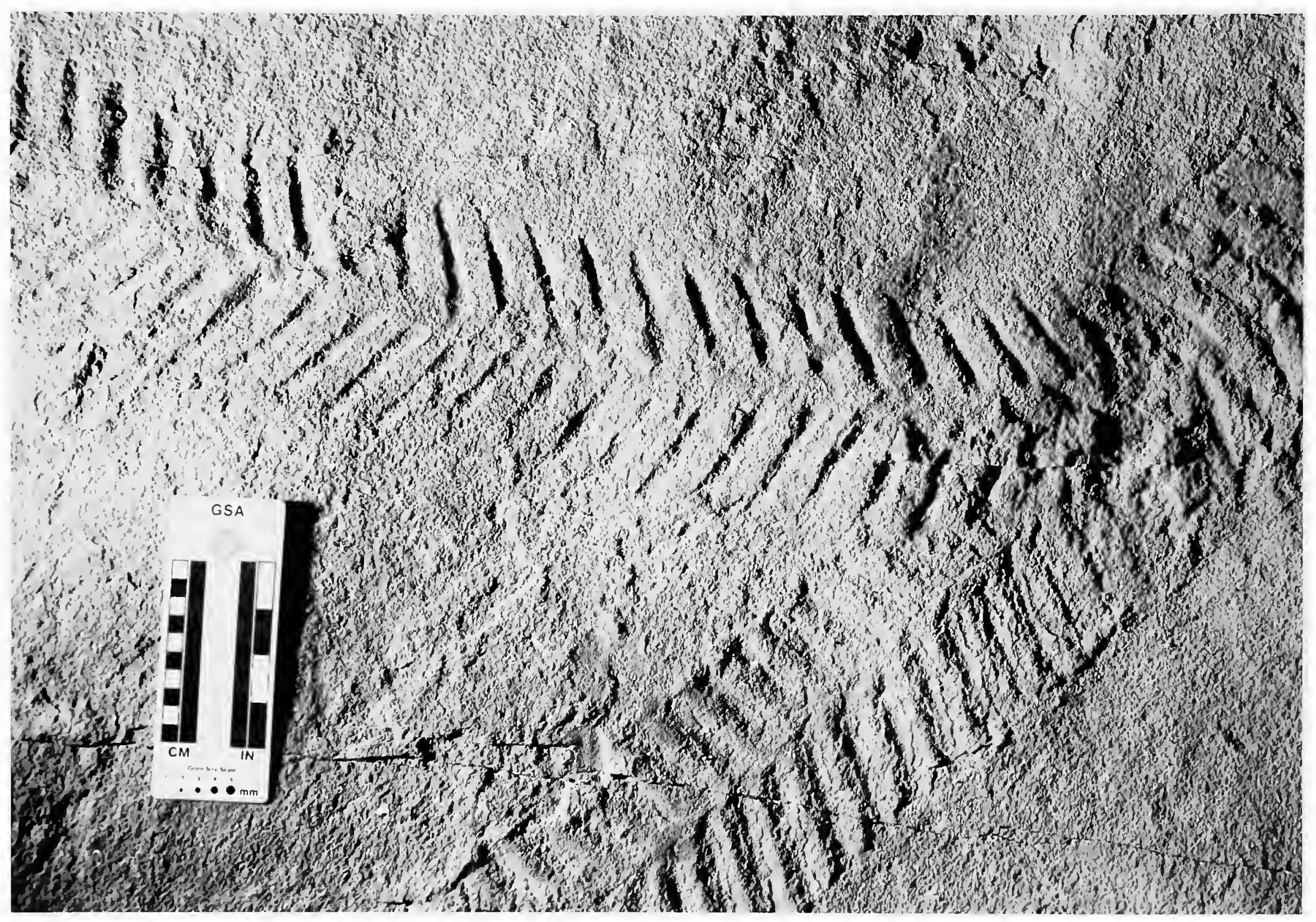

FIGURE 53.-Part of a slab of Potsdam Sandstone, possibly from Mooers, New York (12); this is in the left center of Figure 28. The trail from upper right to near lower center shows bars, furrows, and lateral ridges. The trail from right to left is composed only of furrows, the bedding plane surface extending between them. Scale is indicated by a $10 \mathrm{~cm}$ ruler. PNH 98/1.

is most unlikely that contraction of a polyplacophoran foot would produce the kind of ridges and furrows seen in the New Lisbon, Wisconsin (4) and Mooers, New York (12), impressions (Figures 28, 31). Still further, large extant polyplacophorans are sedentary and when they do move, this is primarily to graze on algae growing on adjacent rock surfaces; it is difficult to conjure up an abundant food source for a grazing herbivore on a sand flat. After foraging, typically chitons return to the place where they were clinging and never wander far from their homing spot. As an ancillary point, the largest modern specimens are most common in colder waters, at variance with the presumed ecological conditions for Climactichnites.

Although the record of body fossils is not directly germane to this argument, the earliest authentic polyplacophoran parts are in the latest Trempealeauan, uppermost Cambrian. Matthevia has been considered by several authors to be a polyplacophoran, but in the unlikely event that interpretation is correct, this form is still in the Trempealeauan and only slightly older.
Accounts of polyplacophoran plates from the Early Cambrian of China seem to be based on misassignment, and belong to a fundamentally different type of multipartite animal (Qian and Bengtson, 1989). Regardless of where any of these other, older fossils are placed, all known plates are significantly smaller than the smallest Climactichnites. Indeed, the largest Paleozoic polyplacophoran plate is about one-third the width of the narrowest of the trails that we have observed.

It may seem strange that mollusks require more in the way of discussion than arthropods, but mollusks do have a foot and arthropods do not. It is because the oval impression in Climactichnites mimics in part the shape of a molluscan foot that the mollusk hypothesis for Climactichnites is more difficult to dismiss. However, just as a considerable body of knowledge has accumulated concerning arthropod locomotion during the last century, information on the movement of mollusks has also advanced since Logan's day. In particular, the crawling of gastropods has been found to be more complex 


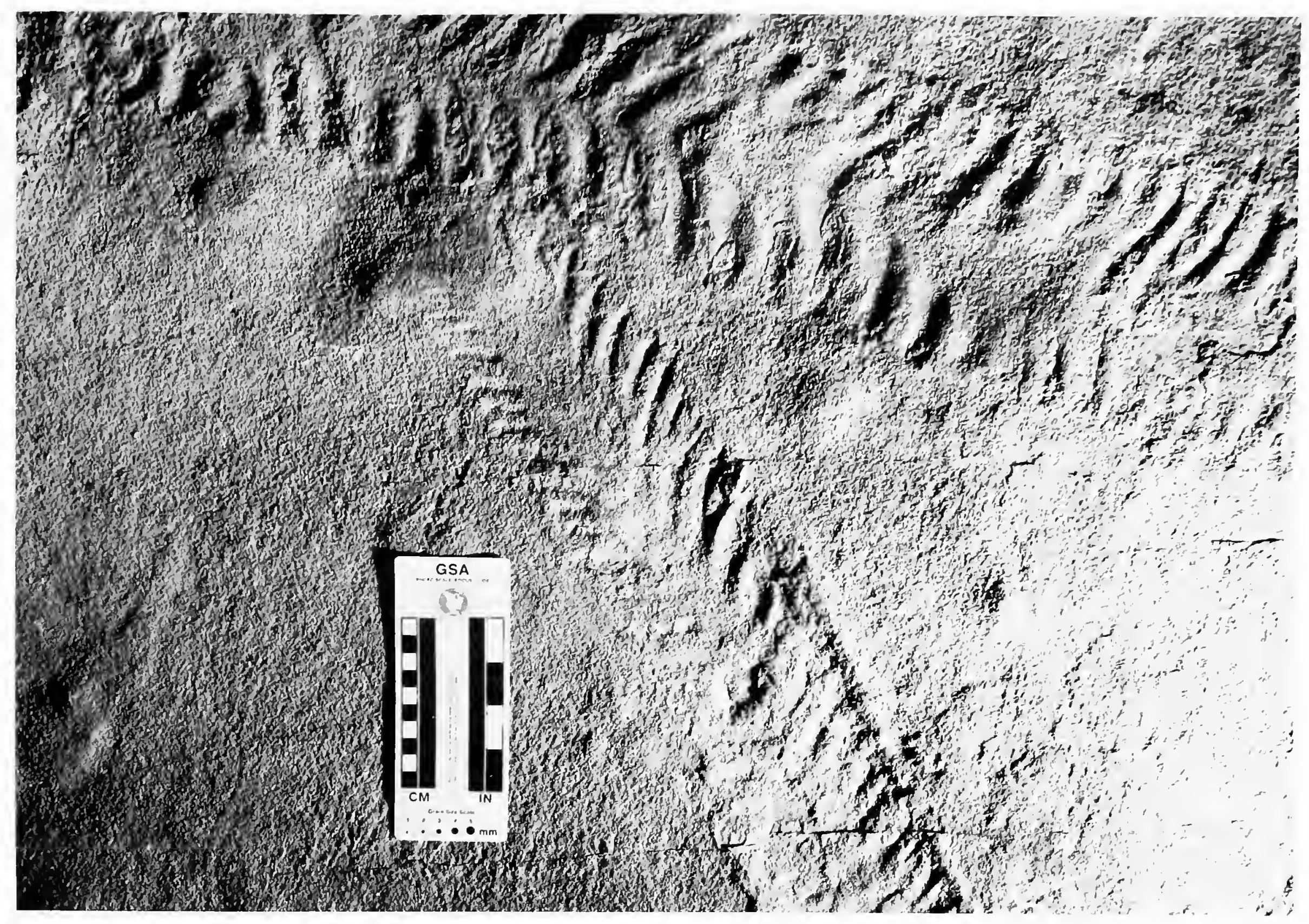

FIGURE 54.-Another portion of the same slab shown in Figure 28. The trail from upper left to upper right shows bars and furrows but lacks the lateral ridges. The trail from lower center has lateral ridges and bars for part of the distance, but then only furrows; it ends abruptly. Scale is indicated by a $15 \mathrm{~cm}$ ruler. PNH $98 /$.

than assumed by earlier investigators. Walcott's comment on the presence of features resembling growth lines atop the pattern of bars and furrows is still the single most powerful argument against a gastropod origin for the trail of Climactichnites, but there are other features that also argue against such an interpretation.

Living gastropods show both monotaxic movement, involving the entire width of the foot, and ditaxic movement involving first one side, and then the other. Muscular pedal waves may be direct, a wave of compression from the back of the foot forward, or, less commonly, retrograde, by waves of elongation from the front traveling backward (Miller, 1974:234-238). The bars and furrows of the Climactichnites trail may vary at all angles from right angles to the lateral ridge to oblique in a $V$ or alteration of oblique bars more or less around an ill-defined mid-line. Emphasis on the $V$ pattern by earlier workers has obscured the remarkably large amount of individual variation in trails. One point particularly germane here is the occasional insertion of a bar and furrow which are neither paired nor alternating. A gastropod moving along by regular alternation of one side of the foot or the other could not produce such a feature. Another point of interest is that many of the trails lack bilateral symmetry, for the bars and furrows may be longer on one side than the other, gastropod trails on the other hand are bilaterally symmetrical. In some large Climactichnites trails, the bars and furrows are complete, but are strongly oblique from one lateral ridge to the other (Figure 52); seemingly no known gastropod foot could produce this pattern.

Although the musculature of the gastropod foot might provide sufficient flexibility to sculpt one or two forms of the trail, even the most complex musculature of Cypraea, one of the few modern gastropods which can move backwards, could not possibly produce the high degree of individual variation seen among trails or even along a single trail. Even more compelling, what is missing from gastropod locomotion is significant movement in the third dimension. In effect, the foot of a non-burnowing gastropod glides over the surface, be it smooth or corrugated, and there is virtually no movement of the 


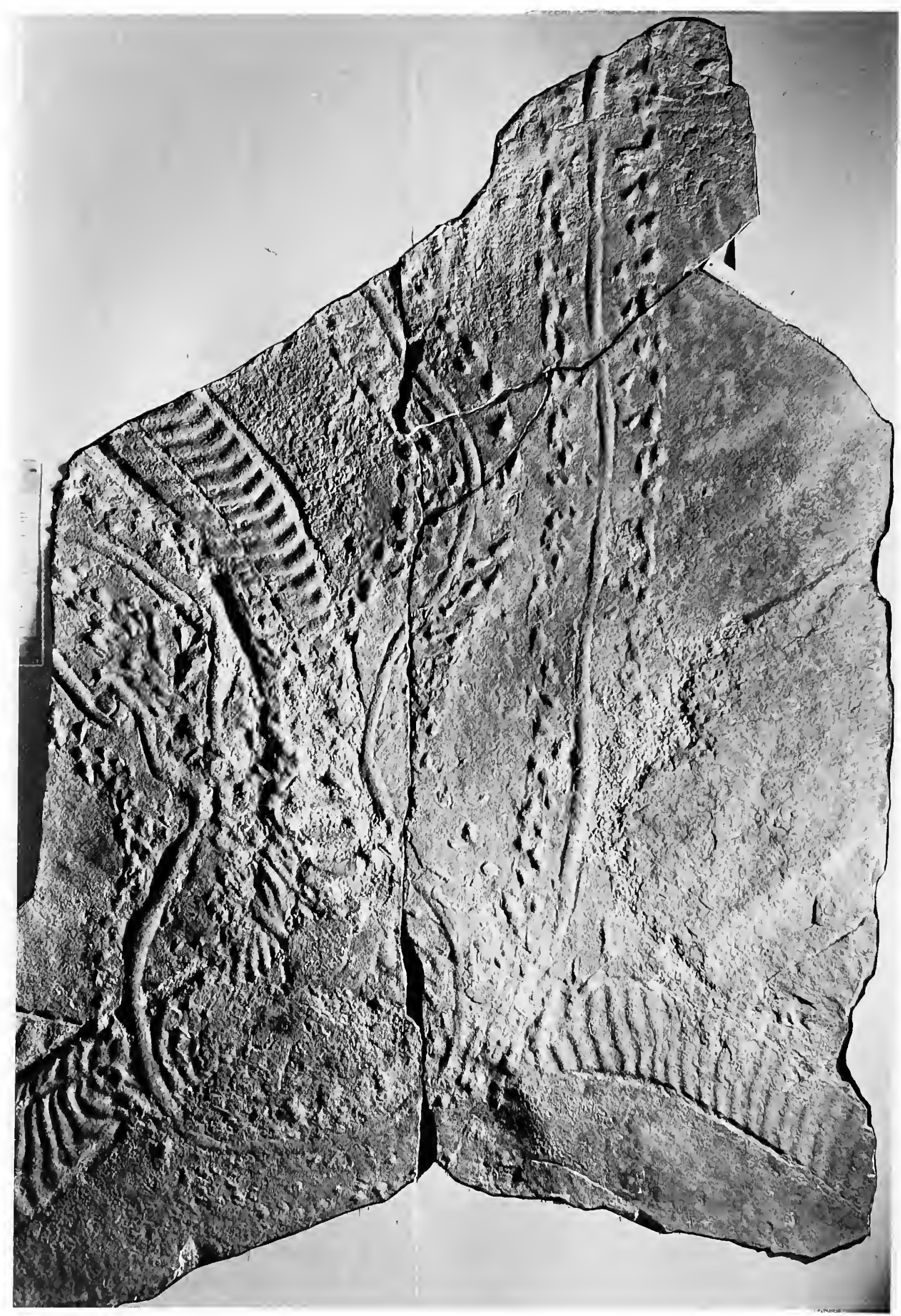

FIGURE 55.-A topotype from Perth, Ontario (8), illustrated by Dawson (1890). Like the type slab, surface relief is reversed. One Climactichnites trail is at the lower right and another is from lower left to upper left. At least two trails of Protichnites are present, one at the right moving in a straight line and one at the left looping around. Scale is indicated by a $15 \mathrm{~cm}$ ruler. RM public display. 


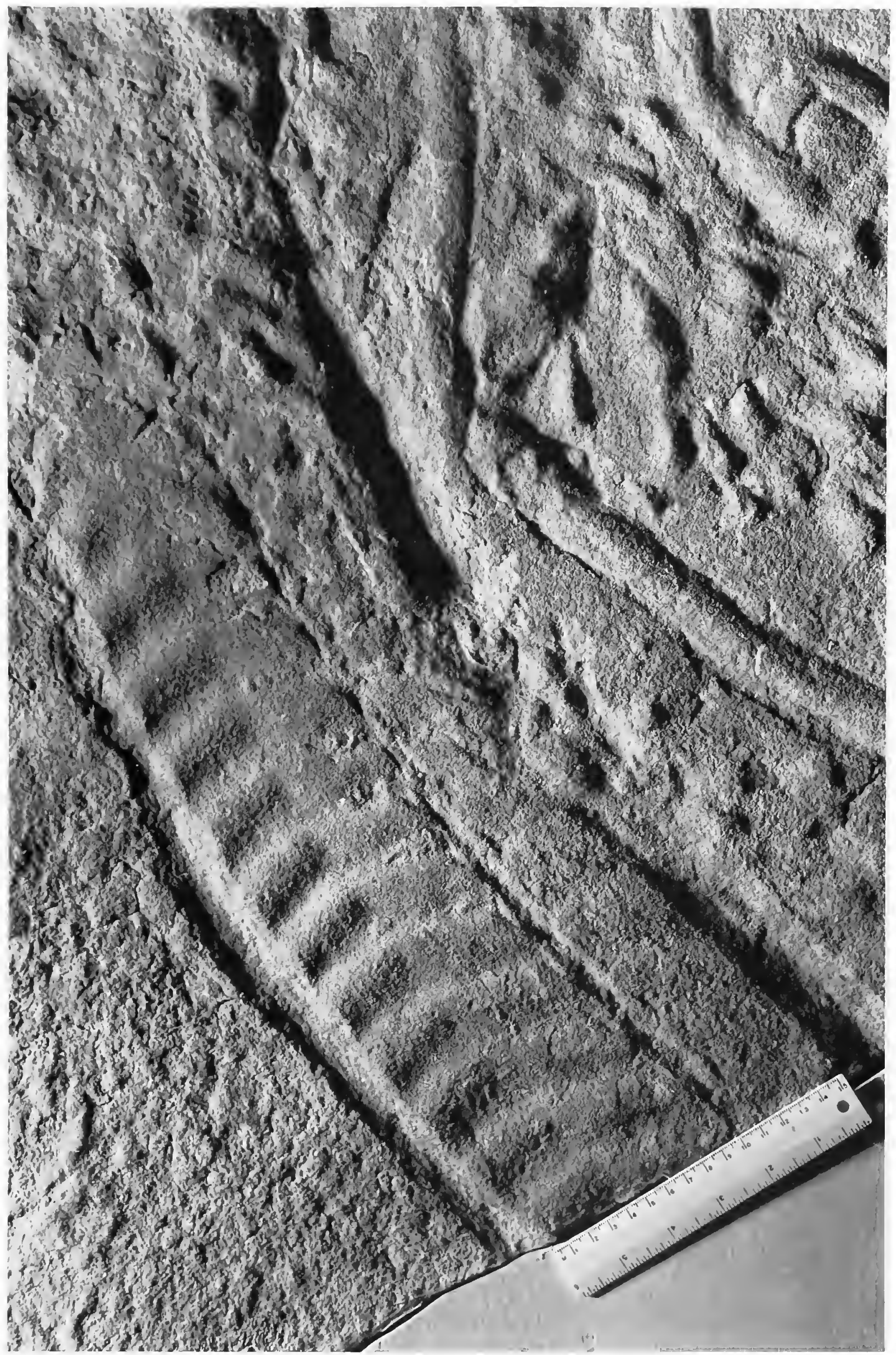

FIGURE 56.-A detail of the upper left of the slab illustrated in Figure 55. The medial ridge, here shown as a furrow, is irregular in position, and in width. Markings of Protichnites are at the upper right. Scale is indicated by a $15 \mathrm{~cm}$ ruler. $\mathrm{RM}$ public display. 
foot upward as a pedal wave moves either forward or backward. In effect, the distance between base of furrow and crest of bar in even the smallest of Climactichnites trails is far in excess of any vertical movement within the gastropod foot of even the largest of modern snails. All these peculiarities show that Climactichnites had a muscular system different from that of the gastropods.

It is also helpful to note that movement by pedal waves of the gastropod foot seems to be related to dorsoventral muscular contraction and relaxation, implying that attachment to a shell is needed for such waves to develop (Kier, 1988:239). Many gastropods also move by ciliary action on the sole of the foot and such gliding motion is best suited to movement over a loose sand substrate (Miller, 1974:254). This form of motion is far less likely to cause any compression of the substrate than are muscular pedal waves.

Abel (1935:247-248) emphasized Bulla-like gastropods forming a ridge on either side of the shell as they crawl forward. Some snails, such as Polinices do plow through the sand as essentially infaunal animals, with the shell below the surface or protruding just above the sediment-water interface; the large foot moves particles to either side as the animal in effect glides forward. This disturbs the sediment but it is unlike surface plowing which produces lateral ridges on either side of a central smooth depressed zone. Those ridges are in effect tossed up in a manner that is quite unlike the piling up of sediment to form a lateral ridge without disturbing the substrate.

Other gastropods, like Littorina, which Abel figured, do move effectively on the surface by retrograde waves. "The foot progresses somewhat in the manner of a person slowly shuffling forward in a potato sack" (Abbott, 1954:453). Neither Abbott nor Abel reported any faint transverse ridges oriented convex forward, as Raymond (1922) noted occurred rarely. This surface movement of Littorina also forms lateral ridges because the lower part of the foot is within the substrate. However, in neither the case of the animal virtually covered by sediment or the foot just within the substrate do the lateral ridges, which are produced, exhibit crenulations that are characteristic of many specimens of Climactichnites. More importantly, the area between lateral ridges is smooth, not undulatory.

On a more theoretical level, pedal wave movement, which is best adapted to a hard substrate, is considered the earliest form of locomotion in gastropods, ciliary movement being a later development (Miller, 1974:234). It is difficult to reconcile advanced forms of gastropod locomotion with early gastropods, though admittedly excessive concern with theory is not always helpful. From the practical standpoint, trails of some gastropods are common on mud flats where an abundant food supply is present, but they are rare on sand flats. In the fossil record almost none of the markings which past generations of paleontologists attributed to gastropod trails occur in environmental settings where gastropods might have lived.

Another major problem with a gastropod hypothesis for
Climactichnites is the width of the fossil trail. Modern large marine gastropod shells have an apertural opening which approaches the width of a small Climactichnites trail, and very large gastropods could occupy the width of a moderate-sized track. However, no known gastropods, either living or fossil, would have a foot as wide as the width of the widest trails (Figures 3, 7).

As with the other hypotheses, the absence of body fossils may not be germane, for it has been repeatedly argued in the past that no shells have been found with the trails because they were either destroyed by sediment motion or moved away by tidal activity. Negative evidence such as this is impossible to refute, but it is difficult to imagine water movement strong enough to sweep away a large heavy shell, yet gentle enough not to disturb a trail.

As with the Polyplacophora, the evidence of body fossils also speaks against assignment of Climactichnites to the Gastropoda. The age of the earliest example of this class is currently a source of considerable argument, but if there were any gastropods in the Early and Middle Cambrian, all fossils now assigned by some authors to this group are in the range of 1-2 cm maximum width of the shell. More likely, the earliest gastropods occur near the Dresbachian-Franconian boundary. The largest examples of this age are known to have a maximum apertural width of $3 \mathrm{~cm}$. It is not until late in the Ordovician that the aperture of a large Maclurites would approximate the size of a small Climactichnites trail, and there is considerable uncertainty as to whether this snail crawled (Yochelson, 1990)

The opisthobranch hypothesis is difficult to grapple with, for it too is based on lack of evidence. Obviously a non-shelled gastropod is unlikely to leave much of a fossil record; consider, for example, the potential number of soft-bodied coelenterates that might have been in the Cambrian seas and how limited a record remains of them. What little is known of the early shelled opisthobranchs suggests that they did not appear until the mid-Paleozoic (Kollmann and Yochelson, 1976). The best modern model for any hypothetical animal among this subclass of gastropods would be the "sea hare" Aplysia, for large specimens are large enough to have filled an oval depression of Climactichnites. However, an exceptionally large specimen may weigh $2 \mathrm{~kg}$, hardly enough to compact sand by its weight. Living Aplysia are best known for swimming, but when they do crawl, it is most often on clumps of marine grasses and only rarely on sand flats. In the instances in which a living animal is stranded on a beach by an abnormally high tide, the body essentially collapses under the force of gravity and the opisthobranch does not attempt to get back into the water (Dr. R.T. Abbott, oral communication, 1990).

To summarize, we are not convinced that Climactichnites is to be associated with any platyhelminth, annelid, or any "worm-like" animal. We are equally convinced that no living or fossil representatives of Arthropoda or Mollusca was capable of producing the trail of Climactichnites or is anyway related to it at the level of phylum. 


\section{Alternative Hypotheses}

No one simply gathers facts and makes observations blindly in the hope that clarification and insight will automatically result from this process. Each of us started this investigation with a hypothesis, and each ultimately rejected it, but these notions served to stimulate discussion and observation, and each contained at least a kernel of useful ideas.

Yochelson first became aware of Climactichnites 40 years ago and for more than 30 years at occasional intervals looked at the large slab on display at the National Museum of Natural History (Frontispiece). His notion was that the animal which formed this trail was unlike any known in the Paleozoic and that it had been swept beachward by unusually high water, there to struggle in its attempt to return to the sea. The discovery in the 1940s of the late Precambrian fauna from the Ediacara Sandstone in Australia, containing forms unlike any others in the fossil record, seemed to reinforce this view of an animal unlike any other. Further, Climactichnites seemed to be a rare fossil, and the random directions of movement on this slab might be interpreted as the struggle of an animal under duress. Finally, the kidney bean shape of impressions, as then known, suggested the asymmetry which appeared to be present in some specimens of the Precambrian fossil Dickinsonia.

On the other hand, Fedonkin was unfamiliar with Climactichnites, except as a name in the literature, until 1989 when he had the opportunity to briefly examine the large slab at the National Museum of Natural History. A few features observed thereon, combined with his field studies on three continents of the preservation of Precambrian biotas, and on more characteristic early Paleozoic trace fossils, suggested to him that this fossil might be interpreted as the imprint of an animal, rather than as a trail. Elongated frond-like organisms having a sympodial mode of growth are prominent members of the Precambrian animal community. In the framework of this hypothesis, the "kidney bean-shaped" body at one end of some trails could be interpreted as a pneumatophore that carried an elongate, band-like colony of polyps similar to pelagic Recent hydrozoans, specifically siphonophores. Because some of the these colonial organisms have tentacles reaching $20-30 \mathrm{~m}$ in length, and thus are even longer than the known trails of Climactichnites, this idea could not automatically be dismissed.

As a variant on this hypothesis, consideration was also given to the notion of a long ribbon-like animal lying on the bottom in shallow water. The discoveries in the Late Precambrian Vendian and the "soft-bodied" Lower and Middle Cambrian faunas have emphasized how little we know of possible body plans and locomotion strategies developed in the past.

Our original notions presented above, like those discussed by earlier investigators, are not supported by morphologic data and have been abandoned.

\section{Paleoecological Interpretation of Climactichnites}

At some localities, Climactichnites is the only fossil observed. In particular, in the Wisconsin outcrops and museum specimens, we saw no clear evidence of other organic forms. The slab at the University of Wisconsin-Madison may bear poorly preserved Protichnites, but the markings are equivocable; Raasch (1939:7) mentioned Protichnites in Wisconsin, but provided no details. In 1990, Mr. W. Nemke found Protichnites in the Northern Stone Company quarry (5), though not on the same bedding plan with Climactichnites.

The type slab from Perth, Ontario (8) (Figure 18), bears abundant Protichnites and the network trace of Protopaleodictyon. At St. Hermas, Quebec (8) (Figure 9), and at Keeseville, New York (13), Protichnites occurs both with Climactichnites and on adjacent bedding planes above and below this fossil. In the Port Henry, New York (14) material, Protichnites is present on some slabs but not on others. We have not observed shelled invertebrates either on the same slab or in outcrops with Climactichnites. Inarticulate brachiopods are reported from slightly younger Dresbachian beds, often from the same sections which yielded Climactichnites.

"Tube" dwelling fossils, such as Skolithos and Diplocraterion are absent, though like the inarticulate brachiopods and rare trilobites, they do occur higher in the section in other sandstone units of the areas studied; presumably these tube-bearing sandstones were deposited in a lower tidal flat facies. The absence of Climactichnites in a slightly deeper water facies that was more favorable for the presence of tube-dwelling bioturbators poses the question of whether this is a coincidence or instead reflects environmental differences. We had earlier concluded that Climactichnites lived in the harsh peritidal environment where its trails are found. In present-day ecologically high-stress environments, diversity is limited but the number of organisms locally present may be quite high. This general rule certainly applies to the fossil under study. Considered on a different level, the absence of any indication of Climactichnites in the less harsh, slightly deeper water facies might mean that it was never present, or alternatively that it left no indication of its presence. Like so many of the points with this fossil, this question of where it lived when it was not crawling on a sand flat remains an enigma.

The common joint occurrence of Protichnites and Climactichnites in Ontario and Quebec suggested to a few of the early investigators that they might have been markings made by the same animal. The distinction between them is now clear and Protichnites is generally attributed to an arthropod. In the instances of co-occurrence, the trail of Protichnites cuts that of Climactichnites. If our interpretation of the environment is correct, Protichnites is well adapted to life on a beach rather than to a marine environment. Without any proof, we offer the suggestion that some essentially soft-bodied Climactichnites could have fallen prey to this faster moving organism. No small Climactichnites are known and a camivorous Protichnites would provide one possible explanation from their absence from the fossil record.

If conditions on a sand flat with fluctuating water levels were 
harsh, and perhaps also a predator was present, one may ask why Climactichnites occurred there. A logical suggestion is that the animal was exploiting a food resource. In this connection, we note that recently the record of foraminifers has been extended backwards by identification of ammodiscid foraminifers in the Early Cambrian (Culver et al., 1990). Naked protists would leave no record and agglutinated foraminifers could not be identified in an indurated sandstone; this discovery of Early Cambrian agglutinated foraminifers required a unusual set of circumstances. On the Late Cambrian sand flats, both agglutinated and naked protists could have abounded in the uppermost layer of sediment. Warm moist conditions would have been ideal for photosynthesis of symbiotic algae. By comparison to extant protists, probably they would not have penetrated much more than a centimeter into the sand, even when the tide was low.

\section{Feeding Behavior}

The abundance of Climactichnites trails and details of their morphology led us to the view that the trail represents purposeful behavior by the animal. Of the various activities that an animal performs, food gathering is fundamental and we consider this the prime reason for formation of most trails.

In a tidal environment such as we have interpreted for this fossil, the time of high water brings in the most suspended sediment, which then settles to the bottom. The troughs of ripples tend to trap fine clay-sized particles, which are richer in occluded organic material than the sand. Although this physical phenomenon is an important feature of the habitat for some living forms and probably for other detritus-ingesting fossils, we are not convinced that Climactichnites fed by collecting organic debris from the upper surface of wet sand. A strong argument against this interpretation is the cross-cutting relationships of trails to ripples where they are present (Figures 8, 37). Many specimens of Climactichnites do not occur on rippled bedding planes, but even in the instances of ripples, not all trails reach the trough of the ripple. Were the animal seeking the organic matter in ripple troughs, the directions of trails and ripples would be parallel; although this does occur, it is very much the exception rather than the rule. Indeed, if Climactichnites was primarily concerned with collecting organic matter concentrated in mud, one would expect that the fossil would be most abundant on mud-rich substrates, rather than sand flats.

Rather, we propose a novel feeding mechanism for this unusual animal, based in part on the features of the trail that it left. A critical detail seen in the New Lisbon, Wisconsin (4), specimens (Walcott, 1912) is the presence of fine, arched lines on the sole of the animal. These occur within the oval, crossing the irregularities of that surface and continue onto the bars and furrows, being seen best on the gentle slope of the bars (Figure 44). These lines may also occur on the slab from Beauhamois, Quebec (10), though the coarser matrix at that locality makes their presence more equivocal, and they cannot be documented by photography.

The arch-like impressions superficially resemble the growth lines which occur on the shells of invertebrates, but it is difficult to imagine why prominent growth lines would occur on the relatively soft and deformable sole of the animal and why they would be reflected on the sediment surface. A more plausible interpretation is that these lines were the sites of rows of cilia on the sole of the animal. Cilia should have been sensitive enough to gauge the water content in the substrate. In addition to thigmotaxis or thermotaxis sensing, the cilia might have had a chemotaxis component to evaluate the amount of protoplasm within the upper layer of the sand.

If our interpretation of locomotion is correct, anterior and lateral clamping of the animal to the damp sand developed a slightly different microenvironment under the sole, probably lowering the cohesiveness of the sand particles. The rows of cilia moved the upper layer of sand forward, brushing it against the anterior of the animal to form the upper part of the bars and digging in a slight distance to accentuate and deepen the furrows. The shape of bar and furrow, having a steep anterior face and gentle posterior slope, is comparable to that to the shape of a sand dune, and the mechanism of movement of the fine sand is similar. It is to be emphasized that the primary shape of the bars was formed under the anterior flap as its forward edge dug into the substrate to form a furrow and then contracted. The more gentle brushing action of the cilia added several inclined laminae to the mound of material; this is why the bars and furrows are more or less straight, not arcuate, below the fine arcuate lines. On the other hand, arcuate lines of cilia would be the appropriate shape for transporting selected particles laterally toward the center of the animal.

By brushing the sand with cilia on the sole of the animal, microorganisms in the first few millimeters beneath the surface would be exposed and forced forward. In addition, the formation of oscillation ripples by wind action disturbs the surface of the sand in the same manner as would the presumed cilia on the sole of the animal. It may be no coincidence that Climactichnites appears to be more abundant in ripple-marked sandstone, for if the feeding mechanism we suggest is correct, the microorganisms would have concentrated in the ridges of the rippled sand. Although there is no evidence in the fossil record as to when a meiofauna as it is known today evolved, it is not necessary for our hypothesis that a meiofauna was present in these Late Cambrian sand flats. From what is known of the life habits of extant benthonic foraminifers, it is likely they would have swarmed in the warm moist environment of a Late Cambrian sand flat; as noted, the occurrence of foraminifers in rocks older than Late Cambrian has been documented.

The theoretical mode of completing bar formation by brushing sand forward from the posterior had been considered prior to our examination of the Port Henry, New York (14), slab in the American Museum of Natural History (Figure 35). For this hypothetical feeding mechanism to work, it would require 
a mouth on the sole of the animal to ingest the organisms collected and concentrated from the sediment, and then transported toward the center of the body. Otherwise enigmatic marks, located at the center of the trail, are in the correct position. When compared with Anomalocaris, for example, they are also of the proper general size and shape to suggest impressions of a mouth. The concentric circles on the Beauharnois, Quebec, slab (Frontispiece), consisting of a ring of low relief enclosing another (Figure 34), are of the same size, as are others from Port Henry, New York (14) (Figure 36) and New Lisbon, Wisconsin (4) (Figure 44).

An elongate worm-like form burrowing either vertically or horizontally would have two alternative feeding mechanisms. Either the animal moves through the sediment or the sediment moves through the animal. In either case, the consequence is a trail of disturbed sediment that has largely or wholly been moved through the digestive tract of a creature. If Climactichnites was a major sediment processor, a continuous large string of sediment-rich fecal matter would be a feature to mark its forward progress. Nothing like this modifies the bars and furrows. Rather, on a few specimens, traces of an irregular ridge occur between the bounding lateral ridges. Such medial ridges vary in strength, in position, and in their presence along a single trail (Figure 18). We interpret this ridge as a relatively fine fecal string. Climactichnites would necessarily ingest some sediment along with the concentrated protists and then have to excrete it at irregular intervals.

\section{Locomotion and Trail Formation}

It is evident from the oval impressions that Climactichnites lay at least partially covered by sand prior to moving upward and beginning to make its trail. Burrowing in the sediment has the obvious advantages of protection from possible predators and shading from increased ultra-violet radiation as water shallowed during the tidal cycle. We have not observed any trails leading to an oval impression, only those crawling away from it. If the animal had lateral flaps, they may have assisted in shallow burrowing under water, as they do in the activity of rays and skates.

In our view, Climactichnites was a swimming form during part of its daily cycle. It moved by manipulating a pair of undulating lateral flaps, discussed below. This movement may not have been a particularly graceful or extended method of traveling through the water column-comparison with the effective but seemingly inefficient movement of pectinacean pelecypods when movement is needed comes to mind. It would, however, have been sufficient to permit the animal to settle onto a sand flat during a falling tide and, later, swim away on the rising tide to rest on the bottom in deeper, cooler water when the flat was again awash and feeding terminated. Whether the animal was capable of such movement through the water may never be resolved, for it is founded on the assumption of the presence of lateral flaps, a feature that seems reasonable from the trail formation, but one that cannot be conclusively proven in the absence of soft parts.

Instead, we concentrate on the problem of trail forming. The relatively high bounding lateral ridges and the depth of furrows originally suggested to us that the animal was plowing through the upper level of the sediment, not gliding over the sand surface. This plowing appearance is particularly striking where a trail cuts through a ripple mark, for there is essentially no lateral disturbance of a ripple crest adjacent to a trail. However, anyone who has ever molded a structure out of damp sand will immediately recognize that the pushing of water soaked sand is extremely difficult and requires a large amount of energy.

As a result, our original notion that the animal pushed through the sand by means of a dorsoventral locomotionary wave was soon abandoned. A person standing on damp sand has about the same surface area in contact with the sediment as would the animal, but has a far larger body weight. We found it impossible to reconcile the apparent depth of plowing, no matter how slight, with the weight and musculature that would be needed for this activity. We were thus led to the view that basically the trail was built on the surface of the sediment, a point later proven by discovery of the internal dune-like structure of the bars (Figure 45)

Yet another consideration against any plowing of the sediment is the bars and the furrows themselves. If the animal had more than one locomotionary wave to move it forward, the motion of the later ones would destroy or strongly modify any internal structure of the trail. The presence of fine arched lines on the bars (Figure 31) argues against any such significant modification once the basic shape of these structures was established.

Having been the first person to find any indication of the beginning or end of a trail, Woodworth (1903) was also the first to have any basis for an attempt to analyze the direction of movement. He concluded that the oval impressions marked the end of the trail. Apparently, Walcott (1912) concurred with his interpretation for on the caption of plate 38 of his work, he noted: "Forward arching lines on the transverse ridges made by backward push of the animal in creeping forward." Thus, the interpretation of Burling (1917) that movement began at the oval impression was a dramatic change.

Confirmation that the impression marked the start of the trail, not the end, was provided by Clark and Usher (1948) with their sketch of a trail crossing over its earlier portion (Figure 38). The $V$ of the bars points toward the origin of the trail. The short turning radius of the animal when a trail crosses itself (Figure 39) not only supports the concept of a short compact body, but one that had some sort of internal support, perhaps cartilage, perhaps an elaborately musculated hydroskeleton, so that it did not change width when curving strongly. The force required to form the lateral ridges would seem to tip the balance in favor of strong muscles. In other words, Climactichnites did not deform like an earthworm during its movement.

The overall bilateral symmetry of the oval impressions is far 
from perfect, for in the few examples available one side or one end is deeper (Figures 25, 26). We infer that the sole of the animal wiggled a centimeter or so up the surface of damp sand and that slumping or compaction modified the imprint. A special problem is presented by several oval impressions which are flat and appear to be on the bedding plane, not below it (Figures 27, 34). The animal might have come to rest on the sand bottom after swimming and then moved back into the water column without crawling because the texture of the bottom at that spot was not satisfactory. Alternatively, the sediment surface may have been scoured and these oval impressions remain because they were a few centimeters below the surface. Insufficient information is available to choose between these two hypotheses.

The bilateral symmetry is not so evident at the anterior part of the oval impression. Even though few oval impressions are known, one has an anterior smooth area to the left side of the animal (Figure 28), one has a similar area to the right side (Figure 26), and one appears to have a triangular, relatively smooth area along the axis of bilateral symmetry (Figure 20). From this, we infer that the animal extended an anterior flap, found purchase against the damp sand, and pulled itself forward, undulating the sand surface under the flap. Subsequently, it put forward a flap on the other side and repeated the motion. This would allow for the formation of the $V$ shape to the bars. Because the flap was more constrained medially near the anterior than laterally, the result of muscle contraction would move sand so that the bars would be inflected toward the posterior.

Individual variation in the flaps, combined with local variation in the substrate, thus provides the raw material for the considerable amount of variation seen along one trail and among trails. A few trails show a nearly complete obliquely inclined bar, rather than a $V$ (Figures 42,53 ). In these instances, for some reason, the animal concentrated all its effort on one side; as suggested earlier, this might be rapid locomotion without feeding. In no way does that conflict with the concept of a coelomic pouch and a hydroskeleton to help direct the various muscles.

Forward movement was slight during feeding, perhaps on the order of about $5-10 \mathrm{~mm}$ with each extension of a lateral flap. Having pulled itself forward, the animal then used lateral flaps to clamp onto the sediment by moving sand inward parallel to the body. This lateral clamping require musculature at least as strong and probably stronger than that in the anterior flaps. To summarize, we infer that forward movement was a four stage process consisting of: forward extension of an anterior flap on one side and pulling forward of the body; lateral clamping in the new position and relaxation of the musculature in the anterior flaps; lateral expansion of the other anterior flap and pulling forward; and lateral clamping and relaxation of the anterior. A close connection between presumed anterior flaps and presumed lateral flaps is shown by the small lower structure adjacent to the lateral ridge and anteriorward of the bar (Figure 43). More or less simultaneous with these movements, cilia on the sole brushed sand forward, moving organic material toward the central mouth of the animal, and sand particles onto the bars to complete dune formation.

Where the lateral ridges cross ripple crests, the contact of the two is relatively sharp (Figure 22); there is no area of disturbed sediment between ripple crest and lateral ridge. The implication is that the anterior part of the animal cut through the ripple mark before the lateral ridge formed, as our hypothesis demands. A trail may curve gradually, but it does not weave from side to side. Lateral clamping and sediment ridges extended most of the length of the animal to prevent such irregularity.

Both smooth and crenulated lateral ridges (Figures 17, 18) occur and we attribute this difference to the condition of the sand and the muscle tension requirements of the animal at the instant of ridge formation. We take the absence of lateral bounding ridges on some trails to be a result of their secondary removal by sedimentary processes. Although there are bars and furrows without lateral ridges, we know of no examples in which the ridges remain and the interior features are gone.

The presence of a continuous line of bars and furrows between the lateral ridges effectively destroys any notion that the trail was made by plowing activity. It also imposes considerable restraint on any constructional hypothesis, for either bars and furrows were formed entirely by the posterior of the animal or somehow the animal could move over the anteriorward constructed bars and furrows without modifying them to any great extent. We judge the latter to be much more probable.

Perhaps the most remarkable feature of Climactichnites is its excellent preservation in an environment where preservation is most unlikely, as a result of repeated movement of the sediment. Most surface trails, in the early Paleozoic at least, occur in environments characterized by slightly deep quiet water and "event" movement of sediment to bury them, rather than periodic shifting of sands. The amount of local sediment transport on a mud flat is far less than on a sand flat, and seldom are modern-day trails preserved on a tidal mud flat. We suggest that secretion of mucus would aid in preservation of the trail. Production of large amounts of mucus probably was the reason that Climactichnites could move over the sand and compress the damp particles without the sharp particles wearing away its body tissue. A mucus-covered trail would also explain how an animal was able to move over bars and furrows without destroying them. Ciliary action on the posterior part of the animal rather than waves of muscle contraction would also help preserve the trail from modification.

Our proposal for movement of the animal, ignoring the morphology of the constructional trail, resembles that of the "inch worm" whereby the anterior moves forward and attaches to the substrate, the body then moves forward and the posterior attaches, allowing the anterior to move forward again. Such 
locomotion is quite efficient and a tiny animal may move more than 3-4 cm in less than a minute.

Speculation on the height and the duration of tides in the Late Cambrian epicontinental seas must be uncertain, but a plausible assumption is that slack low water probably was in the range of one to two hours. Evaporation toward the end of this period might have been partially compensated by a rising water table as the tide increased, particularly if the tidal amplitude was low. Thus, the moisture of the sand should have remained nearly constant or varied within small limits. The longest Climactichnites trail known is about $4 \mathrm{~m}$, and there is no trace of a beginning or an end. Notwithstanding that further uncertainty, in a two hour interval this would require the animal to travel at a rate of slightly less than $4 \mathrm{~cm}$ a minute. Such a rate would appear to be reasonable for the mechanisms that we have proposed, both for locomotion and for feeding.

\section{Climactichnites and the Early Ichnological Record}

The stratigraphic interval of the Vendian and the Cambrian is characterized by a rapid increase in diversity, morphologic complexity, and size of bioturbators. This increase is demonstrated by different traces emphasizing various activities, preserved in rocks recording shallow marine environments. During this same time, there ensued a change from essentially a two dimensional pattem of paleoichnologic activity to a three dimensional one. This phenomenon is related to penetration and colonization of the subsurface, that is the transfer of activities for some animals from on the sediment surface to within the sediment (Fedonkin, 1977, 1981).

Near the close of the Cambrian Period, the degree of biological processing of sediment seems to have reached its critical point as a result of niche partitioning in the shallow marine shelf environment. The ichnocoenoses of the Vendian and much of the Cambrian contain typical shallow water forms, such as Bergaueria and Skolithos, along with more morphologically complex and diverse trails and burrows; the latter are characteristic of deeper water facies in the younger part of the Phanerozoic record. It is difficult to apply the excellent model of bathymetric zonation of trace fossil developed by Seilacher (1967) to this more ancient admixture of forms.

Apart from the Cambrian grazing trail Oldhamia, which may have lived in a deeper marine environment, few of the Vendian-Cambrian traces occur in deep water sediments. Active colonization of this habitat did not begin until the Early Ordovician (Crimes, 1974, 1992), reflected in a dramatic increase in diversity of bioturbation. During the same interval, in the shallow water environment, the diversity of trace fossils appears to have remained constant or perhaps even decreased slightly.

There are at least two possible interrelated reasons for movement of bioturbating organisms to deeper water environments. First, there may have been an increase in population density of the bioturbators, and second, there may have been an increase in diversity of new predators in the shelf environment. It is important to note that the penetration of the deep sea by bioturbators was a shift in environment that was not accompanied by any obvious major change in morphology, for the features of the traces involved in this ecological shift remained constant.

Climactichnites also left the shallow marine environment, but moved up slope, not down. In contrast to the bioturbators who descended down into deeper water, Climactichnites was forced to adapt to a dramatic change in habitat. The environment on the sand flats was very much harsher than that of deeper water. Among the most obvious problems were those of drying out and of gravity, difficulties not encountered in the aquatic realm. Less obvious, but equally present, were the dangers of higher temperature, excess oxygen, and ultraviolet light.

Climactichnites was a pioneering type developing a different body shape to compensate for the pull of gravity and a different mode of life to utilize a new food source. As such, its adaptation was far more remarkable than those of the bioturbators who had moved downslope. The tidal flats served as a staging area and barrier between sea and land, but one in which essentially no fossil record is preserved. Understandably, Little (1990) begins his brief account of the development of terrestrial ecosystems with the reputed terrestrial forms in the Ordovician and does not consider earlier time (see also Gray and Shear, 1992). To our mind, Climactichnites is remarkable in showing a first attempt to cross this barrier. In the sense that this did not lead to permanent colonization of land, it was a premature attempt.

From a more theoretical standpoint, the pioneer phase in the evolution of communities is considered to be related to trophic flexibility and large body size, as it is reflected in the record of trace fossils (Seilacher, 1977). To some extent, a large body may represent the phenomenon of "reserve biomass" which allows an animal to survive in extreme situations of an environment characterized by unstable food resources (Ponomarenko, 1984). Climactichnites and its occasional fellow traveller Protichnites seem to be organisms which fit this theory.

Seilacher (1977:374-375) briefly described a meandering pattern made on putative Late Cambrian rocks of Saudi Arabia, which he attributed to gastropod grazing tracks, an interpretation based on presumed radular bites and scratches. He compared this material to Climactichnites, from the standpoints of age and paleoenvironment. McMenamin and McMenamin (1990:124, 125) reproduced part of the sketch of Clarke (1905) and extended Seilacher's argument further, suggesting that Climactichnites was exploiting bacterial mats to the very limits of their ecological niche and grazing them to extinction. Except perhaps in the case of an exotic predator introduced onto a small island, we can think of no case in which a predator might eat all of its food supply and thereby also become extinct. Climactichnites does not exhibit any evidence of a radula, nor 
is there any direct or indirect evidence of its grazing on a surface mat; bacterial mats are still extant.

\section{Reconstruction of Climactichnites}

Burling (1917:397) assembled a solid foundation of facts to arrive at a "flexible slug-like animal which was frequently stranded at low-tide, but was able to swim in the waters of full tide..." We have had the benefit of observing many more specimens of this fossil combined with access to more than a half century of ancillary data on sedimentation and marine biology, along with a somewhat different approach to evolution. We are not in conflict with Burling so much as we are grateful to him for providing a solid base from which we started our reconstruction.

Although many of our inferences concerning Climactichnites have been presented already, by way of a summary, we shall repeat some of the conclusions. Climactichnites was a triploblastic, bilaterally symmetrical animal. The ventral part was a strongly muscled foot, but with considerable flexibility; the thick skin of a large mammal perhaps provides a rough analogue of its characteristics. At least part of the sole in the posterior portion of the animal was covered with rows of cilia, arch-like in arrangement and with curvature following that of the posterior margin of the creature. The organism was perhaps twice as long as wide, and more or less lozenge-shaped. Because of the tough integument, strong muscles, and perhaps some sort of internal cartilaginous structure, the body retained its shape during movement.

The animal was low and broad, flattened more toward the posterior. A large form was perhaps about $5 \mathrm{~cm}$ high. The dorsal surface of the creature was modified into two large flaps of musculated tissue which hung down on either side of the animal extending a few centimeters out over the sediment when fully relaxed. These were intermittently compressed against the sides of the animal.

Because of the problems of heat and evaporation on an exposed sand flat, whatever kind of breathing apparatus the organism possessed, it was likely to be covered by these flaps, rather than exposed on the dorsum of the animal. The sole of the animal, the sides, and least the lower surface of these strong prehensile flaps probably produced great quantities of mucus, that coincidentally helped to preserve its trail in the damp sand.

Climactichnites probably gathered microorganisms from the upper few millimeters of the sand by brushing the surface with cilia. Particles of food were selected and moved along the curved, ciliated tracks toward a mouth located somewhere on the sole. A digestive track ran from the mouth to posterior anus. At irregular intervals, the organism discharged some of the ingested matrix as a fecal string.

During feeding, the animal moved forward spasmodically, but more or less continuously. Its anterior had two large strongly muscular flaps of tissue, approximately triangular in shape. The outer edge of each flap extended laterally and was approximately parallel to the sides of the animal. One of the
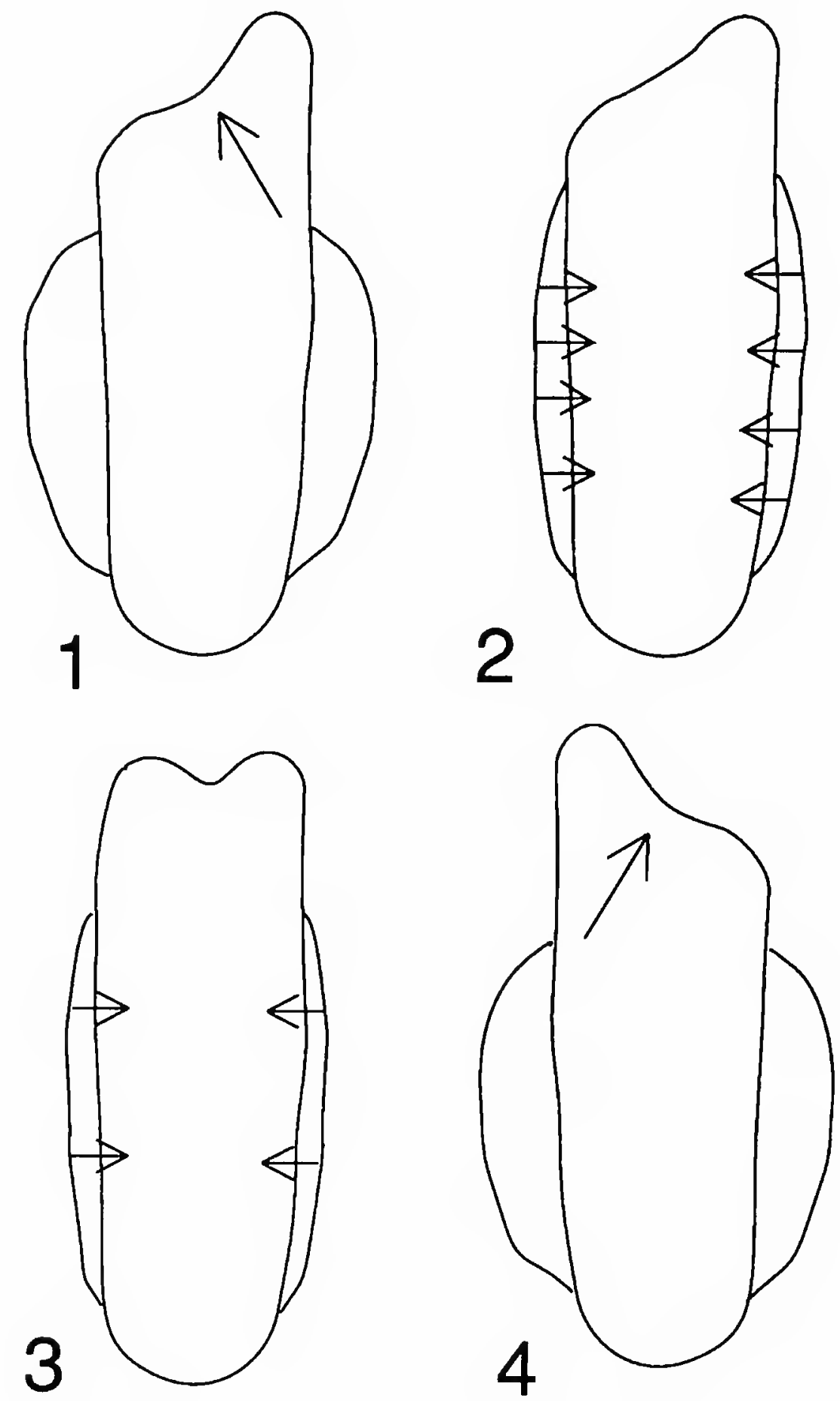

FIGURE 57.-Schematic interpretation of the movement of Climactichnites. Phase 1: The right side of the anterior of the organism has expanded as a wedge-shaped flap, dug into the substrate, and pulled the main mass of the body forward. Phase 2: The lateral flaps have compressed, pulling sand inward and holding the body in one place. Phase 3: The main mass of the body is still being held in place by the lateral flaps, though not so tightly, and fluid is being transferred from the right side of the anterior to the left side. Phase 4: The left side of the anterior of the organism has expanded forward, dug into the substrate, and pulled the body forward. Arrows indicate general movement, not the precise direction of the pull of complex musculature.

angles of each triangular flap attached near the mid-line of the animal. The flaps were extended alternately to grasp the sediment and pull the main part of the body forward. Between each forward movement of an anterior flap, the animal compressed the lateral flaps to hold it in place while anterior muscles relaxed for the next forward movement (Figure 57).

To regulate this complex movement of muscles, the nervous system was highly developed. As one method of mitigating the harsh environmental conditions of the sand flat, the animal may have been nocturnal or crepuscular, moving only during times of low light. If this supposition is correct, the animal possessed 

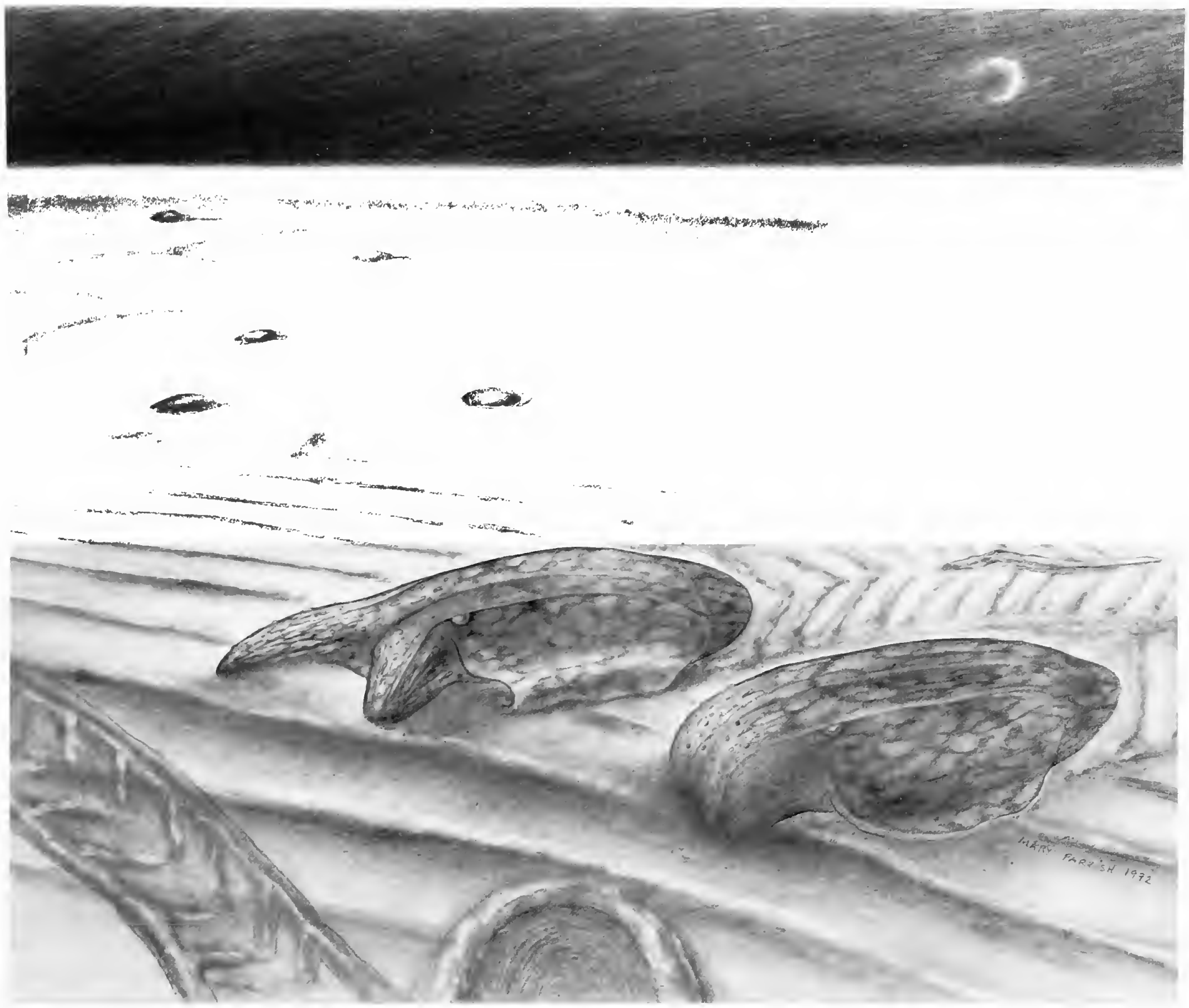

FIGURE 58.-Drawing of Climactichnites in life. To the lower right, one animal is moving, using most of the anterior edge to pull itself forward; compare the trail with the upper part of Figure 14 or Figure 52. It has just dug into the substrate and the lateral flaps are still relaxed. The animal near the center is proceeding by extending alternate sides of the anterior edge, as is more characteristic. It has already moved forward, and even though the lateral flaps still grasp the sand pulled inward, the animal is in the process of transferring fluid to the left anterior. To the far right of its trail is an irregular median discharge of sediment within the lateral ridges; compare with Figure 19. The organs near the anterior of the animals sense the low level of light and, hence, the relative cool temperature of the exposed sand flats at night. Not seen on the two animals is the ventral mouth and cilia piling sand up into small dunes between the furrows dug by the ephereral anterior extensions. In the immediate forground is the posterior portion of a resting impression, showing the traces of fine lines which bear rows of cilia to sweep sand into dunes beneath the sole of the animal; compare with Figure 31. Several other impressions of the sole and of animals crawling are in the middle distance. Many individuals crawl over the sand flat or have crawled away. Reconstruction by Mary Parrish.

some kind of dorsal light receptor.

As reconstructed, Climactichnites has morphology which in part was not unlike that of modern marine skates and rays. These animals swim by undulations of the flattened body and rest by burrowing shallowly into a sandy bottom. If Climactich- nites could swim, it was not so efficient as these graceful, more streamlined forms. The principal physical activity of this Late Cambrian fossil was to move on damp sand. Its body shape and musculature appear to have been designed for that function, rather than a principally aquatic life (Figure 58). 


\section{Ichnogenera and High-level Taxa}

Nomenclature to be applied to the "work" of animals, including such examples of life activity as bioturbation, borings into hard substrate, and coprolites, have constituted a serious issue for the International Commission on Zoological Nomenclature. The philosophical approach as to how to treat names based on such work has changed during several editions of the International Code of Zoological Nomenclature. These changes are aptly summarized by Bromley (1990:143-145). Currently (ICZN, 1985), no valid binomial can be based on the work of an extant animal, but the validity of ichnotaxa in the fossil record is recognized. There is no doubt that Climactichnites Logan and $C$. wilsoni Logan are names in good standing within zoological nomenclature.

Still further, the Code (ICZN, 1985:5I) notes: "(iii) a name established for an ichnotaxon does not compete in priority with one established for an animal, even for one that may have formed the ichnotaxon." One consequence of this wording may be to treat ichnotaxa as entities entirely distinct from any zoological considerations. Once it is established, for example, that Rusophycus is the name for the resting place of a trilobite, there may be little incentive in determining whether more than one kind of trilobite formed Rusophycus. For ichnofossils with fewer features than that one, such as the well known Skolithos, it is possible to examine the works of Recent tube-dwelling animals and determine that several different unrelated forms are capable of producing a tube like that of the fossil genus named Skolithos. Bromley (1990:137-142) again has most ably summarized the problems and pitfalls of attempting to correlate a particular trace fossil with a particular fossil organism.

In the face of such obstacles, one is strongly tempted to forego any serious biological consideration of ichnotaxa, but we are troubled that this attitude may be retrogressive. Biological nomenclature is concemed with organisms, not sedimentary structures. Where sufficient detail is provided by a trace fossil to allow more detailed speculation regarding the organism which formed it, we judge that this line of inquiry should be vigorously pursued. Accordingly, once we had described the features of the trail of Climactichnites, we next attempted to reconstruct the organism which could have produced this particular structure.

To state this matter more formally, we consider the name Climactichnites to apply to a fossil animal that so far is known only from its trail, not as the scientific name for a trail with certain characteristic features of morphology. In doing so, we recognize full well that such an approach is less readily applied to other ichnotaxa which have fewer features or less distinctive morphology, and that Bromley (1990) is correct in cautioning against too much biologic interpretation of traces. However, to treat Climactichnites purely as a trail and not as indication of an organism would seem to defeat the purpose of paleontology, the study of ancient life. Fortunately, our problem is somewhat simpler than with other collective group names, for no generic name of a body fossil has ever been linked to the trail of Climactichnites. Even the general group of animals which have been suggested in the literature as possible trail formers are, in our view, inappropriate. Climactichnites may be the exception which tries the rule, for if one cannot speculate about the organism that formed such a remarkable trail, one cannot properly speculate about the biological origin of almost any other trace fossil.

Häntzschal $(1962,1975)$ discusses ichnogenera in alphabetical order. This has considerable merit for finding a name, but once again conveys a subliminal message that one is dealing with "things" rather than organisms. The Code does indicate that family-group names based on ichnogeneric names are valid, implying that even though ichnotaxa are in a sense artificial assemblages, a zoological classification is a goal for which to aim.

\section{Discussion}

The trail of Climactichnites is like that of no other trace fossil. We do not mean by this statement that it is simply a different genus; rather, its morphology is so strikingly different that it is not liable to confusion with any other traces of fossils known to us. Were one to apply a hierarchical classification to trace fossils, the form would be unique in its own high level taxon. As a direct conclusion, we judge that in its morphology Climactichnites was like no other animal. Based on our interpretation of its locomotion and feeding, we suggest that no skeletal material was present. Any slight similarities to present-day organisms are at best analogies, and, in our interpretation, indicate no relationship. We know of no other forms in the Precambrian or Paleozoic that in any way would be similar to it.

Preservation of soft-bodied organisms is now generally accepted as a possibility in the fossil record, although deposits yielding such atypical fossils are still exceedingly rare in the Phanerozoic. In contrast, this is the norm for preservation in the Vendian. Based on what is known of the occurrence of such forms in the Paleozoic and what has been interpreted as the environment of deposition of the rocks yielding Climactichnites, the prospect of directly obtaining any part of the animal itself appears to be extremely remote.

The mode of life suggested, that is brushing away the sediment surface to collect tiny organisms living interstitially in the upper layers of sand, seems to have no parallel in the modern fauna. In retrospect, this should come as no great surprise for, just as the vast carbonate-depositing epicontinental seas of the Paleozoic have no close present-day analog, the huge sand flats of the Late Cambrian in eastern North America differed from our modern high energy beaches. Apparently, by its nature, Climactichnites left only a trace and no body fossil for us to study. Although our interpretation of the animal contains many inferences, in our view, these fit all available data, yet do not consist of unbridled speculation. 
This now brings us to the crux of a dilemma concerned with the issue of high-level taxa in classification. During the past generation there has been a dramatic change in the approach of many paleontologists from a more biostratigraphic interest to a more paleobiologic one. Included in this change has been the recognition that the early record of fossils at the taxonomic levels of order, class, and phylum might be dramatically different from that of the Recent biota. Whereas in the past, the erection of orders and classes of organisms having no present-day representatives was rare, now such categories are relatively common in the paleontologic literature. Two decades ago, proposal of an extinct phylum was a daring and somewhat unpopular step (Yochelson, 1977); today the pendulum has swung so far that there is concern in some quarters that certain unique fossil forms in such carefully documented faunas as the Middle Cambrian Burgess Shale have not been accorded their own phyla.

A contrary view of this development is given by those who are concerned with what have been called "junk" phyla. This implies taxa which can only be recognized in exceptional preservation and are limited in both time and space. We reject this interpretation, for taxa at all levels are based on similarities and differences with other taxa. Neither abundance of the organism classified or its distribution in time are pertinent to taxonomic rank. If stratigraphic range were a serious consideration of taxonomy, the "junk phylum" logic would dictate that a number of generally accepted Recent phyla, which have no fossil record, should be downgraded in rank.

Another facet of this issue is the question of the origin of high-level taxa at the Precambrian-Cambrian boundary. For some investigators, development of new phyla at that time was an "explosion." In opposition to that is the presence of at least one major phylum-Bryozoa-appearing in significantly younger beds. If the Agmata (Yochelson, 1977) and the Conulariida (Feldmann and Babcock, 1986) are accepted as phyla, the force of the Cambrian explosion is weakened.

The increase in the number of kinds of fossils with hard parts at the base of the Phanerozoic is true enough, but we judge the concept of "explosive evolution" to be more apparent than real. We hold that regardless of the time when it occurs, if an organism develops the means to exploit a major new environment, the result may be a form which fits no previously recognized taxonomic category, even at the highest systematic level. Because of the rapid filling of the most common ecological niches, the development of high-level taxa in post-Early Cambrian time was more difficult, but obviously not impossible. In a sense, we see Climactichnites as yet another attempt at a novel body plan in the post-Early Cambrian interval.

Having written all this, we do not propose any formal high-level taxonomic assignment for Climactichnites at this time! It is unconventional to construct any animal from its work. It is even more unconventional to use the indication of the work of an animal, an ichnogenus if you will, as the basis for a high-level taxon. There are limits as to how far one can defy convention and still be accepted by ones colleagues.

Classification differs from any other sciences in that it is an additive process, not episodically revised by new paradigms. Each new paper in systematics adds a modicum of data to our understanding of the interrelationships of organisms. Fortunately, the term incertae sedis is available to the systematist, and, like the term taxon, does not imply any particular level of classification (see Yochelson, 1991). Although it may have been inadvertent on his part, Häntzschel (1975) took a dramatic step forward when he suggested that Climactichnites was the trail made by an unknown organism, rather than that of a mollusk, arthropod, or worm, and by implication classified the genus incertae sedis.

In the final analysis, the position of taxa within a hierarchy of classification is subjective, for it depends entirely on subsequent acceptance or rejection by other interested systematists. We are satisfied in our own minds that Climactichnites constitutes a form deserving of phylum-level rank, which for a brief time exploited the vast tidal sand flats of the Late Cambrian, becoming extinct when conditions changed only slightly. We have deliberately used the term incertae sedis in higher level classification of this fossil for two reasons. First, such usage dramatizes its distinctiveness, and, second, this avoids for the moment the issue of an ichnogenus as the basis for a phylum. If our interpretation of just how novel is Climactichnites is accepted by our scientific peers, and if the conventions are changed, a phylum name can be proposed later. For now, Climactichnites may speak for itself. 


\section{Literature Cited}

Abbott, R.T.

1954. Review of the Atlantic Periwinkles, Nodilittorina, Echinus, and Tectarius. Proceedings of the United States National Museum. 103:449-469.

Abel, $\mathrm{O}$.

1935. Vorzeitliche Lebensspuren. 644 pages. Jena, Germany: Gustav Fischer.

Bell, Robert

1907. Sir William Logan and the Geological Survey of Canada. 28 pages. Ottawa, Ontario: Privately printed.

Billings, E.

1870. Notes on Some Specimens of Lower Silurian Trilobites. Geological Society of London Quarterly Journal, 26:479-486.

Brand, U., and B.R. Rust

1977. The Age and Upper Boundary of the Nepean Formation in its Type Section near Ottawa, Ontario. Canadian Journal of Earth Sciences, 14:2002-2006.

Briggs, D.E.G.

1991. Extraordinary Fossils. American Scientist, 79:130-141.

Bromley, R.G.

1990. Trace Fossils: Biology and Taphonomy. 280 pages. London: Unwin Hyman.

Burling, L.D

1917. Protichnites and Climactichnites: A Critical Study of Some Cambrian Trails. American Journal of Science, series 4, 44:387398.

Chamberlin, T.C.

1883. General Geology. In Wisconsin Geological Survey; Survey of 1873-1879, volume 1, part 1:1-301. Madison, Wisconsin: David Atwoods.

Chapman, E.A.

1862. A Popular and Practical Exposition of the Minerals and Geology of Canada, Part V. Canadian Journal of Science, Literature, and History, new series, 8:185-216.

1877. On the Probable Nature of the Supposed Fossil Tracks Known as Protichnites and Climactichnites. Canadian Journal of Science. Literature, and History, new series, 15:486-490.

Clark, T.H., and J.L. Usher

1948. The Sense of Climactichnites. American Journal of Science, 246:251-253.

Clarke, J.M.

1905. Report of the State Paleontologist, 1903. New York State Museum Bulletin, 80:3-133.

Clarke, J.M., and R. Ruedemann

1912. The Eurypterida of New York. New York State Museum Memoirs 14: 439 pages.

Conway Morris, S.

1977. Fossil Priapulid Worms. The Palaeontological Association, Special Papers in Palaeontology, 20: 95 pages.

Crimes, T.P.

1974. Colonisation of the Early Ocean Basin. Nature, 248:328-330.

1992. The Record of Trace Fossils Across the Proterozoic-Cambrian Boundary. In J.H. Lipps and P.H. Singer, editors, Origin and Early Evolution of the Metazoa, pages 177-202. New York: Plenum Press.

Culver, S.J., J.E. Repetski, J. Pojeta, Jr., and D. Hunt

1990. Early Cambrian Foraminifera and Metazoan Shelly Fossils from West Africa. Geological Society of America, Abstracts with Programs, 22(7):68.
Dana, J.D.

1895. Manual of Geology, Treating of the Principals of the Science with Special Reference to American Geological History. Fourth edition, 1087 pages. New York: American Book Company.

Dawson, J.W.

1862. On the Footprints of Limulus as Compared with the Protichnites of the Potsdam Sandstone. Canadian Naturalist, 7:271-277. [Abstract in American Journal of Science, series 2, 34:416-417.]

1890. On Burrows and Tracks of Invertebrate Fossils in Paleozoic Rocks, and Other Markings. Geological Society of London Quarterly Journal, 46:595-617.

Dott, R.H., Jr., and C.W. Byers [conveners]

1981. SEPM Research Conference on Modern Shelf and Ancient Cratonic Sedimentation: The Orthoquartzite-Carbonate Suite Revisited. Journal of Sedimentary Petrology, 51:329-347.

Dott, R.H., Jr., C.W. Byers, A.W. Fielder, S.R. Stenzel, and K.E. Winfree

1986. Aeolian to Marine Transition in Cambro-Ordovician Cratonic Sheet Sandstones of the Northern Mississippi Valley, USA. Sedimentology, 33:345-367.

Driese, S.G., C.W. Byers, and R.H. Dott, Jr.

1981. Tidal Deposition in the Basal Upper Cambrian Mt. Simon For mation in Wisconsin. Journal of Sedimentary Petrology, 51:367-381.

Emery, K.O

1945. Entrainment of Air in Beach Sands. Journal of Sedimentary Petrology, 15:39-49.

Emery, K.O. and J.E. Foster, Jr.

1948. Water Tables in Marine Beaches. Journal of Marine Research, 7:644-654.

Fedonkin, M.A.

1977. Precambrian-Cambrian Ichnocoenoses of the East European Platform. Geological Journal, Special Issue 9, Trace Fossils 2:183-194.

1981. White Sea Biota of the Vendian (Precambrian Non-skeletal Fauna of the Russian Platform North). Transactions of the Geological Institute, 342:1-100. [In Russian.]

Feldmann, R., and L. Babcock

1986. The Phylum Conulariida. In A. Hoffman and M.H. Nitecki, editors, Problematic Fossil Taxa, pages 135-147. New York: Oxford University Press.

Fisher, D.W

1968. Geology of the Plattsburgh and Rouses Point, New York-Vermont, Quadrangles. New York State Museum and Science Service, Map and Chart Series, 10.

Gislen, $\mathrm{T}$.

1940. Investigations on the Ecology of Echinus. Lunds Universitets Årskrift, 36(2): 38 pages.

Globensky, Y.

1987. Géologie des Basses-Terres du Saint-Laurent. Québec Departement de l'Exploration Géologique et Minérale, Service de la Géologie, MM 85-02: 63 pages.

Grabau, A.W., and H.W. Shimer

1910. North American Index Fossils. Volume 2, 909 pages. New York A.G. Seiler and Company.

Gratacap. L.P.

1901. Paleontological Speculations. American Geologist, 27:75-100.

Gray, J., and W. Shear

1992. Early Life on Land. American Scientist, 80:444-456. 
Hall, J.

1889. Report of the Director for 1888. Annual Report of the New York State Museum of Natural History, 42:17-34.

Häntzschel, W.

1962. Trace Fossils and Problematica. In Raymond C. Moore, editor, Treatise on Invertebrate Paleontology, Part W Miscellanea:W177W245. Lawrence, Kansas: University of Kansas Press.

1975. Trace Fossils and Problematica, Second Edition (revised and enlarged). In Raymond C. Moore, editor, Treatise on Invertebrate Paleontology, Part W Miscellanea, Supplement 1: 269 pages. Lawrence, Kansas: University of Kansas Press.

Hitchcock, C.H., and W. Patten

1908. Studies of the Tracks of Climactichnites. Science, new series, 28:382.

Houseknecht, D.W.

1975. Transportational and Depositional History of the Lamotte Sandstone of Southeastern Missouri. 145 pages. Unpublished Master's thesis, Southern Illinois University, Carbondale Illinois.

Houseknecht, D.W., and F.G. Ethridge

1978. Depositional History of the Lamotte Sandstone of Southeastern Missouri. Journal of Sedimentary Petrography, 48:575-586.

Howell, B.F. et al.

1944. Correlation of the Cambrian For mations of North America. Bulletin of the Geological Society of America, 55:993-1003.

International Commission on Zoological Nomemclature (ICZN)

1985. International Code of Zoological Nomenclature. Edition 3. Adopted by the 20th General Assembly of the International Union of Biological Sciences. 338 pages. Berkeley: University of California Press.

Jones, T.R.

1862a. Trails, Tracks, and Surface-markings. The Geologist, 5:128-139.

1862b. Tracks, Trails, and Imprints. The Geologist, 5:454-456.

Kier, W.W.

1988. The Arrangement and Function of Molluscan Muscle. In E.R. Trueman, and M.R. Clarke, editors, The Mollusca, Volume 11: Form and Function, pages 211-252. San Diego, California: Academic Press.

Kollmann, H.A., and E.L. Yochelson

1976. Survey of Paleozoic Gastropods Possibly Belonging to the Subclass Opisthobranchia. Annalen Naturhistorisches Museum Wien, 80: 207-220.

Lesley, J.P.

1890. A Dictionary of the Fossils of Pennsylvania and Neighboring States Named in the Reports and Catalogues of the Survey: Volume 3. Geological Survey of Pennsylvania Report, P 4:915-1283.

Little, $\mathrm{C}$.

1990. The Terrestrial Invasion. 304 pages. Cambridge, England: Cambidge University Press.

Logan, W.E.

1851. On the Occurrence of a Track and Footprints of an Animal in the Potsdam Sandstone of Lower Canada. Geological Society of London Quarterly Journal, 7:247-250.

1860. On the Track of an Animal Lately Found in the Potsdam Formation. Canadian Naturalist and Geologist, 5:279-285. [Reprinted 1861 in American Journal of Science, series 2, 31:17-23.]

Malz, $\mathrm{H}$.

1968. Climactichnites-die Kreichspur einer noch unbekannten kambrischen Tieres. Natur und Museum, 98:369-373.

McMenamin, M.A.S., and D.I.S. McMenamin

1990. The Emergence of Animals: The Cambrian Breakthrough. 217 pages. New York: Columbia University Press.

Miller, S.A.

1889. North American Geology and Palaeontology for the Use of
Amateurs. Students, and Scientists. 664 pages. Cincinnati, Ohio: Western Methodist Book Concern.

Miller, S.L.

1974. The Classification, Taxonomic Distribution, and Evolution of Locomotor Types Among Prosobranch Gastropods. Proceedings of the Malacological Society of London, 41:233-272.

Nathorst, A.G.

1881. [On Traces of Invertebrate Animals, etc., and Paleontologic Significance]. Kungliga Svenska Vetenskaps akademiens Handlingar, 18(7): 104 pages. [English translation made for C.D. Walcott. currently in the Department of Paleobiology reprint collection.]

Nicholson, H.A., and R. Lydeckker

1889. A Manual of Palaeontology for the Use of Students: Third Edition. Volume 1, 885 pages. Edinburgh and London: William Blackwood and Sons.

Odom, E.J., T.W. Doe, and R.H. Dott, Jr.

1976. Nature of Feldspar-grain Size Relations in Some Quartz-rich Sandstones. Journal of Sedimentary Petrology, 46:862-870.

Packard, A.S.

1900. On Supposed Merostomatous and other Paleozoic Arthropod Trails, with Notes on Those of Limulus. Proceedings of the American Academy of Arts and Sciences, 36:63-71.

Ponomarenko, A.G.

1984. Evolution of Ecosystems, the Major Events. 27th International Geological Congress, Moscow 4-14 August, 1984 Reports (2) Paleontology. pages 71-74. Moscow: Nauka. [In Russian.]

Qian $Y i$, and S. Bengtson

1989. Palaeontology and Biostratigraphy of the Early Cambrian Meishucunian Stage in Yunnan Province, South China. Fossils and Strata, 24: 156 pages

Raasch, G.O.

1939. Cambrian Merostomata. Geological Society of America Special Paper, 19: 146 pages.

Raymond, P.E.

1922. Seaside Notes. American Journal of Science, series 4, 3:108-114.

Resser, C.E

1933. Preliminary Generalized Cambrian Time Scale. Bulletin of the Geological Society of America, 44:735-756.

1938. The Cambrian System (Restricted) of the Southern Appalachians. Geological Society of America Special Paper, 15: 104 pages.

Runnegar, B., J. Pojeta, Jr., M.E. Taylor, and D. Collins

1979. New Species of the Cambrian and Ordovician Chitons Matthevia and Chelodes from Wisconsin and Queensland: Evidence for the Early History of Polyplacophoran Mollusks. Journal of Paleontology, 53:1374-1394.

Seilacher, A.

1967. Bathymetry of Trace Fossils. Marine Geology, 5:413-428.

1977. Evolution of Trace Fossil Communities. In A. Hallam editor, Patterns of Evolution, as Illustrated by the Fossil Record, pages 359-376. Amsterdam: Elsevier Scientific Publishing Company.

Shimer, H.W., and R.R. Schrock

1944. Index Fossils of North America. 837 pages. New York: John Wiley and Son.

Stearn, C.W. and R.L. Carroll

1989. Paleontology: The Record of Life. 453 pages. New York: John Wiley and Son.

Sumerson, C.H.

1951. Cambrian Tracks in the Lamotte Sandstone. Journal of Paleontology, 25:533.

Sun, Y.C.

1924. Contributions to the Cambrian Faunas of North China. Geological Survey of China, Palaeontologica Sinica, series B, 1(4): 108 pages.

Todd, J.E.

1882. A Description of some Fossil Tracks from the Potsdam Sandstone. 
Transactions of The Wisconsin Academy of Arts, Sciences, and Letters, 5:276-281.

Van Ingen, $G$.

1902. The Potsdam Sandstone of the Lake Champlain Basin. New York State Museum Bulletin, 52:529-545.

Walcott, C.D.

1912. Cambrian Geology and Paleontology, II: New York Potsdam-Hoyt Fauna. Smithsonian Miscellaneous Collections, 57(9):249-304. Weston, T.C.

1899. Reminiscences Among the Rocks, in Connection with the Geological Survey of Canada, 328 pages. Toronto, Canada: Warwick Brothers and Rutter.

Wilson, M.E., and J. Dugas

1961. Geology: Perth—Lanark and Leeds Counties, Ontario. Geological Survey of Canada Map 1089A, scale 1:63,360.

Woodworth, J.B.

1903. On the Sedentary Impression of the Animal Whose Trail is Known as Climactichnites. New York State Museum Bulletin, 69:959-966.

Yochelson, E.L.

1977. Agmata, a Proposed Extinct Phylum of Early Cambrian Age. Journal of Paleontology, 51:437-454.
1990. Billings' Second Operculum: A Late Early Ordovician Maclurites (Gastropoda) from Western Newfoundland and the Canadian Arctic. Canadian Journal of Earth Sciences, 27:669-676.

1991. Problematica/Incertae Sedis. In A. Simonetta and S. Conway Morris, editors, The Early Evolution of Metazoa and the Significance of Problematic Taxa, pages 287-296. Cambridge, England: Cambridge University Press.

Yochelson, E.L., and M.A. Fedonkin

1991. A Color-marked Early Paleozoic Trail. National Geographic Research and Exploration, 7:453-455.

Zazlow, M.

1975. Reading the Rocks. 599 pages. Toronto, Canada: The McMillan Company Ltd.

Zittel, K.A.

1881-1885. Handbuch der Palaeontologie: Band II, Mollusca und Arthropoda. 893 pages. Munich and Leipzig: R. Oldenbourg.

1913. Textbook of Paleontology, Volume J, Second Edition, 839 pages. London: McMillan and Company. [Translated by C.R. Eastman.] 




\section{REQUIREMENTS FOR SMITHSONIAN SERIES PUBLICATION}

Manuscripts intended for series publication receive substantive review (conducted by their originating Smithsonian museums or offices) and are submitted to the Srrithsonian Institution Press with Form SI-36, which must show the approval of the appropriate authority designated by the sponsoring organizational unit. Requests for special treatment-use of color, foldouts, case-bound covers, etc.-require, on the same form, the added approval of the sponsoring authority.

Review of manuscripts and art by the Press for requirements of series format and style, completeness and clarity of copy, and arrangement of all material, as outlined below, will govern, within the judgment of the Press, acceptance or rejection of manuscripts and art.

Copy must be prepared on typewriter or word processor, double-spaced, on one side of standard white bond paper (not erasable), with $1 \frac{1 / 4^{\prime \prime}}{}$ margins, submitted as ribbon copy (not carbon or xerox), in loose sheets (not stapled or bound), and accompanied by original art. Minimum acceptable length is 30 pages.

Front matter (preceding the text) should include: title page with only title and author and no other information; abstract page with author, title, series, etc., following the established format; table of contents with indents reflecting the hierarchy of heads in the paper; also, foreword and/or preface, if appropriate.

First page of text should carry the title and author at the top of the page; second page should have only the author's name and professional mailing address, to be used as an unnumbered footnote on the first page of printed text.

Center heads of whatever level should be typed with initial caps of major words, with extra space above and below the head, but no other preparation (such as all caps or underline, except for the underline necessary for generic and specific epithets). Run-in paragraph heads should use period/dashes or colons as necessary.

Tabulations within text (lists of data, often in parallel columns) can be typed on the text page where they occur, but they should not contain rules or numbered table captions.

Formal tables (numbered, with captions, boxheads, stubs, rules) should be submitted as carefully typed, double-spaced copy separate from the text; they will be typeset unless otherwise requested. If camera-copy use is anticipated, do not draw rules on manuscript copy.

Taxonomic keys in natural history papers should use the aligned-couplet form for zoology and may use the multi-level indent form for botany. If cross referencing is required between key and text, do not include page references within the key, but number the keyed-out taxa, using the same numbers with their corresponding heads in the text.

Synonymy in zoology must use the short form (taxon, author, year:page), with full reference at the end of the paper under "Literature Cited." For botany, the long form (taxon, author, abbreviated journal or book title, volume, page, year, with no reference in "Literature Cited") is optional.

Text-reference system (author, year:page used within the text, with full citation in "Literature Cited" at the end of the text) must be used in place of bibliographic footnotes in all Contributions Series and is strongly recommended in the Studies Series: "(Jones, $1910: 122)$ " or "...Jones (1910:122)." If bibliographic footnotes are required, use the short form (author, brief title, page) with the full citation in the bibliography.

Footnotes, when few in number, whether annotative or bibliographic, should be typed on separate sheets and inserted immediately after the text pages on which the references occur. Extensive notes must be gathered together and placed at the end of the text in a notes section.

Bibliography, depending upon use, is termed "Literature Cited," "References," or "Bibliography." Spell out titles of books, articles, journals, and monographic series. For book and article titles use sentence-style capitalization according to the rules of the language employed (exception: capitalize all major words in English). For journal and series titles, capitalize the initial word and all subsequent words except articles, conjunctions, and prepositions. Transliterate languages that use a non-Roman alphabet according to the Library of Congress system. Underline (for italics) titles of journals and series and titles of books that are not part of a series. Use the parentheses/colon system for volume (number):pagination: "10(2):5-9." For alignment and arrangement of elements, follow the format of recent publications in the series for which the manuscript is intended. Guidelines for preparing bibliography may be secured from Series Section, SI Press.

Legends for illustrations must be submitted at the end of the manuscript, with as many legends typed, double-spaced, to a page as convenient.

Illustrations must be submitted as original art (not copies) accompanying, but separate from, the manuscript. Guidelines for preparing art may be secured from the Series Section, SI Press. All types of illustrations (photographs, line drawings, maps, etc.) may be intermixed throughout the printed text. They should be termed Figures and should be numbered consecutively as they will appear in the monograph. If several illustrations are treated as components of a single composite figure, they should be designated by lowercase italic letters on the illustration; also, in the legend and in text references the italic letters (underlined in copy) should be used: "Figure 9b." Illustrations that are intended to follow the printed text may be termed Plates, and any components should be similarly lettered and referenced: "Plate $9 \underline{b}$." Keys to any symbols within an illustation should appear on the art rather than in the legend.

Some points of style: Do not use periods after such abbreviations as "mm, ft, USNM, NNE." Spelf out numbers "one" through "nine" in expository text, but use digits in all other cases if possible. Use of the metric system of measurement is preferable; where use of the English system is unavoidable, supply metric equivalents in parentheses. Use the decimal system for precise measurements and relationships, common fractions for approximations. Use day/month/ year sequence for dates: "9 April 1976." For months in tabular listings or data sections, use three-letter abbreviations with no periods: "Jan, Mar, Jun," etc. Omit space between initials of a personal name: "J.B. Jones."

Arrange and paginate sequentially every sheet of manuscript in the following order: (1) title page, (2) abstract, (3) contents, (4) foreword and/or preface, (5) text, (6) appendices, (7) notes section, (8) glossary, (9) bibliography, (10) legends, (11) tables. Index copy may be submitted at page proof stage, but plans for an index should be indicated when the manuscript is submitted. 




